\title{
Recent progress on natural fiber hybrid composites for advanced applications: A review
}

\author{
M. J. Mochane ${ }^{1 *}$, T. C. Mokhena ${ }^{2,3}$, T. H. Mokhothu ${ }^{4}$, A. Mtibe ${ }^{2}$, E. R. Sadiku ${ }^{1}$, S. S. Ray, \\ I. D. Ibrahim 6 , O. O. Daramola 1 \\ ${ }^{1}$ Institute of Nano Engineering Research (INER), Department of Chemical, Metallurgical and Materials Engineering \\ (Polymer Technology Division), Tshwane University of Technology, Pretoria, South Africa \\ ${ }^{2}$ CSIR Materials Science and Manufacturing, Polymers and Composites, Port Elizabeth, South Africa \\ ${ }^{3}$ Department of Chemistry, Nelson Mandela University, Port Elizabeth, South Africa \\ ${ }^{4}$ Department of Chemistry, Durban University of Technology, Durban, South Africa \\ ${ }^{5}$ DST-CSIR National Center for Nanostructured Materials, Council for Scientific and Industrial Research, 0001 Pretoria, \\ South Africa \\ ${ }^{6}$ Department of Mechanical Engineering, Tshwane University of Technology, Pretoria, South Africa
}

Received 9 July 2018; accepted in revised form 20 September 2018

\begin{abstract}
Natural fibers, as replacement of engineered fibers, have been one of the most researched topics over the past years. This is due to their inherent properties, such as biodegradability, renewability and their abundant availability when compared to synthetic fibers. Synthetic fibers derived from finite resources (fossil fuels) and are thus, affected mainly by volatility oil prices and their accumulation in the environment and/or landfill sites as main drawbacks their mechanical properties and thermal properties surpass that of natural fibers. A combination of these fibers/fillers, as reinforcement of various polymeric materials, offers new opportunities to produce multifunctional materials and structures for advanced applications. This article intends to cover recent developments from 2013-up to date on hybrid composites, based on natural fibers with other fillers. Hybrid composites preparation and characterization towards their applicability in advanced applications and the current challenges are also presented.
\end{abstract}

Keywords: polymer composites, hybrid composites, advanced applications, natural fibers, synthetic fibers

\section{Introduction}

Apart from energy, environmental protection is one of the top problems facing the current generation. Novel strategies are required now more than ever to either protect the environment or generate products, which are not harmful to the environment. Natural fibers have received a lot of attention as possible alternative replacement for synthetic fibers, as reinforcement of various resins for advanced applications due to their properties, such as: low density, high specific strength and they are renewable, sustainable, and eco-friendly [1-3]. Natural fibers have unique features, such as: low cost, abundant availability and their renewable resources absorb carbon dioxide, which mitigates environmental pollution. During processing, natural fibers do not generate any harmful gases and they are not abrasive to the processing equipment. The main concern of natural fibers is their inherited hydrophilic character and they are highly flammable which limits their success in polymer reinforcement. Their hydrophilic character results in high moisture absorption, poor matrix-fiber interfacial adhesion and poor fiber dispersion. A quite significant research has been done on the surface 
treatment of the natural fibers to overcome these limitations $[1,2,4,5]$. It can be argued that a tremendous success has been made on the surface treatment of natural fibers to improve the overall properties of the resulting composite materials as discussed in these review studies $[1,2,4,5]$. On the other hand, different flame-retardants have been added and/or used to treat natural fibers in order to improve their flame resistance as recently reviewed in [6].

Synthetic/artificial fibers deserve, however, special interest due to their superior properties as compared to natural fibers. It is recognized that various aspects such as growth condition, harvesting methods, and maturity often affect natural fibers properties. The limitations of synthetic fibers include their accumulation in the environment and/or landfill sites, high cost and they are derived from finite resources, viz. fossil fuels [1]. The processing of fossil fuels alone generates various gases (e.g. $\mathrm{CO}_{2}$, methane, nitrous oxide and many others), which contribute to the unwanted environmental pollution. Furthermore, during composite production, harmful gases are liberated, which cause dreadful diseases, e.g. cancer and again, they can be abrasive to the processing equipment. On the other hand, synthetic fibers have prolonged lifespan, which offers more advantage towards high-end applications [1-5]. These fibers have high strength and can be produced with special functionalities required for intended application. For example, carbon fibers render high electrical conductivity; high thermal conductivity and they have less or no moisture absorption, high strength and thermal stability. These properties offer as-prepared composite material an opportunity towards high-end applications, such as: large-scale energy storage, wind turbines and aerospace. The shortcomings of the synthetic fibers can be solved by adding fillers/fibers, which can be significantly cheaper, without compromising their valuable properties.

Over the past years, there has been an ever-increasing interest to incorporate two or more filler into a common matrix, as shown in Figure 1. There has been a steadily increase in the number of published works that are related to hybrid composites since 2013. Figure 1a represents the number of published outputs, based on hybrid composites (between 2013 to date), found in the Web of Science by entering/ searching the words 'hybrid composites' with 25343 research outputs and $90 \%$ of these, being research articles. The growth resulted from one objective, i.e. to improve the properties of the resulting composite material in order to achieve desired properties and a better performance of such composite. The main aim was to overcome the limitation of single filler reinforced matrix with the other filler(s) that have similar or even better properties when compared to the initial fiber. This new concept is known as 'hybridization', in which two or more fillers can be incorporated into a common matrix to overcome the shortcomings of the other filler. However, this concept also applies to the blending of two or more polymers and reinforced with one filler or more fillers and again, by adding the same filler type that has two or more sizes or dimensions, i.e. auto-hybridization. Figure $1 \mathrm{~b}$ presents the top ten countries that are relatively more active in hybrid composites, with China being the most active, followed by India and USA. Hybridization process cross over many research areas, such as: mechanics, chemistry, engineering, physics, science and technology, polymer science, electrochemistry, metallurgy
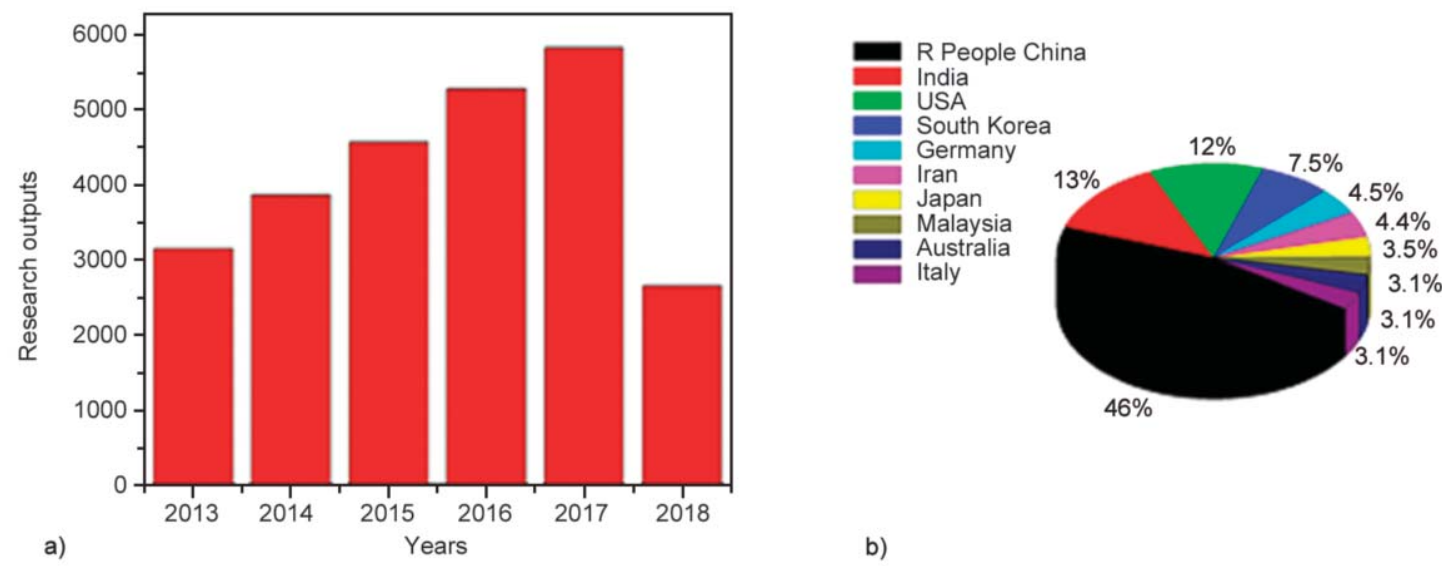

b)

Figure 1. (a) Number of outputs per year and (b) contribution of the countries in hybridized composites. Data analysis completed using Web of Science search system on 7 July 2018. 
and metallurgy engineering and energy fuels. Irrespective of the research area, the main objective was to come up with the combination of three or more materials that have better performance/properties when compared to each material for an intended application. However, in this article, we are focusing on two or more fillers reinforcing one polymer matrix or polymer blend. The aim of two or more fillers added into a polymer matrix and/or polymer blend is to ensure that they can learn from each other and match in coordination, so that they have an excellent performance and lower overall cost.

The main objective of these research works was to come up with an optimal combination of fillers and/or blends hybridized composites towards intended application. The sequence and fiber orientation were found to play a major role on the resulting properties. Similar to the conventional single fiber reinforced composite materials, the interfacial adhesion between the matrix and fillers was found to play a paramount influence on the ensuing properties. Different chemical treatments were also investigated in order to improve the interfacial adhesion. Some of the prerequisites of the resulting hybridized composite include: low cost and a balance of the weight-to-performance ratio. Depending on the intended application, the term 'hybrid effect' was adopted to define the results obtained during the investigation. Basically, the hybridized composite is compared with the conventional composite product viz. single fiber reinforced composite and the results can either be negative or positive 'hybrid effect'. The positive hybrid effect can be defined as better performance obtained from hybridized composite material as compared to the single reinforced composite material, while the opposite prevails for negative hybrid effect. More attention has been on replacing certain percentage of classic fibers used for intended application with other fillers, which are lighter, easily accessible, and cheaper. The natural fibers features some of these properties such as low density, cheaper and availability hence more research works has been dedicated in utilizing them to replacing certain percent of classic synthetic fibers. This review highlights the recent works on hybrid composite materials from 2013 till to date.

\section{Hybridization}

A hybrid composite is generally, defined as a combination of two or more fillers into a common matrix [3]. The matrix can be ceramic, steel or polymer. In this review, only polymeric matrices will be discussed. In the case of polymeric materials, the definition of hybrid can further be extended to a blend of two or more polymers reinforced with one or more fillers. In the case of the same type of filler having different size/dimensions, a new word auto-hybrid is usually used. Hybridization offers a new opportunity to broaden the applicability of the composite materials, especially in advanced applications. There are three principal parameters, which have significant effect on the properties of the resulting hybrid composite product. First are the materials used (matrix and filler), which depend mostly on the intended application. For example, it was found that jute/glass hybrid displayed higher reinforcement under compressive load than bamboo/glass composites, while the opposite scenario was observed under tensile load [7]. It can be argued that each application requires certain properties in order to achieve the desired goal. For instance, Mansor et al. [8] used Analytical Hierarchy Process to choose the suitable natural fibers from 13 candidates in an attempt to combine (individually) with glass fiber in order to produce automotive brake lever. They found out that kenaf fibers produced the top score when compared to others. The second factor involves the preparation method, which often relies on the filler and the matrix under investigation, as will be discussed in subsequent sections. It is worth mentioning that in order to design a new product, there are certain specifications that have to be met, such as the conditions (viz. outdoors or indoors) in which that product will be used. This can be achieved by carrying out researches in comparison with commercially available product in the market and formulate according to their specifications. A balance between the sustainability and performance of the product to accommodate both the consumer and the environment has also to be considered. Other factors that have to be taken into account such as whether the product will be used in open environment or indoors/under, protection storage needs to be considered as explained earlier. The following aspects have to be taken into account in order to produce the final product, viz.: weight, mechanical strength, density, recyclability, disposability, water absorption, raw material cost, manufacturing costs, compatibility with current recycling system in place and test methods (depending on the intended application). The third most important parameter includes the interaction between the fillers and 
the matrix. Treatment of the fibers and/or the use of a coupling agent, especially for natural fibers in order to enhance the interfacial adhesion between these components, which in most instances, will result in the improvement of the overall properties of the hybrid product. The desired properties can be predicted by using the rule of mixture equation (Equation (1)), by assuming that there is no chemical/physical interaction between the fillers [9]:

$P_{\mathrm{H}}=P_{\mathrm{c} 1} V_{\mathrm{c} 1}+P_{\mathrm{c} 2} V_{\mathrm{c} 2}$

where $P_{\mathrm{H}}$ is the resulting properties of the hybrid composite, $P_{\mathrm{c} 1}$ and $P_{\mathrm{c} 2}$ are properties of the respective constituents, $c 1$ and $c 2$ of the composite, while $V_{\mathrm{c} 1}$ and $V_{\mathrm{c} 2}$ are their respective volume fractions, as shown in Equation (2):

$V_{\mathrm{c} 1}+V_{\mathrm{c} 2}=1$

\subsection{Filler selection}

Fillers can be subdivided according to their origin, i.e. as either synthetic or natural fibers as illustrated in Figure 2. The selection of the filler can be linked directly, to the desired properties.

\subsubsection{Natural fibers}

Over the past decades, there has been lot of progress in the use of natural-based fillers because of the volatility in petroleum oil and their resources. The utilization of natural-based fillers, however have some limitations (low thermal stability, highly flammable, high moisture absorption, variation in mechanical properties etc.) especially in advanced/technical applications. This led to more studies in combining the natural-based filler with other fillers to overcome these limitations. The common goal was to replace the synthetic fillers with renewable, inexpensive and biodegradable fillers. This review work covers mostly, the commonly used fillers to improve and/or overcome the limitations of natural fillers and as a result, broadens their technical applicability. The choice of a second filler into the natural filler-reinforced composites depends on the intended application in order to overcome the shortcoming of natural filler as listed in Table 1. Natural fibers are extracted from different renewable resources, namely animals, vegetable plants and minerals. Vegetable fibers are mainly composed of cellulose, hemicelluloses, lignin, pectin and other extractives at low amounts as illustrated in

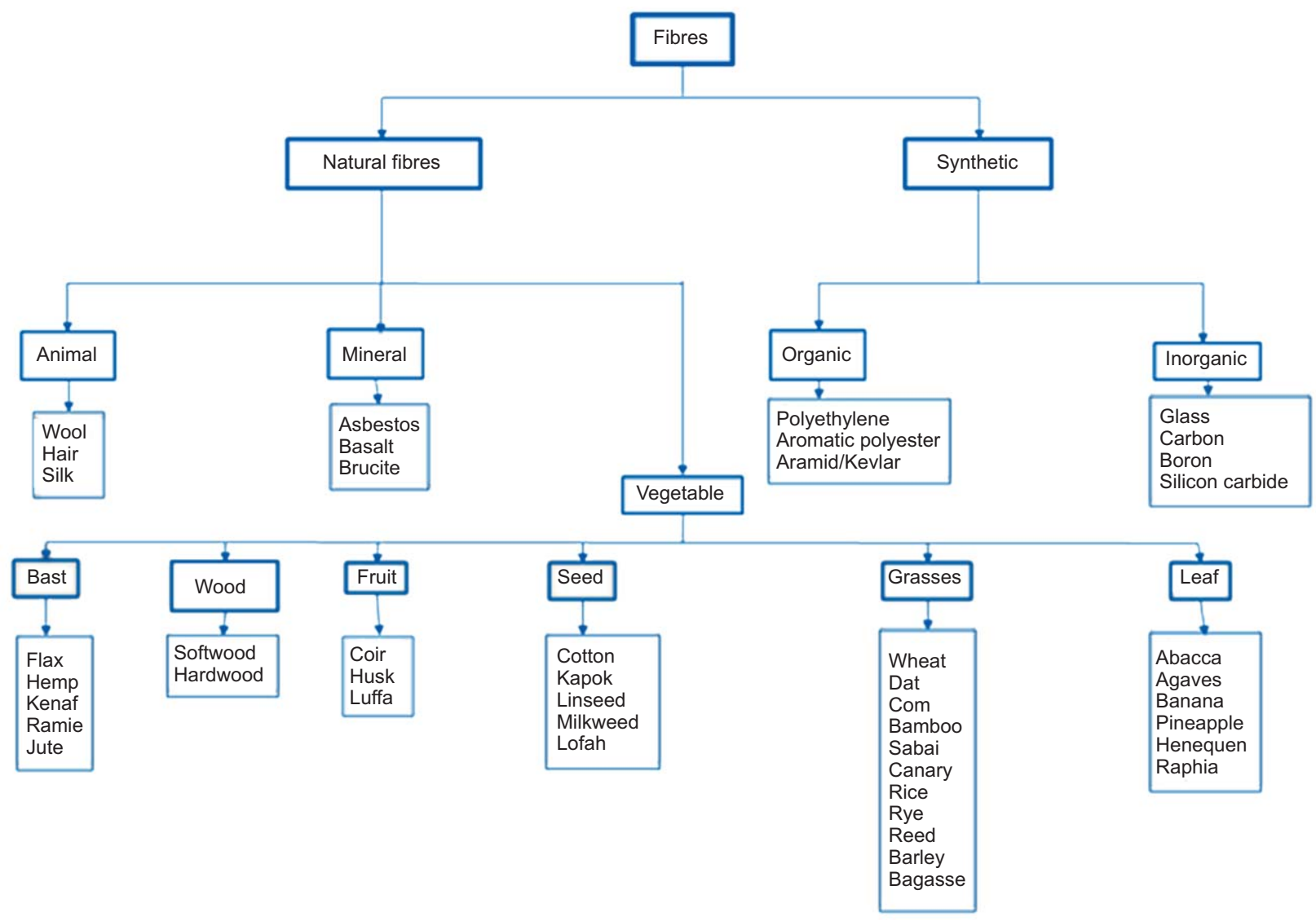

Figure 2. Classification of the fibers. 
Table 1. Natural fibres advantages and their short-comes.

\begin{tabular}{|l|l|}
\hline \multicolumn{1}{|c|}{ Advantages } & \multicolumn{1}{c|}{ Disadvantages } \\
\hline Recyclable & High moisture absorption \\
\hline Low density i.e. lightweight & Dimensional instability \\
\hline Zero finger print $\mathrm{CO}_{2}$ & Flammable \\
\hline High specific mechanical properties than glass & Low strength and thermal resistance than glass fibres \\
\hline Non-abrasive to processing equipment & Anisotropic behavior \\
\hline Generate non-harmful gases during processing and no skin irritation & Odour generation during degradation \\
\hline Production energy is less that of glass fibres i.e. one third & Limited processing temperatures as compared to glass \\
\hline & Sensitive to UV, microbial and fungus attack \\
\hline Good thermal and acoustic properties & Variability of properties and price depending on the location \\
\hline
\end{tabular}

Table 2. Chemical composition of selected vegetable fibres [1-3].

\begin{tabular}{|l|c|c|c|c|c|c|c|}
\hline \multicolumn{1}{|c|}{ Fibre-type } & $\begin{array}{c}\text { Cellulose } \\
{[\%]}\end{array}$ & $\begin{array}{c}\text { Lignin } \\
{[\%]}\end{array}$ & $\begin{array}{c}\text { Hemicellulose } \\
{[\%]}\end{array}$ & $\begin{array}{c}\text { Pectin } \\
{[\%]}\end{array}$ & $\begin{array}{c}\text { Wax } \\
{[\%]}\end{array}$ & $\begin{array}{c}\text { Ash } \\
{[\%]}\end{array}$ & $\begin{array}{c}\text { Microfibrillar angle } \\
{[\%]}\end{array}$ \\
\hline Abaca & $53-63$ & $7-9$ & $20-25$ & - & 3 & & $20-25$ \\
\hline Bamboo & $26-43$ & $1-31$ & 30 & - & 10 & - & - \\
\hline Banana & $63-83$ & 5 & - & - & 11 & - & $3-12$ \\
\hline Coconut coir & $36-43$ & $0.15-0.25$ & $41-45$ & $3-4$ & - & - & -49 \\
\hline Cotton & $83-91$ & - & 3 & 0.6 & $8-9$ & - & $5-10$ \\
\hline Flax & $64-72$ & $2-2.2$ & $64-72$ & $1.8-2.3$ & - & - & $2-6.2$ \\
\hline Hemp & $70-74$ & $3.7-5.7$ & 0.9 & 0.8 & $1.2-6.2$ & 0.8 & 8 \\
\hline Jute & $61-72$ & $12-13$ & $18-22$ & 0.2 & 0.5 & $0.5-2$ & $2-6.2$ \\
\hline Kenaf & $45-57$ & 22 & $8-13$ & 0.6 & 0.8 & $2-5$ & - \\
\hline Nettle & 86 & 4.0 & 5.4 & 0.6 & 3.1 & - & $-28-37$ \\
\hline Rachis & 43 & 26 & - & - & - & - & $69-83$ \\
\hline Ramie & $69-91$ & $0.4-0.7$ & $5-15$ & 1.9 & - & - & - \\
\hline Rice husk & $38-45$ & - & - & - & - & 20 & - \\
\hline Sisal & 78 & 8 & 10 & - & 2 & 1 & - \\
\hline Hardwood & $43-47$ & $25-35$ & - & - & - & - & - \\
\hline Softwood & $40-44$ & $25-29$ & - & - & - & - & \\
\hline
\end{tabular}

Table 2. The chemical composition relies on the fiber source and varies within different parts, even if they are from the same family or type. Their performance depends on their chemical composition, crystallinity, microfibrillar angle, defects and physical properties. The information based on these parameters is of significance in order to obtain their highest potential. It is recognized that natural fibers are susceptible to degradation (viz. biological, chemical, mechanical, thermal, photochemical and aqueous), depending on individual constituents. For instance, lignin is mainly responsible for UV and fire degradation, whereas, hemicelluloses are responsible for biological degradation, thermal degradation and high moisture absorption $[10,11]$.

Physical properties include: fiber dimensions, defects, strength and structure. Vegetable fibers are subdivided into: leaf, fruit, stem, grass and wood with regard to their sources, as presented in Figure 2 and
Table $3[4,12,13]$. The inherited hydrophilic character has been one of the major drawbacks impeding their technical applications $[4,14,15]$. This results in poor interfacial interaction with hydrophobic polymeric materials limiting the stress transfer between the composite components. Chemical (viz. alkaline, silane, acetylation, benzoylation, acrylation and acrylonitrile grafting, maleated coupling, permanganate, peroxide and isocyanate treatments) and physical (viz. corona discharge and plasma treatments) modifications have been major topics in natural fiber reinforced composites in order to improve the interfacial adhesion and in turn the overall properties of the composite product. These studies reported an improvement in the resulting properties because of the strong interaction between the polymer matrix and the fibers. Furthermore, the treatment of the natural fibers can improve their biodegradation stability when exposed to different environments [10]. Other suitable effort 
that can be employed to overcome and/or improve the overall properties of the natural fiber reinforced composites, is to add second filler as will be discussed in subsequent sections. The animal fibers are made-up of proteins, while minerals fillers include basalt, asbestos and brucite, as shown in Figure 2.

\subsubsection{Synthetic fillers}

Different engineered or man-made fillers have been introduced into research communities with regard to their unique valuable properties, as summarized in Table 3 and Figure 2. Glass fibers and carbon fibers are the most used synthetic fillers in the hybridized composites. Most of these materials have experienced their success in different industrial sectors, such as: large-scale energy production, construction, entertainment and many others. Interestingly, the manufacturing processes can be designed in such a way that the fibers produced have the properties associated with the intended application. This property gives the synthetic filler an edge over the natural fillers which are affected by the nature of the growth conditions as well as their harvesting conditions. The cost-to-performance ratio has been the subject to the producers of these fillers in order to come up with cheaper manufacturing process. Nonetheless, high tensile strength (e.g. 1.9 to $3.5 \mathrm{GPa}$ for glass fiber) and tensile modulus (e.g. ranging between 50 to $90 \mathrm{GPa}$ for glass fibers) overshadow their disadvantages, which resulted in the success for commercial products.

\subsubsection{Other fillers}

Although most of the published research works revolves around the mechanical properties, other physical properties and flame retardancy, are of significant importance. Natural fibers are more flammable, which is accompanied by the liberation of toxic or corrosive gases and smoke during combustion and this impedes their success in various applications, such as household goods, building-construction and others. Flame-retardants and nanoparticles can be

Table 3. List of fibres, origin and physical properties [4, 5, 15-22].

\begin{tabular}{|c|c|c|c|c|c|c|c|c|}
\hline Source & $\begin{array}{c}\text { Annual } \\
\text { production } \\
\text { [million }\end{array}$ & Origin & $\begin{array}{c}\text { Price } \mathbf{k g}^{-1} \\
\text { [USD] }\end{array}$ & $\begin{array}{l}\text { Density } \\
{\left[\mathrm{g} / \mathrm{cm}^{3}\right]}\end{array}$ & $\begin{array}{c}\text { Tensile } \\
\text { strength } \\
\text { [MPa] }\end{array}$ & $\begin{array}{c}\text { Young's } \\
\text { modulus } \\
\text { [GPa] }\end{array}$ & $\begin{array}{c}\text { Elongation } \\
{[\%]}\end{array}$ & $\begin{array}{c}\text { Moisture } \\
\text { content } \\
{[\%]}\end{array}$ \\
\hline Abaca & 0.07 & Leaf & $1-1.5$ & 1.5 & $430-813$ & $31.1-33.6$ & $2.9-10$ & 14 \\
\hline Bagasse & Abundant & Grass & 0.2 & 0.89 & 350 & 22 & 5.5 & \\
\hline Bamboo & 100 & Grass & $2.2-3.25$ & $0.6-1.25$ & 290 & $11-17$ & - & 9 \\
\hline Banana & 2.5 & Leaf & $0.1-0.75$ & 1.35 & $529-914$ & $27-32$ & $2.6-5.9$ & $10-11$ \\
\hline Coir & Abundant & Fruit & $0.2-0.4$ & $1.15-1.25$ & $131-220$ & $4-6$ & $15-40$ & 10 \\
\hline Cotton & 0.0185 & Seed & $1.5-2.2$ & 1.51 & 400 & 12 & $3-10$ & $33-34$ \\
\hline Date palm & 4.2 & & 0.025 & $0.7-1.2$ & & $60-80$ & $2-19$ & \\
\hline Flax & 0.81 & Stem & 3.11 & 1.4 & $800-1500$ & $60-80$ & $1.2-1.6$ & 7 \\
\hline Hardwood & & Wood & 0.44 & $0.3-0.88$ & $51-121$ & $5.2-15.6$ & & \\
\hline Hemp & & Stem & 1.55 & 1.48 & $550-900$ & 70 & $1.6-4.0$ & 8 \\
\hline Jute & 0.25 & Plants & 0.926 & $1.3-1.48$ & $393-800$ & $13-26.5$ & $1.16-1.8$ & 12 \\
\hline Kenaf & 0.77 & Stem & 0.378 & -1.4 & 284-930 & $21-60$ & 1.6 & $6.2-20$ \\
\hline Nettle & & Bast & - & 1.51 & 650 & 38 & 1.7 & $11-17$ \\
\hline Pineapple & Abundant & Leaf & $0.1-018$ & 1.44 & $413-1627$ & $60-82$ & 14.5 & $10-13$ \\
\hline Ramie & 0.1 & Stem & 2 & 1.5 & 500 & 44 & 2 & $12-17$ \\
\hline Sisal & 0.3 & Plants leaf & 0.65 & $1.3-1.4$ & $390-450$ & $12-41$ & $2.3-2.5$ & 11 \\
\hline Softwood & & Wood & $0.44-0.55$ & $0.30-0.59$ & $45.5-111$ & $3.6-14.3$ & - & - \\
\hline Wool & & Animal & & & & & & \\
\hline \multicolumn{9}{|l|}{ Silk } \\
\hline \multicolumn{9}{|l|}{ Feather } \\
\hline Basalt & & Mineral & & 2.8 & 2800 & 8.5 & 2.8 & \\
\hline S-Glass & - & - & 2 & 2.5 & $2000-3500$ & $70-73$ & $1.8-3.2$ & - \\
\hline E-Glass & - & - & 2 & 2.55 & $3-3.5$ & $63-67$ & 2.5 & - \\
\hline Aramid & - & - & & 1.44 & 3000 & 124 & 2.5 & - \\
\hline Carbon & - & - & $8-14$ & 1.4 & 400 & $230-240$ & $1.4-1.8$ & - \\
\hline Silicon carbide & & & & 3.16 & & $360-440$ & - & - \\
\hline
\end{tabular}


incorporated into the polymeric material to enhance specifically flame resistance of the resulting hybrid products to necessitate their application in environments where fire safety is of paramount importance. On the other hand, these fillers also contribute to the overall hybrid composites properties. In most cases, the introduction of flame retardant materials adversely affects the mechanical properties of the composite [17]. Therefore, researches have been dedicated on the optimization of these fillers in order to overcome the latter [17]. In this review, the inclusion of other fillers with flame retardant properties into natural polymer reinforced composites will be discussed, since they are of utmost importance in advanced applications, especially in the transportation and building/construction sectors.

\subsection{Resin selection}

Resin governs the shape, surface appearance, environmental tolerance, and overall durability of the hybrid composite product. Depending on the processing technique two resins i.e. thermoplastic and thermosets are often reinforced with different fillers [9]. Table 4 and 5 list the hybrid composites with the processing techniques utilized. Thermoplastics, often, are chosen over thermosets because of the moldability into various shapes. The former can be re-melted and reprocessed into a new shape, which is not the case for thermosets. In general, the processing techniques for thermoplastics involve heating to melt the polymer into viscous form in order to afford fiber impregnation. These techniques include melt mixer, single/twin screw extruder, and compression molding which can be used alone or in combination. Nevertheless, solution casting in which the polymer is dissolved in a suitable solution followed by fiber/s infusion has been also studied [23]. The most extensively studied thermoplastic matrices, are: polypropylene (PP), polyethylene (PE), polystyrene (PS) and polyvinyl chloride (PVC). Thermosets are often used for more advanced composite applications, such as: aerospace, wind turbines blades and automotive due to their high tensile strength, high modulus and chemical stability. The common processing methods for thermosets-based composites include: resin transfer molding (RTM), sheet molding compound (SMC), pultrusion, vacuum-assisted resin transfer molding (VARTM) and hand lay-up which requires less pressure [24]. Thermosets have the advantage of incorporating large amounts of fibers when compared to thermoplastics. The most used matrices and their fillers are summarized in Tables 4 and 5.

\subsubsection{Thermoplastic}

Thermoplastics have been a center of reinforced composites materials because of their inherited properties, such as: lightweight, inexpensive and readily moldable into various shapes. Significant researches have been dedicated to improving the interfacial adhesion between the matrix and natural fibers. Chemical, physical and biological treatments are often applied on the natural fibers to improve the interfacial adhesion, which in turn enhances the overall properties of the resulting composite materials [1, 25]. The chemical treatments can include alkali alone or in combination with other treatments, such as: acetylation, salinization and many others, as explained earlier. Furthermore, coupling agents or compatibilizers are also utilized to improve interfacial adhesion, which in turn improves the properties of the resulting composite products. Physical treatments include Soxhlet extraction and electric discharge (corona and cold plasma), while biological treatment was recently reported [25]. These types of treatments enhance the interfacial adhesion between the thermoplastics and plant fibers, which result in good stress transfer between the composite constituents. Melt compounding and melt pressing are the most used processing techniques with regard to the behavior of thermoplastic, i.e. they become viscous solution when heated and can be molded into various shapes [2629]. The melt compounding processing techniques include single/twin-screw extruder, extrusion, and internal melt mixer, which can be used alone or in combination. The main concern about these techniques is the heat involved, which may degrade the plant fibers, hence affecting their valuable properties. This had been one of the major parameter, which controls the selection of polymeric matrix, which must at least melt well below the thermal degradation of the plant fibers. Of interest, is the inclusion of high thermal stable synthetic fiber or flame retardant material as second filler can protect these fibers from thermal degradation during processing.

Polyolefins are used in many different applications from packaging to high-end performance and they are the most studied polymers. The most often-studied polyolefins, include polyethylene and polypropylene. These plastics feature a range of properties with 
a combination of lightweight, high strength and ease processability. Some of polyolefins melt below $200^{\circ} \mathrm{C}$, which makes them suitable candidates for the production of natural-fiber based hybridized composites [29-33]. As mentioned earlier, the hydrophobic polyolefin and inherently hydrophilic natural fibers result in weak interfacial adhesion. Therefore, resulting in weak stress transfer between these components and hence there has been a lot of interest in creating other means of their hybridization in order to enhance adhesion between these parties [34].

The welcomed paradigm shifts towards green composites have opened doors for reinforced naturalbased polymers, such as: polylactic acid (PLA), poly (butylene succinate-co-lactate) (PBSL), thermoplastic starch (TPS), polyhydroxyalkanoates (PHA) and many others [26-28]. However, the highly deficient interfacial adhesion has also been reported as one of the major challenges to overcome in order to enhance the overall properties of the composite materials. Different treatments, preferably chemical treatments, have been employed in order to improve interfacial adhesion between these components [26, $28,35,36$ ]. Chen et al. [35] found out that the use of silane coupling agent resulted in chemical bonding, which improved the interfacial adhesion, which in turn improved the overall properties of the hybridized biocomposite material. Numerous studies have been reported on PLA-based hybrid composites. This is due to its comparable properties to synthetic polymers such PP and polystyrene [35, 37]. Chen et al. [35] and Birnin-Yauri et al. [38] reported the hybridized PLA composites processed by the compression technique. Melt pressing was conducted in some studies because this processing method offers an opportunity, not only to incorporate nonwoven random fibers, but also woven fiber fabric and unidirectional fibers $[35,38]$ (Table 4). Twin-screw extruder followed by compression molding of biopolymers were also reported in [27] and [26], while melt mixing was reported in [27, 35]. Yet another preparation method that affords good dispersion without degrading natural fibers is solution casting. In this case, the polymer is dissolved in a suitable solvent followed by inclusion of the filler. In most cases water is a preferable solvent since it is cheaper and environmentally benign. It is recognized that for industrial production this method would be expensive with regard to recovery of utilized solvent, while only a limited number polymers are soluble in most available solvent, which in turn, limit the choice of polymer. Using solution casting Edhirej et al. [23], prepared green hybrid composite based on cassava starch (as matrix) and fructose (as a plasticizer) reinforced with cassava bagasse and sugar palm fiber (SPF) using water as a suitable solvent. Although, natural-based polymers are considered as promising candidates to replace fossil fuel resources-based polymeric materials, from ecological point of view, their degradation, moisture absorption and cost limit their success in the high-performance applications, such as: automotive, wind turbine and aerospace components. However, it can be argued that due to their short service-life, they can be considered for packaging. The main concern on the application of these biopolymers is their contamination of the available recycling processes/system. Amongst other polymeric materials, rubber materials were also utilized to produce hybrid composite materials via two roll mill followed by hydraulic pressing were used to produce hybridized composites [39, 40].

\subsubsection{Thermosets}

Thermosets are known by their unique identity of forming three-dimensional crosslinked networks via curing. Examples of thermosets include: epoxy resins, phenolic resins, polyurethanes, acrylics, alkyds, furans, polyimides, vinyl esters and unsaturated polyester. In the case of the hybridized composites, polyester and epoxy are the most studied thermosets, as discussed below [41]. The main concern for thermosets is the long duration associated with processing. Furthermore, with low recyclability of thermosets-based composite, they require new strategies of designing sustainable recycling mechanisms. For example, they can be ground and used again as fillers. Over several years, the main objective has been the modification of the toughness of the thermosets and maximizing the processing temperatures. Moreover, the processing temperatures (ranging from 25 to above $100^{\circ} \mathrm{C}$ ) are well below the degradation temperature of the plant fibers. Resin impregnation is carried out by hand layup, vacuum assisted transfer molding (VARTM), vacuum bag resin transfer molding (RTM) and vacuum-assisted resin infused repairing, vacuumassisted transfer molding, as summarized in Table 5. Vacuum-assisted methods, are often implemented in order to produce thermosets-based composites for high-end applications, such as aerospace and automotive [42-45]. The advantages of vacuum-assisted 
methods, include low preparation cost and relatively low volatile organic compounds (VOCs) emissions when compared to the conventional processing techniques (e.g. compression molding). Hand layup, followed by light compression during curing is one of the processing techniques that are usually employed for the preparation of thermosets hybrid composites; this is because they are cheaper and easily applied on a laboratory scale [46]. Compression molding alone, was also reported elsewhere in the literature [47]. Commercialized in the 50s, epoxy resin features high strength, stiffness and good creep, heat and solvent resistance. They can be identified by the presence epoxy group (oxirane rings) in their backbones. Crosslinking networks result from a reaction with a hardener or a curing agent. Of interest, they have lower shrinkage than most unsaturated polyesters. Moreover, the pressure required for epoxy composite preparation is lower than other thermosets. With wide variety of viscosities, it is possible to choose desired epoxy resin towards intended application/performance. The former, can be tailored by changing the resin type and the curing agent. It has been applied for high structural components, such as: wind turbine blades, automotive and aerospace. This contributes to the production of green energy and fuel consumption reduction (viz. light vehicles and airplanes). There are a number of studies based on the hand lay-up processing technique [48-51]. Frequently, this method is used together with light compression by using some weight during curing, either in the presence of heat or at room temperature. On the other hand, Saba et al. [3], and others [52, 53] also employed compression molding alone and VARTM was also used by Xia et al. [54]. Similar to epoxy resins, there are various polyester resins, such as: saturated polyester, alkyd, vinyl ester and unsaturated polyester. Amongst all these resins, unsaturated polyester and vinyl ester are the most studied, particularly in the case of hybrid composites, as listed in Table 5. The chemical and mechanical properties of the polyester resins depend on the choice of resin, crosslinking agents and initiators in use. Different processing techniques, such as: hand layup, compression molding, pultrusion, vacuum assisted resin transfer were used to fabricate hybrid composites (Table 5).

Table 4. Recent reports on thermoplastic based hybrid composites composites [23, 26, 27, 29, 30, 32, 35, 37-40, 55-71].

\begin{tabular}{|c|c|c|c|}
\hline Matrix & Reinforcement & Preparation method & Refs. \\
\hline Polypropylene & Luffa/coir fibres treated with $\mathrm{NaOH}$ & Compression molding & {$[30]$} \\
\hline Polypropylene & $\begin{array}{l}\text { Kenaf/exfoliated graphene nanoplatelets with maleic anhydride } \\
\text { grafted polypropylene }\end{array}$ & $\begin{array}{l}\text { Twin-screw extruder followed by } \\
\text { injection molding }\end{array}$ & {$[55]$} \\
\hline Polypropylene & Wood flour/carbon fibre & Injection molding & {$[56]$} \\
\hline PP & Wood flour/glass fibre & $\begin{array}{l}\text { Twin-screw extruder followed by } \\
\text { injection molding }\end{array}$ & {$[57]$} \\
\hline Polypropylene & $\begin{array}{l}\text { Sisal fibre/ammonium phosphate (APP), Magnesium hydroxide } \\
\left(\mathrm{Mg}(\mathrm{OH})_{2}\right) \text {, Zinc borate }(\mathrm{Zb}) \text { as well as combination of APP with } \\
\mathrm{Mg}(\mathrm{OH})_{2} \text { and } \mathrm{Zb} \text { with maleic anhydride grafted polypropylene }\end{array}$ & Internal mixer & {$[58]$} \\
\hline Recycled polypropylene & $\begin{array}{l}\text { Wood particles/Aminoplast resin and ammonium phosphate with } \\
\text { Maleic anhydride as coupling agent }\end{array}$ & $\begin{array}{l}\text { Twin-screw extruder }+ \text { injection } \\
\text { molding }\end{array}$ & {$[32]$} \\
\hline Recycled polypropylene & Wood flour/glass fibre & Injection molding & {$[57]$} \\
\hline High density polyethylene & Sawdust/silica with 3-methacryloxypropyl-trimethoxysilane & Internal mixer & {$[29]$} \\
\hline High density polyethylene & Kenaf/CaCO) & $\begin{array}{l}\text { Twin screw extruder followed by } \\
\text { compression molding }\end{array}$ & {$[59]$} \\
\hline High density polyethylene & Rice Husk $/ \mathrm{CaCO}_{3}$ & $\begin{array}{l}\text { Twin screw extruder followed by } \\
\text { compression molding }\end{array}$ & \\
\hline HDPE & $\begin{array}{l}\text { Wood flour (WF) of oak species/E-glass with maleic anhydride } \\
\text { as coupling agent }\end{array}$ & $\begin{array}{l}\text { Counter-rotating twin-screw ex- } \\
\text { truder }\end{array}$ & {$[60]$} \\
\hline $\begin{array}{l}\text { Recycled High density poly- } \\
\text { ethylene/PET }\end{array}$ & Rice husk/Organoclay & $\begin{array}{l}\text { Twin screw extruder followed by } \\
\text { compression molding }\end{array}$ & {$[61]$} \\
\hline RPP/RLDPE/RHDPE & Palm & $\begin{array}{l}\text { Twin screw extruder }+ \text { injection } \\
\text { molding with maleic anhydride as } \\
\text { coupling agent }\end{array}$ & {$[62]$} \\
\hline PVC & Wood flour/Zinc borate (ZB) & $\begin{array}{l}\text { Twin-screw/single-screw extrud- } \\
\text { er }+ \text { melt press }\end{array}$ & {$[63]$} \\
\hline Polylactic acid & Unidirectional flax fibre/flax paper layers & Compression molding & {$[37]$} \\
\hline
\end{tabular}


Table 4. Continuation of Table 4.

\begin{tabular}{|c|c|c|c|}
\hline Matrix & Reinforcement & Preparation method & Refs. \\
\hline Polylactic acid & $\begin{array}{l}\mathrm{NaOH} \text { treated Kenaf fibre/multiwalled carbon nanotubes with } \\
\text { 3-glycidoxypropyltrimethoxysilane }\end{array}$ & Internal mixer & {$[35]$} \\
\hline Polylactic acid & Kenaf fibre/corn husk flour & $\begin{array}{l}\text { Twin-screw extruder followed by } \\
\text { injection molding }\end{array}$ & {$[27]$} \\
\hline PLA/polyethylene glycol & $\mathrm{NaOH}$ treated Kenaf/ammonium phosphate & $\begin{array}{l}\text { Twin screw extruder }+ \text { compres- } \\
\text { sion molding }\end{array}$ & {$[64]$} \\
\hline Polylactic acid & fruit bunch fibres (EFBF)/Kenaf core fibres & Compression molding & {$[38]$} \\
\hline PLA & TEMPO oxidized Flax/ $/ \mathrm{TiO}_{2}$ & Hot press molding process & {$[65]$} \\
\hline $\begin{array}{l}\text { Poly(butylenes succinate- } c o- \\
\text { lactate)/starch }\end{array}$ & $\mathrm{NaOH}$ treated Luffa fibre & $\begin{array}{l}\text { Twin-screw extruder followed by } \\
\text { injection molding }\end{array}$ & {$[26]$} \\
\hline $\begin{array}{l}\text { Poly(butylenes succinate-co- } \\
\text { lactate)/starch }\end{array}$ & $\mathrm{NaOH}$ kenaf fibre & $\begin{array}{l}\text { Twin-screw extruder followed by } \\
\text { injection molding }\end{array}$ & {$[26]$} \\
\hline Polubutylene succinate (PBS) & $\begin{array}{l}\text { Ethanol treated Flax/ammonium phosphate } \\
\text { Ethanol treated Flax/dihydrogen ammonium phosphate } \\
\text { Ethanol treated Flax/phosphoric acid }\end{array}$ & $\begin{array}{l}\text { Internal mixer }+ \text { compression } \\
\text { molding }\end{array}$ & {$[66]$} \\
\hline Cassava starch & Cassava bagasse/ sugar palm fibre & Casting & {$[23]$} \\
\hline Corn Starch & $\begin{array}{l}\mathrm{NaOH} \text { treated date palm fibre/ } \mathrm{NaOH}+\text { Acetic acid treated flax } \\
\text { fibres }\end{array}$ & $\begin{array}{l}\text { Compression molding/Hot press- } \\
\text { ing }\end{array}$ & {$[67]$} \\
\hline Starch-grafted-polypropylene & Kenaf fibres & $\begin{array}{l}\text { Internal mixer + compression } \\
\text { molding }\end{array}$ & \\
\hline Natural rubber & Wood saw dust/ ground flax waste & $\begin{array}{l}\text { Mixed by two-roll mill followed } \\
\text { by Hydraulic pressing }\end{array}$ & {$[40]$} \\
\hline Natural rubber & Short pineapple leaf fibre/carbon black & $\begin{array}{l}\text { Mixed by two-roll mill followed } \\
\text { by Hydraulic pressing }\end{array}$ & {$[39]$} \\
\hline $\begin{array}{l}\text { Acrylonitrile butadiene } \\
\text { styrene (ABS) }\end{array}$ & Sisal/kenaf & $\begin{array}{l}\text { ABS dissolved in acetone and in- } \\
\text { fused into the hybrid fibres in a } \\
\text { mold }\end{array}$ & {$[68]$} \\
\hline $\begin{array}{l}\text { Recycled polypropylene } \\
\text { Recycled HDPE } \\
\text { Recycled polypropylene }\end{array}$ & $\begin{array}{l}\text { Wheat straw/inorganic filler (heavy calcium carbonate, silicon } \\
\text { dioxide, and fly ash) } \\
\text { chopped strand mat (CSM) glass fibres/short oil palm fibres } \\
\text { Halloysite/Kenaf fiber }\end{array}$ & $\begin{array}{l}\text { (i) Speed mixer, while stirring an } \\
\text { aqueous solution } \\
\text { (ethanol:water }=9: 1 \text { by } \\
\text { weight } \\
\text { (ii) Two-roll mill } \\
\text { (iii) Compression molding } \\
\text { Hot press techniques } \\
\text { Solution mixing (boiled xylene) }\end{array}$ & $\begin{array}{l}{[69]} \\
{[70]} \\
{[71]}\end{array}$ \\
\hline
\end{tabular}

Table 5. Recent reports on thermosets based hybrid composites [3, 7, 15, 18-20, 41-44, 46-48, 50-54, 72-85].

\begin{tabular}{|l|l|l|c|}
\hline \multicolumn{1}{|c|}{ Matrix } & \multicolumn{1}{|c|}{ Reinforcement } & \multicolumn{1}{|c|}{ Processing technique } & Refs. \\
\hline \multirow{5}{*}{ Unsaturated Polyester resin } & Nonwoven Hemp/woven basalt fibre & Compression molding & {$[46]$} \\
\cline { 2 - 4 } & Iron nanoparticles/kenaf fibre & Compression molding & {$[47]$} \\
\cline { 2 - 4 } & Kenaf/copper film & $\begin{array}{l}\text { Vacuum assisted resin transfer } \\
\text { molding (VARTM) }\end{array}$ & {$[44]$} \\
\cline { 2 - 5 } & Powdered activated carbon/kenaf fibre & $\begin{array}{l}\text { Vacuum assisted resin transfer } \\
\text { molding (VARTM) }\end{array}$ & {$[43]$} \\
\cline { 2 - 5 } & MgCO 3 particles/kenaf fibre & $\begin{array}{l}\text { Vacuum assisted resin transfer } \\
\text { molding (VARTM) }\end{array}$ & {$[42]$} \\
\cline { 2 - 5 } & Kenaf bast/glass fibre & Compression molding & {$[69]$} \\
\hline Polyester & NaOH treated Kenaf/woven E-glass & Compression molding & {$[41]$} \\
\hline Unsaturated polyester & Needle punched non-woven hemp fibre/basalt fabric & $\begin{array}{l}\text { Hand layup + compression mold- } \\
\text { ing }\end{array}$ & {$[46]$} \\
\hline Polyester & Jute/glass & Pultruded & {$[73]$} \\
\hline Epoxy resin & Palm nano filler/kenaf fibre & Compression molding & {$[3]$} \\
\hline Epoxy resin & Kenaf/MMT clay & Compression molding & {$[3]$} \\
\hline Epoxy resin & Kenaf/OMMT clay & Compression molding & {$[3]$} \\
\hline
\end{tabular}


Table 5. Continuation of Table 4.

\begin{tabular}{|c|c|c|c|}
\hline Matrix & Reinforcement & Processing technique & Refs. \\
\hline Epoxy resin & Hemp/basal fibre & Compression molding & {$[52]$} \\
\hline Epoxy resin & Jute/sisal & Hand layup & {$[13]$} \\
\hline Epoxy resin & Bagasse/banana & Hand layup & {$[51]$} \\
\hline Epoxy resin & Kenaf/glass/carbon nanotubes & Hand layup & {$[50]$} \\
\hline Epoxy resin & Kenaf/oilpalm nano filler & Hand layup & {$[48]$} \\
\hline Epoxy resin & Kenaf/ MMT & Hand layup & {$[48]$} \\
\hline Epoxy resin & Coconut coir/glass fibre & Hand layup & [74] \\
\hline \multirow[t]{4}{*}{ Epoxy resin } & Kenaf/OMMT & Hand layup & {$[48]$} \\
\hline & Basalt/sisal & Hand layup & {$[75]$} \\
\hline & Basalt/sisal/glass & Hand layup & {$[75]$} \\
\hline & Glass/sisal & Hand layup & {$[75]$} \\
\hline Epoxy & $\begin{array}{l}\text { Weaved bamboo/weaved E-glass } \\
\text { Weaved jute/weaved E-glass }\end{array}$ & Hand layup & [7] \\
\hline \multirow[t]{2}{*}{ Epoxy } & Jute-abaca/glass & Hand layup & {$[18]$} \\
\hline & Banana/jute/multi walled carbon nanotubes & Compression molding & {$[53]$} \\
\hline Epoxy & Unidirectional flax or cross-ply flax/ carbon fibre & Compression molding & {$[76]$} \\
\hline \multirow[t]{2}{*}{ Epoxy } & Short flax fibres mats/unidirectional flax yarns & Resin transfer molding (RTM) & {$[77]$} \\
\hline & Hemp mats/aluminium sheets & $\begin{array}{l}\text { Vacuum assisted resin transfer } \\
\text { molding (VARTM) }\end{array}$ & {$[54]$} \\
\hline \multirow[t]{4}{*}{ Epoxy } & Sisal/coir & Compression molding & {$[78]$} \\
\hline & Flax/carbon fibre & Compression molding & {$[76]$} \\
\hline & Woven Jute/ woven glass fibre & Brushing and roller & [79] \\
\hline & Woven kenaf/silicon/mesoporous silica & Resin transfer infusion & {$[80]$} \\
\hline Epoxy & Jute/glass/Sisal & Hand layup process & {$[81]$} \\
\hline Epoxy & Flax/glass & Compression molding & [82] \\
\hline Epoxy & Carbon/Flax & $\begin{array}{l}\text { Vacuum bagged and in an auto- } \\
\text { clave }\end{array}$ & {$[83]$} \\
\hline Epoxy & $\begin{array}{l}\text { Interwoven kenaf/jute } \\
\text { Interwoven kenaf/hemp }\end{array}$ & Vacuum infusion technique & {$[20]$} \\
\hline Epoxy & Flax/basalt & Vacuum bagging technique & {$[84]$} \\
\hline Epoxy & $\begin{array}{l}\text { Glass fibre/abaca } \\
\text { Glass fibre/jute } \\
\text { Glass/jute/abaca }\end{array}$ & Hand layup & {$[85]$} \\
\hline Epoxy & $\begin{array}{l}\text { E-woven glass/banana } \\
\text { E-woven glass/sisal } \\
\text { E-glass/sisal/banana }\end{array}$ & Compression molding & {$[19]$} \\
\hline Epoxy & Flax/ twill carbon & Compression molding & {$[86]$} \\
\hline Epoxy & Sisal/glass & Hand layup & {$[87]$} \\
\hline Epoxy & Hemp/flax/basalt & Vacuum infusion & {$[88]$} \\
\hline Vinyl ester & Flax/basal & $\begin{array}{l}\text { Resin infusion followed by heat } \\
\text { and autoclave }\end{array}$ & [89] \\
\hline Vinyl ester & Flax/basalt & Vacuum infusion technique & [90] \\
\hline
\end{tabular}

\section{Mechanical properties of hybrid polymer composites}

Mechanical properties of hybrid polymer composites depend on several factors. These factors include: the dispersion and distribution of reinforcements in the chosen polymer matrix, interfacial adhesion between polymer and reinforcements, large surface area, high aspect ratio of reinforcements, mechanical properties of reinforcements, effect of loading, surface modification, fiber dimension and orientation in the case of natural fibers. In many studies, mechanical properties are usually reported as a function of loading, size and fiber treatment [21,91-94]. Numerous researches have been reported on the development of hybrid 
polymer composites from both thermosets and thermoplastic by utilizing both synthetic and natural fibers as well as the combination of fibers with nanomaterials and their mechanical and thermomechanical properties elucidated [73, 92, 94, 95]. The reason of using more than one type of reinforcement is the fact that the advantage of one type can complement the disadvantage of another and thus, improve the properties and performance of the resultant material, as are listed in Table 6. Moreover, the demand for the development of such materials is increasing because they meet the requirements of many products, such as door panels and car interior in transport vehicle [92]. The prediction of the mechanical behavior of hybrid materials depend on material parameters, such as: the reinforcements (fibers or particles) mechanical properties, matrix mechanical properties, distribution and dispersion of reinforcements, volume fractions of the reinforcements and test conditions. Rule of mixture (ROM) is, often applied to predict the mechanical behaviors of hybrid materials. There are several models reported in the literature, based on ROM for the prediction of the mechanical properties of hybrid composite materials. These theoretical models, include Voigt, Reuss, Hirsch and Tsai-Pagano [96]. In the case of modulus prediction by using ROM from the hybridization Equation (3), $P$ as property of the components of the hybrid composites is replaced by $E$, which stands for modulus of each components, as in Equation (2). Yusoff et al. [97] reported that the modulus of a single type polymer reinforced with reinforcement (fibers or particles) can be calculated by using Equation (3). The volume fractions of the reinforcement (fibers in most cases) and polymer matrix are also determined, as shown in Equations (4) and (5):

$E_{\mathrm{c}}=E_{\mathrm{f}} V_{\mathrm{f}}+E_{\mathrm{m}} V_{\mathrm{m}}$

where

$V_{\mathrm{f}}+V_{\mathrm{m}}=1$ or $V_{\mathrm{m}}=1-V_{\mathrm{f}}$

$\therefore E_{\mathrm{c}}=E_{\mathrm{f}} V_{\mathrm{f}}+E_{\mathrm{m}}\left(1-V_{\mathrm{f}}\right)$

where, $E$ and $V$ are the Young's modulus and volume fractions of the reinforcement, respectively. The subscript $c, f$ and $m$ represent composite, fibers as reinforcement and matrix, respectively.

Venkateshwaran et al. [98] calculated the Young's modulus $\left(E_{\mathrm{hc}}\right)$ of hybrid composites as a sum of two systems (polymer composite reinforced with fiber 1 and polymer composite reinforced with fiber 2), as shown in Equation (6), by assuming that the strain of the hybrid equals to that of each system.

$E_{\mathrm{hc}}=E_{\mathrm{c} 1} V_{\mathrm{c} 1}+E_{\mathrm{c} 2} V_{\mathrm{c} 2}$

where, $E_{\mathrm{c} 1}$ and $E_{\mathrm{c} 2}$ are the elastic moduli for composites 1 and 2, respectively, while $V_{\mathrm{c} 1}$ and $V_{\mathrm{c} 2}$ represent the volume fractions of systems 1 and 2 , respectively (Equations (7)-(9):

$$
\begin{aligned}
& V_{\mathrm{c} 1}=\frac{V_{\mathrm{f} 1}}{V_{\mathrm{t}}} \\
& V_{\mathrm{c} 2}=\frac{V_{\mathrm{f} 2}}{V_{\mathrm{t}}} \\
& V_{\mathrm{t}}=V_{\mathrm{f} 1}+V_{\mathrm{f} 2}
\end{aligned}
$$

where, $V_{\mathrm{t}}$ is the total reinforcement volume fraction. However, in the case of Yusoff et al. [97], Kureemun et al. [92], Banerjee and Sankar [99] and Essabir et al. [96] the Young's modulus of the hybrid composites were calculated using the Equation (10):

$E_{\mathrm{hc}}=E_{\mathrm{f} 1} V_{\mathrm{f} 1}+E_{\mathrm{f} 2} V_{\mathrm{f} 2}+E_{\mathrm{m}}\left(1-V_{\mathrm{f} 1}-V_{\mathrm{f} 2}\right)$

Before using these equations, it is important to assume that there is no interaction between the fibers in the hybrid, the fibers are well aligned, dispersed and distributed throughout polymer matrix, good interfacial adhesion between the fibers and the matrix and that the load applied is parallel to the fibers direction. It was observed, in most studies that the predicted elastic moduli were in agreement with experimental values [92, 97, 98]. For instance, Venkateshwaran et al. [98] reported that the incorporation of sisal fibers in a hybrid composite reinforced with banana fibers resulted in an increase in both tensile strength and modulus up to the 50:50 ratio for materials tested in both the longitudinal and transverse directions. A further increase in sisal fiber loadings led to a decrease in the tensile strength and modulus of hybrid composite materials. It was also found that the calculated tensile modulus, by using ROM, followed similar trend as experimental results.

As mentioned earlier, ROM predicts the elastic modulus of continuous well-aligned fibers hybrid composites. However, this model does not predict the elastic modulus of hybrid composite reinforced with discontinuous fibers and small particles. Essabir et al. [96] applied Tsai-Pagano equation (shown in Equation (11)) to predict the elastic modulus of polypropylene hybrid composites reinforced with core fibers and core shell particles: 
$E_{\mathrm{hc}}=\frac{3}{8} E_{1}+\frac{5}{8} E_{2}$

where $E_{1}$ and $E_{2}$ are elastic moduli of the composite reinforced with core shell particles and core fibers, respectively. Similar to ROM, Tsai-Pagano theory assumes that there is a good dispersion, distribution and alignment of fibers, interfacial adhesion between reinforcements and polymer matrix. The authors [96], reported that the best fit was obtained when a force of $5000 \mathrm{MPa}$ for the core shell particles was utilized. It was also found that the predicted elastic modulus was comparable with the experimental elastic modulus.

On the other hand, in the case of the tensile strength $(\sigma)$ of the hybrid composite prediction, Equation (14) was derived through the application of an equilibrium force $\left(F_{\text {hc }}\right)$ on the hybrid cross-section area $(A)$ [92] (Equations (12), (13)). However:

$F_{\mathrm{hc}}=F_{\mathrm{f} 1}+F_{\mathrm{f} 2}+F_{\mathrm{m}}$ and $F=\sigma \cdot A$

Then,

$\sigma_{\mathrm{hc}} A_{\mathrm{hc}}=\sigma_{\mathrm{f} 1} A_{\mathrm{f} 1}+\sigma_{\mathrm{f} 2} A_{\mathrm{f} 2}+\sigma_{\mathrm{m}} A_{\mathrm{m}}$

$\therefore \sigma_{\mathrm{hc}}=\sigma_{\mathrm{f} 1} V_{\mathrm{f} 1}+\sigma_{\mathrm{f} 2} V_{\mathrm{f} 2}+\sigma_{\mathrm{m}}\left(1-V_{\mathrm{f} 1}-V_{\mathrm{f} 2}\right)$

Similarly to tensile modulus, the predicted tensile strength using ROM were in agreement with experimental tensile strength $[92,97]$. For example, Yusoff et al. [97] developed a PLA hybrid by the incorporation of two and three fiber systems. They discovered that the experimental tensile strength of the hybrid composites, reinforced with bamboo and coir fibers, matched perfectly well with the predicted tensile strength by ROM, whereas kenaf, coir fiber reinforced hybrid composites and kenaf, bamboo and coir fiber reinforced hybrid composites, were slightly different, with 9 and $15 \%$ higher, respectively than those predicted by using ROM. Naito and Oguma [100] predicted the tensile strength of the hybrid composites reinforced by using Equation (15). The authors reported that the estimated tensile strength (from Equation (15)) was in agreement with the experimental strength value:

$\sigma_{\mathrm{hc}}=\frac{F_{\max }}{A}=\frac{F_{\max }}{\frac{\pi d^{2}}{4}}$

where $F_{\max }$ and $d$ are maximum fracture load and diameter of the hybrid rod as measured by using a micrometre, respectively.
The prediction models of mechanical properties offer several advantages such as reduction of cost and minimize time consuming for the design of the new product for certain application since these models can be used to predict the resulting mechanical properties of the hybrid composite which are closely comparable to the of experimental results. It is noteworthy to mention that some models which account for other variables which affect the mechanical properties of the resulting composite materials can be modified for hybrid composite as reported in [101, 102, 103]. For instance, Pukanszky's model, which is often applied for quasi-spherical filler, could be used to describe the effects of filler volume fraction, and interface interactions on the mechanical properties.

\subsection{Synthetic-natural fibers reinforced hybrid composites}

Synthetic and natural fibers reinforced hybrid polymer composites have been used to enhance the performance of the resultant material, reduce moisture absorption, balance the costs of the fibers, reduce the negative environmental impact and lower the energy and carbon footprint [95]. Natural fibers are hydrophilic in nature because they contain hydroxyl groups on the surface and therefore, they swell when in contact with water/moisture, thereby resulting in unsatisfactory properties. Surface modification methods have been employed in order to mitigate the aforementioned problem but, the majority of those methods apply harsh chemicals, which are not environmentally-benign. Hybridization offers an alternative to chemical treatment by combining natural fibers with synthetic hydrophobic fibers [95]. This method involves the simultaneous reduction of water absorption and improving the properties of the resultant material.

There has been a lot of work, documented in the literature on hybrid materials, consisting of synthetic and natural fibers. Among these studies, Akil et al. [73] investigated the hybridization of synthetic glass fibers and high modulus jute fibers. Their results showed that the inclusion of glass fibers in a hybrid system of polyester composites reinforced with jute fibers resulted in the improvement of the tensile and flexural properties. It was also observed that the addition of glass fibers reduced water absorption of the material. Similar findings were reported in other studies $[92,94]$. These authors hybridized woven flax and carbon fabrics laminates as well as carbon and jute, 
respectively. In addition, Kureemun et al. [92]also highlighted that the increase in carbon content led to increase in tensile properties, while Ramana and Ramprasad [94] stated that the replacement of jute fibers portions with carbon fibers makes the material to be significantly stronger.

\subsection{Natural-natural fibers reinforced hybrid composites}

Polymer composites reinforced with natural fibers have shown a great potential in automotive as body parts, domestic furniture, food packaging, agricultural, biomedical building and residential applications [104]. Natural fibers can be blended with other natural fibers and can also be incorporated into a polymer matrix to form a hybrid composite. This can balance the costs of the natural fibers, improve the performance and properties of the resultant material [23]. Edhirej et al. [23] reported that the optimum tensile strength of a natural-natural fiber reinforced hybrid can be obtained when high strain is achieved. Researches are currently focusing on natural-natural fibers reinforced hybrid composites as suitable alternatives to synthetic fibers, such as carbon and glass fibers. Many researchers have investigated the mechanical properties of natural-natural fibers reinforced hybrid composites [20, 89, 105-107]. Amongst these researchers, Das [105] developed polyester hybrid composites reinforced with woven jute fabric and waste paper and studied their mechanical properties together with the mechanical properties of the individual composites. From the results, polyester composites-reinforced with woven jute fabric displayed high tensile and flexural properties, followed by hybrids and then polyester composites reinforced with waste paper (i.e. polyester composites-reinforced with woven jute fabric $>$ hybrids $>$ polyester composites reinforced with waste paper, in terms of their tensile and flexural properties). The reason for the decrease in the tensile and flexural properties of the hybrid composites was the fact that waste paper consists of short fibers, which contributed to the decrease in tensile properties of the materials. These results were in agreement with the interlaminar shear strength (ILSS) properties. Similarly, the tensile and flexural properties results reported by Fragassa et al. [89], followed a similar trend presented in the findings reported by Das [105]. In the case of Fragassa et al. [89] data, vinylester composites reinforced with basalt fiber exhibited high tensile and flexural properties; basalt-flax fibers reinforced vinylester hybrid followed and then vinylester composites reinforced with flax fibers. Conversely, vinylester composites reinforced with flax fibers had higher energy absorbed, followed by the hybrid and then vinylester composites reinforced with basalt fiber. Maslinda and co-workers [20] reported contrary findings. In their study, they reported that kenaf-jute fibers and kenaf-hemp fibers reinforced hybrids exhibited high flexural and tensile properties in comparison to the individual composites at both dry and saturated states. Very recent study on the mechanical properties (viz. tensile, compressive, hardness and impact strength) of woven banana fiber and groundnut shell ash reinforced epoxy hybrid composite was reported in [107]. It was found that hybrid composite composed of $82 \%$ epoxy, $1.5 \%$ banana fiber and $3 \%$ groundnut shell ash had good mechanical properties than other composites, except impact strength. It had a tensile strength of $12.02 \mathrm{MPa}$, hardness of 37.3, impact strength of $0.340 \mathrm{~J} / \mathrm{mm}^{2}$ and compressive strength of $24.4 \mathrm{MPa}$, whereas composite composed of $85 \%$ epoxy and $15 \%$ banana had tensile strength of $10.21 \mathrm{MPa}$, hardness of 35.6, impact strength of $0.252 \mathrm{~J} / \mathrm{mm}^{2}$ and compressive strength of $20.7 \mathrm{MPa}$. A maximum impact strength $\left(0.65 \mathrm{~J} / \mathrm{mm}^{2}\right)$ was obtained for hybrid composite composed of $77.5 \%$ epoxy, $15 \%$ banana and $7.5 \%$ groundnut shell ash.

Of recent, the development of biodegradable hybrids after the end of service life, has been a research hotspot. A biodegradable hybrid should consist of biodegradable polymer matrix and natural fibers. For instance, Sarasini et al. [108] developed biodegradable polycaprolactone (PCL)-based hybrid reinforced with ramie and borassus fibers. The inclusion of ramie fibers in PCL matrix resulted in increases in both the tensile strength and modulus. Further increases in both the tensile strength and modulus were observed when the content of ramie fibers was increased. However, the addition of borassus fibers in that system did not improve both the tensile strength and modulus, irrespective of the fiber content. In addition, the inclusion of fibers did not influence the hardness of the hybrid to a great extent. Jumaidin et al. [109] and Edhirej et al. [23] developed hybrid composites by using starch as a matrix and reinforced with seaweed and sugar palm fibers (SPF), cassava and SPF, respectively. In the case of Jumaidin et al. [109] work, the results demonstrated that hybrid showed higher tensile and flexural strength in 
comparison to the individual composites. An increase of SPF content from 25 to $50 \%$ led to improvements in the tensile and flexural strengths. The highest tensile (17.74 MPa) and flexural strength (31.24 MPa) was achieved for hybrid composite with 50:50 ratio of seaweed/SPF due to good compatibility between seaweed, SPF and the matrix. In contrast, the impact strength decreased with increase in SPF content by 1.2, 8.4 and 7.3\%, respectively for $75: 25,50: 50$ and 25:75 ratio of seaweed/SPF. This was attributed to an increase in the rigidity of the material following incorporation of SPF. In addition, the hybridization of seaweed and SPF, led to slower biodegradation activity.

\subsection{Hybrid nanocomposite materials}

Hybrid nanocomposites involve the inclusion of nanofiller in polymer composites [110, 111]. The addition of different nano-scale materials (oil palm nanofiller (OPN), montmorillonite (MMT) and organically modified montmorillonite (OMMT)) at 3\% by weight, in kenaf fibers-reinforced hybrid nanocomposites, increased the tensile strength, tensile modulus and impact strength in comparison to the individual epoxy composite reinforced with kenaf fibers. Nano-scale materials have large surface areas and therefore, the incorporation of such materials induces the connection between kenaf fibers and the epoxy resin, which led to the enhancement of the mechanical properties of hybrid nanocomposites. However, hybrid nanocomposites reinforced with OPN displayed lower tensile properties when compared to hybrid nanocomposites reinforced with both MMT and OMMT. In addition, hybrid nanocomposites reinforced with OMMT, showed relatively high tensile properties and impact strength due to the strong reinforcing effect influenced by the treatment [55]. Similar observations were reported in other studies [110, 112]. In the work of Arrakhiz et al. [113], they reported that hybridization of pinecone fibers and clay, led to an increase in the stiffness of the material and a further increase of clay content up to $30 \%$, resulted in increased stiffness of the material but the tensile strength values remained constant. In contrast, Piekarska et al. [114] and Essabir et al. [96] reported that the hybridization of fibers and nanomaterials, led to the decrease in tensile properties. Battegazzore et al. [101] reported that the addition of modified clay (Cloisite 30B) into rice husk ash (RHA)/to different polymers (viz. polyamide (PA6.10 and PA 10.10) and polylactic acid (PLA) generally increased modulus at the expense of elongation. The modulus increased by 94,85 and 53\% for PA6.10, PA10.10 and PLA based hybrid composite, whereas 45, 44 and $40 \%$ were obtained for their composites with $20 \%$ rice husk ash (RHA). General decrease in tensile strength was observed and Pukanszky's model was employed to determine if there is some different interaction between fillers and matrices. It was found that the application of Pukanszky's model do not follow the composite behavior from 10 to $20 \mathrm{wt} \%$ loading which could be related to a loss of matrix-filler interaction especially at higher filler loadings.

\subsection{Thermomechanical properties of hybrid composites}

Thermomechanical properties of hybrid composite materials are expressed in terms of storage modulus $\left(E^{\prime}\right)$, loss modulus $\left(E^{\prime \prime}\right)$ and $\tan \delta$, which is also called the damping factor and they are plotted as a function of time, temperature and/or frequency. Other researchers have investigated these properties as functions of reinforcement content $[96,112]$. The thermomechanical properties of hybrid composites reinforced with treated and untreated grass fibers and glass fibers were investigated by Ridzuan et al. [115]. As expected, storage modulus decreased with increase in temperature because the polymer chains started to move freely. All the hybrids had higher storage modulus in comparison to neat epoxy. Hybrid composite reinforced with 5\% alkali-treated grass fibers and glass fibers, had the highest storage modulus and loss modulus, followed by the hybrid composite reinforced with $10 \%$ alkali-treated grass fibers and glass fibers and then hybrid composite, reinforced with untreated grass fibers and glass fibers. According to Romanzini et al. [116], the improvement of storage modulus in the hybrid composites was due to the higher molecular mobility restriction imposed by the fibers on polymer matrix. It was observed that neat resins had the highest damping factor [115] and [116]. However, the height of the damping factor of the hybrid composites decreased and shifted to higher temperatures due to the molecular mobility restriction and good interfacial adhesion between polymer and reinforcements. Other reported work on the thermomechanical properties of hybrid composites reinforced with synthetic-natural fibers [117], synthetic-synthetic fibers [118] and natural-natural fibers $[119,120]$. 
The thermomechanical properties of hybrid nanocomposites were also investigated [3, 121]. Saba et al. [3] developed epoxy-kenaf hybrid nanocomposites reinforced with oil palm empty fruit bunch (OPEFB), MMT and OMMT and subjected them to dynamic mechanical analysis (DMA) in order to investigate their thermomechanical properties. The storage and loss moduli data clearly indicated that the incorporation of nanomaterials in epoxy composite reinforced with kenaf fibers, improved both the storage and loss moduli of the resultant composites. Interestingly, the hybrid composite containing OMMT had the greatest storage and loss moduli, followed by the one containing MMT and lastly, the one containing OPEFB. As mentioned in the foregoing paragraph, the enhancement of storage and loss moduli is due to the restriction in the polymer chain mobility [3]. This results were in agreement with other findings reported by other researchers [116, 121]. In the case of the damping factor, epoxy composite reinforced with kenaf fibers showed high damping factor peak height, whereas the hybrid composite containing OMMT had the lowest due to the restriction in the polymer chain mobility [3]. In addition, it was observed that the damping factor shifted to higher temperatures. Matykiewicz et al. [121] reported that the incorporation of $2.5 \%$ of basalt powder in epoxy hybrid reinforced with basalt fibers led to the increase in storage modulus. However, further increase in basalt powder content to 5 and $10 \%$ did not improve storage modulus. On contrary, epoxy composites reinforced with basalt fibers had lower damping factor in comparison to hybrid materials.

Table 6. Highlights of selected studies on the mechanical properties of hybrid composites reinforced with synthetic-natural, synthetic-synthetic and natural-natural fibers $[20,55,73,92,95,109,112,113]$.

\begin{tabular}{|c|c|c|c|c|}
\hline System & Materials & Highlights & Advantages & Refs \\
\hline \multirow{3}{*}{$\begin{array}{l}\text { Synthetic-natural } \\
\text { fibres hybrids }\end{array}$} & - Glass-jute fibre hybrids & $\begin{array}{l}\text { - Hybrid had higher mechanical properties } \\
\text { when compared with non-hybrid jute rein- } \\
\text { forced composite } \\
\text { - Reduction of degradation of jute fibres }\end{array}$ & $\begin{array}{l}\text { - Balancing performance and cost } \\
\text { - Reducing moisture absorption } \\
\text { - Improved mechanical properties }\end{array}$ & [73] \\
\hline & $\begin{array}{l}\text { - Carbon-flax fibre hy- } \\
\text { brids }\end{array}$ & $\begin{array}{l}\text { - Hybrid had increased mechanical properties } \\
\text { when compared to non-hybrid woven flax re- } \\
\text { inforced composites }\end{array}$ & - Improved mechanical properties & [92] \\
\hline & $\begin{array}{l}\text { - Carbon-jute fibre hy- } \\
\text { brids }\end{array}$ & $\begin{array}{l}\text { - Mechanical properties of hybrid material are } \\
\text { higher than that of non-hybrid jute reinforced } \\
\text { composites }\end{array}$ & $\begin{array}{c}\text { - Improved mechanical properties } \\
\text { - Hybrid can replace non hybrid } \\
\text { carbon reinforced composite }\end{array}$ & [94] \\
\hline \multirow[t]{2}{*}{$\begin{array}{l}\text { Natural-natural } \\
\text { fibre hybrids }\end{array}$} & $\begin{array}{l}\text { - Kenaf-jute fibre hybrids } \\
\text { - Kenaf-hemp fibre hy- } \\
\text { brids }\end{array}$ & $\begin{array}{l}\text { - Hybrid composites absorbed less water in } \\
\text { comparison to non-hybrid kenaf, jute and } \\
\text { hemp reinforced composites } \\
\text { - Hybrid composites had higher mechanical } \\
\text { properties in comparison to non-hybrid kenaf, } \\
\text { jute and hemp reinforced composites }\end{array}$ & $\begin{array}{l}\text { - Low cost } \\
\text { - Minimal improvement of mechan- } \\
\text { ical and water resistance properties }\end{array}$ & [20] \\
\hline & $\begin{array}{l}\text { - Seaweed-sugar palm } \\
\text { fibre hybrids }\end{array}$ & $\begin{array}{l}\text { - Hybrid composites had slightly improved ten- } \\
\text { sile and flexural strengths with lower impact } \\
\text { resistance }\end{array}$ & \begin{tabular}{|l|} 
- Low cost \\
- Minimal improvement of mechan- \\
ical and water resistance properties
\end{tabular} & [109] \\
\hline \multirow{3}{*}{$\begin{array}{l}\text { Hybrid } \\
\text { nanocomposites }\end{array}$} & $\begin{array}{l}\text { - Oil palm fibres-clay } \\
\text { hybrid }\end{array}$ & $\begin{array}{l}\text { - Mechanical properties of hybrid showed sig- } \\
\text { nificant increase when compared to non-hy- } \\
\text { brid oil palm fibre reinforced composites }\end{array}$ & $\begin{array}{l}\text { - Low cost } \\
\text { - Significant improvement of me- } \\
\text { chanical properties }\end{array}$ & {$[112]$} \\
\hline & $\begin{array}{l}\text { - Pine cone fibres-clay } \\
\text { hybrid }\end{array}$ & $\begin{array}{l}\text { - Tensile modulus of hybrid composite increase } \\
\text { with increasing loading }\end{array}$ & $\begin{array}{l}\text { - Low cost } \\
\text { - Significant improvement of ten- } \\
\text { sile modulus }\end{array}$ & {$[113]$} \\
\hline & $\begin{array}{l}\text { - Kenaf fibres- oil palm } \\
\text { nanofiller } \\
\text { - Kenaf- Montmorillonite } \\
\text { (MMT) and organically } \\
\text { modified montmoril- } \\
\text { lonite (OMMT) }\end{array}$ & $\begin{array}{l}\text { - Mechanical properties of hybrid showed sig- } \\
\text { nificant increase when compared to non-hy- } \\
\text { brid kenaf fibre reinforced composites }\end{array}$ & $\begin{array}{l}\text { - Low cost } \\
\text { - Significant improvement of me- } \\
\text { chanical properties }\end{array}$ & [55] \\
\hline
\end{tabular}

Summary-In general, synthetic-natural fibre hybrids have superior mechanical properties when compared to other hybrids (natural-natural fibre hybrids and hybrid nanocomposites). Despite the promising performance of synthetic-natural fibre hybrids, these materials have also inherent some drawbacks such as: high cost, and they are partially eco-friendly. On the other hand, hybrid nanocomposites displayed significant improvement in mechanical properties when compared to natural-natural fibre hybrids with the added advantage of low cost. 


\section{Moisture absorption}

Moisture absorption is one of the major drawbacks in fiber reinforced polymer composites. This can cause a major restriction in the successful application of natural fibers in durable composites that are not necessarily limited to non-structural and interior applications. Moisture absorption in composites materials is mainly driven by the hydrophilic nature of natural fibers. Natural fibers are made up of a large number of hydroxyl groups $(-\mathrm{OH})$ that are found in hemicellulose and cellulose, but not all the constituents contribute to the moisture absorption. For instance, lignin is hydrophobic in nature and has low -OH-to-carbon (C) ratio. On the other hand, cellulose, which forms the major part of natural fibers, has a large - $\mathrm{OH}$-to-C ratio, of which small amounts of $-\mathrm{OH}$ groups are exposed or accessible to water molecules, since cellulose is semicrystalline. The crystalline region is inaccessible to water molecules but the water molecules are able to gain access to the amorphous region of the cellulose. Another constituent susceptible to moisture is hemicellulose, which has high $-\mathrm{OH}$-to- $\mathrm{C}$ ratio and it is predominantly amorphous, thereby making it highly accessible to water molecules $[122,123]$. When natural fibers absorb water molecules, they swell up because of water molecules occupying the space between the microfibrils, known as the temporary microcapillary
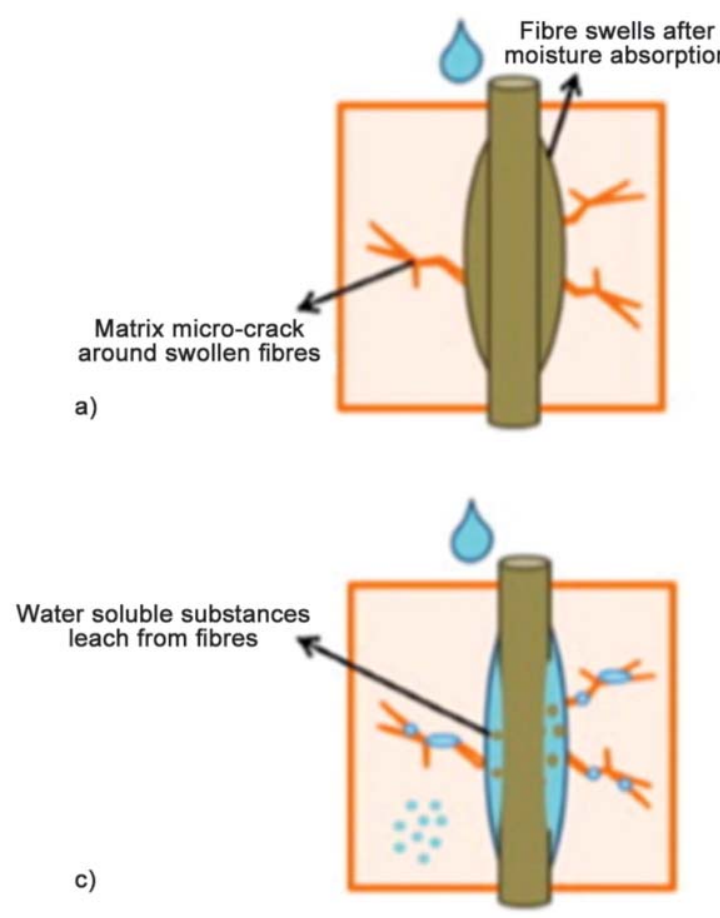

b)

network. The absorbed water molecules within the fibers can either form a multilayer at which not all water molecules are in intimate contact with the available - $\mathrm{OH}$ groups or form a monolayer, which associates closely with the available-OH groups.

In natural fiber reinforced polymer composites, several factors influence the manner in which composite materials absorb water. These factors include: fiber volume fraction, temperature, fiber nature, difference in water circulation within the composite, degree of crosslinking and crystallinity, diffusivity and the response between water and the polymer [124, 125]. Moisture absorption into composite materials is driven by a major mechanism, known as diffusion. Diffusion is a process by which a substance is transported from one part (high concentration) of a system to another (low concentration) because of random molecular motion. The diffusion of water molecules into the composite material, involves: (i) direct penetration of water molecules into the microgaps between polymer chains, (ii) transport of water molecules by microcracks in the matrix, arising from swelling of fibers and (iii) capillary transport of water molecules into flaws and gaps at the interface between the fibers and the polymer, owing to the incomplete/poor impregnation and wetting [73, 126, 127]. Therefore, in natural fiber-based thermoplastic or thermoset-reinforced composites, water absorption

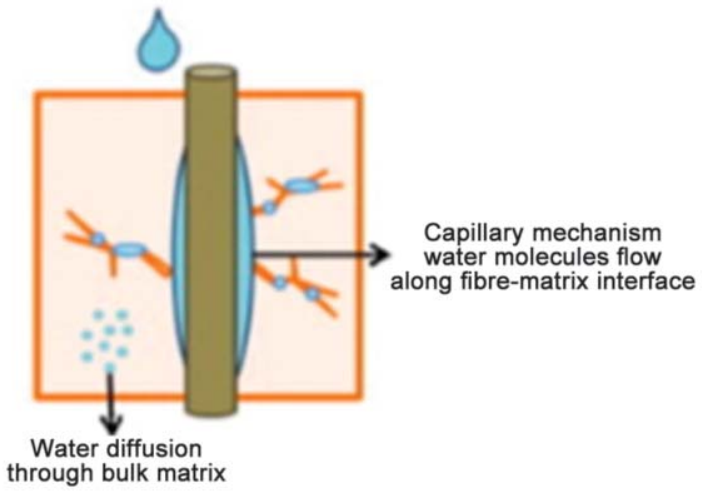

d)

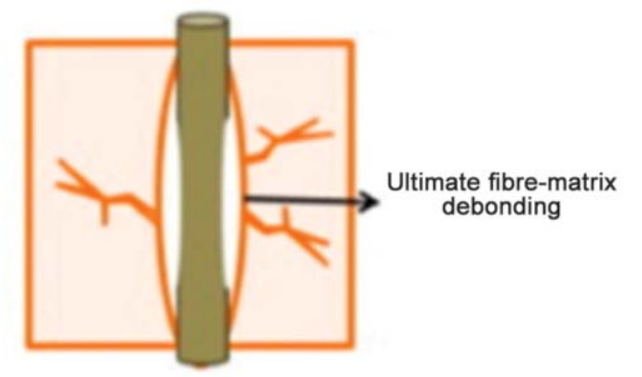

Figure 3. Effect of water absorption on fiber-matrix interface [123]. (a) Formation of micro-cracks due fiber swelling; (b) penetration and transport of water molecules through micro-cracks; (c) water soluble substance leaching; and (d) debonding of fiber-matrix interface 
behavior is observed when the composite is exposed to moisture and the polar nature of fibers causes the fiber to absorb water and swell. The resulting swelling, due to the penetration of water molecules leads to dilapidation, formation of cracks and debonding of the fiber-polymer interface, as illustrated in Figure 3. This is initiated by the development of osmotic pressure pockets at the surface of the fibers due to the leaching of water soluble substances from the fiber surface $[10,128]$. Furthermore, the absorbed water molecules can act as a plasticizer, which can create regions of poor transfer efficiency and results in the reduction of composite mechanical properties.

Water absorption tests in composite materials are usually investigated according to ASTM D 570-98, where the percentage of moisture content/absorption $\left(M_{\mathrm{c}}\right)$ by the composite is determine according to Equation (16) and in some cases, the percentage of thickness swelling (TS) (or dimensional stability) due to absorbed water molecules, is also determined, as described in Equations (16), (17) [69, 129-131]:

$M_{\mathrm{c}}=\frac{M_{\mathrm{t}}-M_{0}}{M_{0}} \cdot 100 \%$

where $M_{\mathrm{t}}$ is the weight of the sample at time $t$ and $M_{0}$ is the initial weight of the sample:

$T S=\frac{T_{\mathrm{h}}-T_{0}}{T_{0}} \cdot 100 \%$

where $T_{0}$ and $T_{\mathrm{h}}$ are the thicknesses of samples in the dry and wet states, at a given time, respectively.

Besides the percentage of moisture content and thickness swelling, in composite materials several mechanisms are responsible for water absorption, but generally the overall effect is usually modelled taking into account the diffusion mechanism. Therefore, the process of water absorption in fibers based composites follows the diffusion mechanism and kinetics in accordance with the Fick's theory, which has been applied in previous fiber reinforced composites [130, $132,133]$. From the theory, penetration of water molecules inside the composite structure can be calculated from the Fickian diffusion coefficient $(D)$ according to Equation (18). The diffusion of water molecules is dependent on three different types of diffusion behaviors, which are extensively, reported in literature $[126,134,135]$. The shape of the sorption curve can, theoretically, distinguish the diffusion behaviors, however, the commonly used diffusion theory, is the Fickian diffusion:
$D=\pi\left(\frac{k h}{4 M_{\mathrm{eq}}}\right)^{2}$

where $M_{\mathrm{eq}}$ is the maximum moisture content at equilibrium, $h$ is the thickness of the composite and $k$ is the initial slope of the moisture content $(M(t))$ as a function of the square root of time $\left(t^{1 / 2}\right)$, as described by Equation (19):

$k=\frac{M_{2}-M_{1}}{\sqrt{t_{2}}-\sqrt{t_{1}}}$

In literature, various studies and reviews have been reported, on: chemical and physical treatments, use of coupling agents, inorganic and bio-based coatings in order to decrease the moisture absorption behavior in natural fiber-reinforced composites [122, 136138]. However, moisture absorption remains as a challenge in natural fiber-based composites. Another alternative technique to mitigate moisture absorption is by hybridization of natural fibers with more water resistant inorganic fillers and/or synthetic fibers, which can have a profound effect on the water absorption behavior of the resulting composites [73]. Studies on hybrid composites produced from synthetic fibers/natural fibers [73, 139-142] and inorganic/natural fibers $[69,129,143,144]$, have been reported to mitigate the moisture absorption of natural fiber-based composites. The influence of moisture absorption on natural fiber-reinforced polymer composites, hybridized with inorganic fillers or synthetic fibers, are summarized in Table 7 [42, 45, 73, 139, 143, 145-147].

Panthapulakkal and Sain [126] investigated water absorption characteristics and its effect on the tensile properties of hemp and hemp/glass fiber hybrid polypropylene (PP) composites, prepared by injection molding. Moisture absorption by immersion method was evaluated at different temperatures, viz: 40, 60 and $80^{\circ} \mathrm{C}$. The hybrid composites showed a Fickian diffusion behavior, but with a deviation at high temperatures, which was attributed to the formation of microcracks and dissolution of lower molecular weight substance from the natural fibers. Furthermore, hemp fiber composite showed a significant reduction in strength and stiffness due to the absorbed moisture, which resulted in the debonding of the fiber-matrix interface. Hybridization of natural fibers with glass fiber, significantly decreased its water absorption by $\sim 40 \%$. However, the absorbed moisture had a detrimental effect on the tensile strength and modulus of both hemp fiber and hemp/glass fiber hybrid 
Table 7. Water absorption studies of various formulated hybrid composites [42, 45, 73, 139, 143, 146-147].

\begin{tabular}{|c|c|c|c|c|c|}
\hline Type of composite & Preparation method & $\begin{array}{c}\text { Moisture absorption } \\
{[\%]}\end{array}$ & $\begin{array}{c}\text { Dimensional stability } \\
{[\%]}\end{array}$ & \begin{tabular}{|c|} 
Diffusion coefficient \\
{$\left[\mathrm{m}^{2} / \mathrm{s}\right]$}
\end{tabular} & Refs \\
\hline Jute/glass fibre/polyester $\left(\mathrm{JGC}^{*}\right)$ & Pultrusion process & $8.34 \pm 0.71$ & - & $2.27 \cdot 10^{-10}$ & \multirow{2}{*}{ [73] } \\
\hline Jute/glass fibre/polyester (JGS*) & & $22.29 \pm 1.72$ & - & $1.43 \cdot 10^{-10}$ & \\
\hline \multirow{2}{*}{$\begin{array}{l}\text { Kenaf/magnettie } 20-40 / \text { polyester } \\
\text { INI }(0.10-13.79 \mathrm{MPa}) \text { treated } \\
\text { fibre/polyester }\end{array}$} & \multirow{2}{*}{ VARTM process } & $4.9-2.6 \pm 0.7-0.2$ & $5.0-2.4 \pm 1.4-0.3$ & - & {$[143]$} \\
\hline & & $11.9-6.9 \pm 0.5-0.4$ & $12.3-7.0 \pm 1.5-1.7$ & - & [42] \\
\hline Epoxy/(coir/jute/coir) & \multirow{3}{*}{$\begin{array}{l}\text { Hand lay-up tech- } \\
\text { nique \& Compres- } \\
\text { sion molding }\end{array}$} & 15.3 & 9.24 & - & \multirow{2}{*}[145]{} \\
\hline Epoxy/(jute/coir/jute) & & 11.2 & 8.35 & - & \\
\hline Epoxy/(20\% kenaf/Kevlar) & & 3.15 & 3.38 & $0.87 \cdot 10^{-9}$ & [139] \\
\hline Epoxy/kenaf/PET (70/15/15) & \multirow{2}{*}{ Vacuum Infusion } & 3.988 & - & $1.50 \cdot 10^{-6}$ & \multirow{2}{*}[148]{} \\
\hline Epoxy/kenaf/PET (60/20/20) & & 2.089 & - & $6.0 \cdot 10^{-6}$ & \\
\hline $\begin{array}{l}\text { INI-treated fibre reinforced com- } \\
\text { posite }\end{array}$ & VARTM process & $6.6 \pm 0.4$ & $6.3 \pm 0.6$ & - & [45] \\
\hline
\end{tabular}

*Jute fibre stacking, chopped strand mat (C) and surface veil (S)

composites. On the other hand, pultruded hybrid composites from jute-glass fibers and unsaturated polyester, showed superior modulus and strength retention at high temperatures of 50 and $80^{\circ} \mathrm{C}$ when compared to jute composites, following water immersion [45]. Moreover, the hybrid composites exhibited a tendency towards a deviation from Fickian behavior with increasing moisture resistance due to the addition of glass fibers. The results provided evidence that durability of natural fiber composites can be tailored by suitable hybridization with synthetic fibers in order to balance cost effectiveness, while reducing the environmental impact emanating from the material. Again, reinforcement of natural fiber with glass fiber may serve as a skin protection, thereby resulting in a drastic reduction in moisture absorption of natural fiber-based hybrid composites, as reported by Sature and Mache [140], in their studies on the mechanical characterization and water absorption on jute/hemp reinforced hybrid composites. Other than synthetic fibers, the presence of inorganic fillers influenced the reduction of moisture absorption in wheat straw (WS)/recycled polypropylene (rPP) hybrid composites investigated by $\mathrm{Yu}$ et al. [69]. Incorporation of: fly ash, heavy calcium carbonate and $\mathrm{SiO}_{2}$ reduced the water absorption by: $1.8,25.8$ and $42.4 \%$, respectively when compared to $\mathrm{WS} / \mathrm{rPP}$ composites. Moreover, the incorporation of $\mathrm{SiO}_{2}$ effectively decreased the water absorption with increasing $\mathrm{SiO}_{2}$ content. This was attributed to the presence of $\mathrm{SiO}_{2}$, which acted as a barrier medium that hindered water flowing into the composites and as a result reduced water absorption and the diffusion coefficient. Similar observations were reported in aluminum hydroxide $\left(\mathrm{Al}(\mathrm{OH})_{3}\right)$-, magnetite- and magnesium carbonate $\left(\mathrm{MgCO}_{3}\right)$-reinforced natural fiber composites [42, 143, 145]. The incorporation of these inorganic fillers significantly decreased the moisture absorption and thickness swelling of the hybrid composites. The reason to the dramatic improvement in the water resistance properties of the composites was due to the adhesion between the fibers and the inorganic fillers. This is because of hydrogen bonding, thus blocking large amounts of $-\mathrm{OH}$ groups to interact with water molecules.

\section{Biological durability}

Natural fibers are recognized by their degradation tendency (viz. biological, chemical, mechanical, thermal, photochemical and aqueous), depending on the environment in which they are exposed to during their service $[10,11]$. This is associated with the individual constituents present in the natural fiber utilized. For instance, it is observed that lignin is responsible for UV degradation, whereas, hemicelluloses are responsible for biological degradation as well as moisture absorption $[10,11]$. Although this property justifies their use as reinforcement of different polymeric materials, their degradation may be undesirable for certain applications. The treatment of the fibers to block the $-\mathrm{OH}$ and other polar groups on their surface can improve the resistance to biological degradation [10]. In the case of the composites, it is recognized that biological degradation is influenced, mainly by the resin and interfacial treatment, and the loss of interfacial strength can greatly influence the entire composite to biological degradation [148]. Very few studies were reported on the biological 
durability of the hybrid composite materials [109, 148-150]. The presence of carbon fiber was reported to reduce the decay rate of the hybrid composite in [149]. It was found that without carbon fibers, the composites exhibited the mass loss rate of 29.35 and $40.99 \%$ after exposure for six weeks to white rot (Trametes versicolor) and brown rot (Coniophora puteana) fungi, respectively. The mass loss, however, reduced to 0.14 and $0.78 \%$ for hybrid composites consist of $5 \%$ sisal fibers and $35 \%$ carbon fibers. Biopolymers are known by their biodegradability, which in turn can be controlled by incorporation of various fillers. Inclusion of Carauá fiber into the biodegradable polyester-based blend by using maleic-grafted polypropylene (MA-g-PP) as compatibilizer led to reduction in water absorption, which in turn, resulted in higher amounts of retained mass of composites in biodegradation tests [151]. The retained mass of polyester blend $/ 20 \mathrm{wt} \%$ Carauá fiber/MA-g-PP composite was $68 \%$ as compared to pure polymer which was $26 \%$ after 210 days under soil burial test. Jumaidin et al. [109] reported that the inclusion of $75 \%$ sugar palm fiber (SPF) reduced weight loss by 53.7 and $73.2 \%$ after 2 and 4 week of burial in the soil, respectively. This was ascribed to the high biodegradation resistance of SPF due to a less hydrophilic characteristic than seaweed. It is recognized that an increase in hygroscopic characteristics of the material facilitates the growth of microorganisms during degradation and hence increases the weight loss of material.

The effect of weathering on polyethylene/wood composites in the presence of nano zinc oxide was investigated in [152]. The presence of zinc oxide decreased surface degradation during weathering due to its capability to absorb UV radiation. Using accelerated weathering with xenon-arc light and water spray, the effect of weathering on the properties of PP-based co-extruded wood plastic composites (WPC) loaded with different fire retardant fillers, i.e., aluminium trihydrate (ATH), zinc borate (ZB), melamine, graphite $(G)$ and titanium were studied by [153]. It was demonstrated that graphite was the best choice to protect the composite against light action. This was attributed to graphite acting as physical screening and light absorber because of the presence of chromophore groups on the graphite surface. The degradation of the hybrid composite, is generally, affected by conditions at which the materials is exposed. The exposure to UV radiation, rain water and high temperature caused micro- and macrocracks in the hybrid composite which accelerated subsequent biodegradation in soil and fungal decay as reported in [150].

\section{Flame resistance \\ 6.1. Flammability properties of hybrid fiber composites (untreated and treated composites)}

Flame retardancy and smoke production characteristics of composites materials are major issues. This is because the composite material must pass a certain fire regulatory to ensure public safety since most of the natural fiber composite materials are used in our homes. When natural fiber composites are exposed to fire or any other high-intensity heat source, they are subjected to thermal decomposition and combustion. As a result, it is important to understand how individual components of the end-products burn and how best can we modify materials to make them flame-resistant without compromising their uniquely valuable low weight to high mechanical ratios. Flammability properties of hybrid natural fiber composites have been investigated by employing the UL 94 burning rates, cone calorimeter and limiting oxygen index (LOI) measurements. Table 8 illustrates the limiting oxygen index (LOI) and the heat release rate (HRR) of selective polymer matrices [63, 154-169]. Generally, a material with a higher LOI will have a lower flammability than the one with a lower LOI value. A cone calorimeter is an instrument that works on a principle that is based on the oxygen consumption of the material during a combustion performance test [170]. The basic parameters of a cone calorimeter are:

Table 8. Limiting oxygen indices (LOI) of polymers and their heat release rates obtained by cone calorimeter at different heat flux [63, 154-169].

\begin{tabular}{|l|c|c|c|}
\hline \multicolumn{1}{|c|}{ Polymer } & LOI & $\begin{array}{c}\text { HRR } \\
{\left[\mathbf{k W} / \mathbf{m}^{2}\right]}\end{array}$ & Refs \\
\hline Polypropylene & 18 & $1145-1395$ & {$[154,155]$} \\
\hline Low-density polyethylene & 17 & 1478 & {$[156]$} \\
\hline Linear Low-density polyethylene & 17 & 1318 & {$[157]$} \\
\hline High density polyethylene & 19 & 1521 & {$[158,159]$} \\
\hline Polycarbonate & 26 & 294 & {$[160]$} \\
\hline ABS & 19 & 704 & {$[161]$} \\
\hline Poly(vinyl chloride) & & 221.3 & {$[63]$} \\
\hline Epoxy resin & 23 & 1261 & {$[162,163]$} \\
\hline Polylactic acid & 20 & 769 & {$[164,165]$} \\
\hline Polystyrene & 18 & $780-840$ & {$[166,167]$} \\
\hline Poly(methyl methacrylate) & 18 & $700-897$ & {$[168,169]$} \\
\hline
\end{tabular}




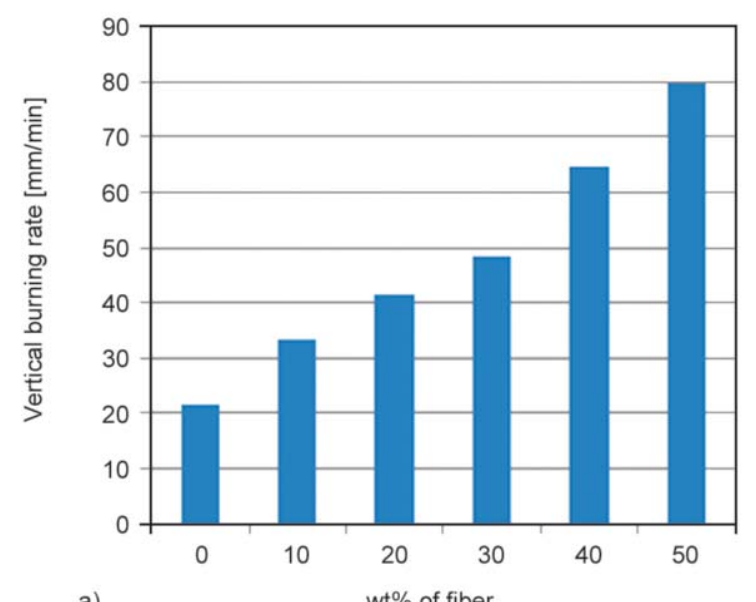

a)

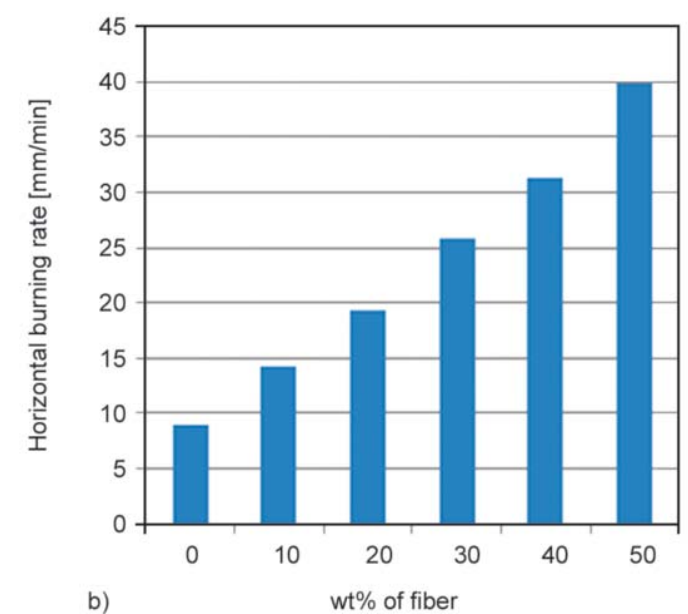

b)

Figure 4. Vertical (a) and horizontal (b) burning rate of hybrid composites with different $w \mathrm{t} \%$ of sisal and coir fiber loading [78]. Open access.

time to ignition (TTI), heat release rate (HRR), mass loss rate (MLR), smoke production rate (SPR), etc. Heat release rate (HRR) is a very important parameter and it can be used to express the intensity of fire. Unlike LOI, a highly flame retardant system normally shows a low HRR peak. The majority of the reinforcing natural fibers in polymers was observed not to help in terms of improving the fire resistance (measured by LOI and Cone calorimeter) of the natural fiber composites (Figure 4) [78]. The results in Figure 4 indicated that the addition of coir and sisal fiber promoted the flammability of the resultant composite and therefore, the majority of natural fibers can be regarded as poor flame retardant materials. A careful inspection of the plots in Figure 4 showed that the burning rates of the vertical and horizontal tests are different, with the flame rate of the vertical test being faster than the horizontal test. This is due to the preheating of the samples in the vertical burning test. However, in some studies $[63,171]$, the incorporation of wood into polymers without any flame retardant filler had a positive effect on fire performance of polymer matrices, but had little effect on the smoke suppression. From the cone calorimeter measuring technique, the peak heat release rate was observed to decrease with the addition of wood flour in comparison to polymer matrices. The authors provided different reasons for the two systems, viz: (i) it was reported that wood flour had a lower peak HRR than PP, thus placing the fire performance of wood flour/PP composite between that of PP and wood flour and (ii) the presence of wood filler in the polyvinyl chloride (PVC), resulted in the early charring in the first stage and hence, suppressing the heat release rate. Furthermore, Subasinghe et al. [172] reported an increase in the combustion rate in long kenaf fiber-reinforced composites in comparison to the short kenaf fiber-reinforced composites; however, both composites performed better than pure PP matrix. A better fire resistance of the short fiber-reinforced composites when compared to the long fiberreinforced composites was attributed to the presence of a more uniform and homogenous blend of fibers and the hollowness of the fibers acting as a heat flux barriers. The studies $[63,171]$ above have shown that the addition of fibers could improve the flammability resistance of the neat polymer, however the improvement in flammability resistance of the composites is not adequate to pass a certain fire regulatory demands in order to ensure public safety. The addition of a third component to the natural fiber-reinforced composites, known as fire retardant, helps to overcome the difficulty of high flammability of natural fiber composites, in the process forming new composites, otherwise, known as hybrid composites. The incorporation of such materials (fire retardants) in natural fiber composites (NFCs), reduces the major drawback of NFCs, which is highly flammable and as result, improving the widespread application of this materials in engineering applications, such as infrastructure and transport [6]. It should be noted that there are a couple of methods mostly employed for manufacturing of flame retardant natural fiber-reinforced composites, i.e. (i) coating of natural fibers or lignocellulosic materials with fire retardants before manufacturing of such composite (ii) the addition of fire retardants during the production of natural fiberreinforced composites. Generally, the addition of 
non-combustible materials is aimed at protecting and separating natural fibers or lignocellulosic materials and this goes together with the incorporation of flame-retardants fillers into the interior of flammable materials and as a result, acting as a barrier for fire protection. The most frequently used flame retardant chemicals include: phosphoric acid [173], zinc borate [63], dicyanodiamide; expandable graphite [174], sodium borate [60], antimony oxide, nanoclay [175] and ammonium polyphosphate [176]. They are added usually, in the form of powder and the amount ranges between 5 to $10 \%$ in relation to dry mass of the matrix. It is worth mentioning that the flammability characteristics of natural fiber hybrid materials depend on the type of fiber, fiber treatment, dispersion of both flame retardant and fiber, content of fiber and flame retardant agent. Yu et al. [177] investigated the flammability properties of kenaf/acrylonitrile butadiene styrene (ABS) nanoclays. When acrylonitrile butadiene styrene (ABS) is exposed to fire, it is easily burned with yellow flame, producing black soothe and smoke and apparently continues to burn even after the removal of fire. In their study, nanoclays were used as a flame retardant agent in order to prevent or minimize the combustion of a polymer. Nanoclay is regarded as a good flame retardant filler because it possesses the capability to prevent polymer combustion, physically and chemically. Physically, it forms a protective layer through cooling or chemically due to a reaction in the condensed or gas phase [175]. The flammability properties, in the work of Karunakaran et al. [175], were determined under two different conditions, viz: controlled and uncontrolled conditions. In both conditions, the addition of $1 \%$ nanoclay decreased the burning rate of $\mathrm{ABS} /$ kenaf composites; irrespective of the fiber or polymer content (Figure 5). This was attributed to the formation of a protective char barrier on the surface of the material. The nanoclay prevents oxygen from entering

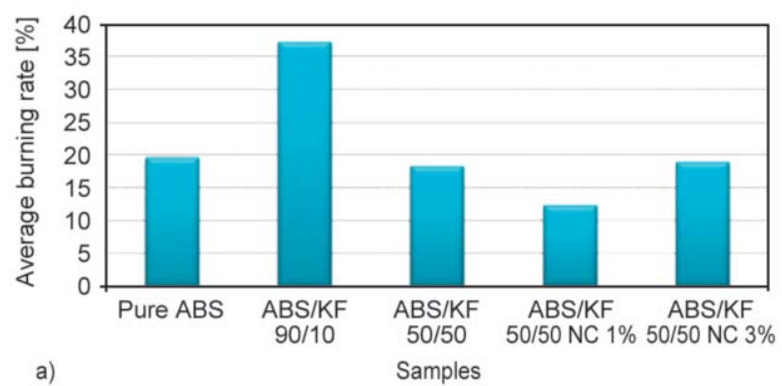

the substrate and/or volatiles from moving out of the substrate into the flame. Based on the above argument, it can be deduced that the mechanism of nanoclay occurs into two different ways, i.e. through the heat release reduction and prevention of volatile flame dripping. Flammability properties of natural fiber reinforced expandable graphite filled composites were studied [174]. Expandable graphite (EG) with contents weighing of: 3,5 and $7 \mathrm{wt} \%$ were added to $20 \mathrm{wt} \%$ natural fiber-reinforced epoxy matrix. Flammability properties in the study of Khalili et al. [174] were characterized by Bunsen burner test and bomb calorimeter. According to the Bunsen burner test results, neat epoxy matrix burned fast with a total flame time (TFT) and a drop flame time recorded as 105 and $50 \mathrm{~s}$, respectively with the entire sample burning out completely. The introduction of natural fibers into epoxy resin did not assist in terms of improving the flame resistance of epoxy, as the whole length of the natural fiber/epoxy composites happened to burn out completely. The addition of natural fiber to the epoxy matrix did not form a protective barrier to heat and fuel transport, resulting in a higher total flame time (TFT) and a drop in the flame time (viz: 160 and $72 \mathrm{~s}$, respectively) in comparison to pure epoxy matrix. The incorporation of expandable graphite at $3 \mathrm{wt} \%$, dropped the TFT as low as 1 second, stopping the dripping flame completely and further reducing the burned length to $1 \mathrm{~mm}$. A possible explanation to this behavior was adduced to the formation of exfoliated graphite layers before the ignition of the natural fiber and the epoxy and as a result, preventing the transfer of gas and heat between the burning substrate and the fire zone. Furthermore, the Bunsen burner test of natural fibers, soaked in an aqueous $\mathrm{NaOH}$ solution with a concentration of $5 \mathrm{wt} \%$ for 24 hours, was reported from the same study. The fiber treated with $\mathrm{NaOH}$ composite with $5 \mathrm{wt} \% \mathrm{EG}$, was found to meet the requirements of the Bunsen

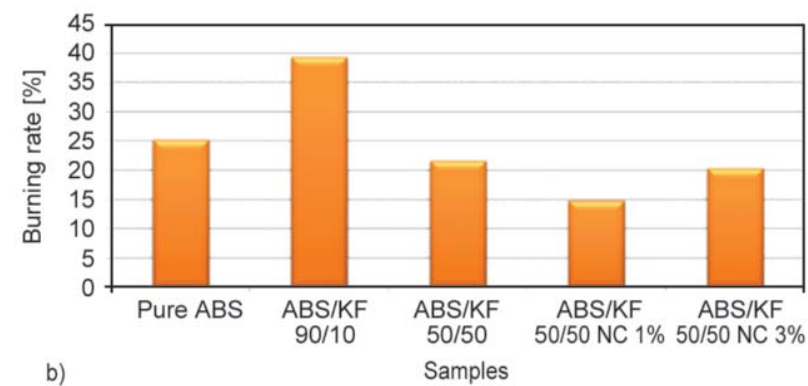

Figure 5. UL-94 horizontal burning rates of ABS/kenaf/nanoclay for a) controlled condition and b) uncontrolled condition [175]. Open access. 
burner test in comparison to both 3 and $7 \mathrm{wt} \%$ contents of EG. This could have been the optimum concentration of EG required to extinguish the treated fiber composite.

The effects of the different surface treatments of natural fiber, flame retardant agents and/or the addition of compatibilizers on the flammability of hybrid composites have been investigated extensively [173, 174, 177]. Treated composites, in most cases, improved the flame resistance properties of the flame retardant natural fiber hybrid composite. It is believed that a better dispersion of the filler in the polymer resulted in a significantly stable interfacial structure. Such structures are strong enough to resist heat and prevent material from cracking and pursuing further degradation. Szolnoki et al. [173] investigated the flammability properties of natural fiber hemp fabricreinforced epoxy resin composites. Hemp fabrics were treated by employing three different techniques, i.e.: (i) thermotex treatment (THF: thermotex treated hemp fiber), (ii) sol-gel treatment with GF9 amino silane (SiHF: silane treated hemp fabric) and (iii) a sol-gel treatment followed a thermotex treatment (SiTHF). In this study, the effect of modifications on the flammability of fibers was compared to the unmodified fabric (NHF). A phosphorus-containing amine-type curing agent (TEDAP) was used as a flame retardant filler. The modifications of the fabrics resulted in an improvement in the flammability resistance, as evident by the increasing LOI values and the reduction in heat release. It was, further observed that the sol-gel treatment and the thermotex method provided better flame resistance properties. The improvement in flammability resistance of the composites was attributed to the difference in the type of char formed by the different samples. For example, SiTHF-treated sample formed a compact, continuous char layer than the NHF, THF and SiHF-treated samples. This type of char is able to delay the penetration of heat and oxygen into the system and the release of flammable decomposition products from the system and as a result, improves the flame resistance properties. Jute fiber/PLA composite was prepared by using a twin-screw extruder with 9, 10-dihydro-9-oxa10-phosphaphenanthrene-10-oxide (DOPO) and maleic anhydride (MA) as a flame retardant agent [177]. DOPO-MA was synthesized by the reaction between DOPO and maleic acid. DOPO is a phosphorus-based intumescent flame retardant and $\mathrm{Yu}$ et al. [177] have used it in the study because of its high thermal stability, good oxidation and water resistance. It is well known that polar fibers have inherently lower compatibility with less polar polymer matrix and furthermore, the addition of DOPO may further weaken the interfacial adhesion between fiber and PLA matrix. As result, the authors synthesized a flame retardant compound with DOPO and MA to form DOPO-MA with the hope that MA may induce reactive groups, such as hydroxyl and carboxyl, which can form hydrogen bonds between flame retardant and plant fiber/PLA that may result in a good solution for weak interfacial bonding. Flammability properties of DOPO-composites and DOPO-MA system were investigated by LOI and UL94 tests. The LOI value of the composites with DOPO was lower than that of the composites with DOPO-MA at the same content, thereby confirming the fact that DOPO-MA had a better flame retardant efficiency than DOPO. Cone calorimeter showed lower PHRR value when DOPO-MA was added to the PLA/fiber composite than the composites with DOPO. This was attributed to a better interface between the flame retardant filler and fibers or matrix, which forms a strong heat barrier and might have probably prevented the decomposition of products from escaping out of the system and the penetration of heat and oxygen into the system. It is envisaged that a heat barrier will become fragmented when many gaseous decomposition products escape in the system, which will eventually make it easier for heat and oxygen to enter the system. Arjmandi and co-workers [176] investigated the effects of ammonium polyphosphate (APP) content on the flammability properties of kenaf/polypropylene $(\mathrm{KF} /$ $\mathrm{PP})$ and rice husk/polypropylene (RH/PP) composites, prepared by melt mixing technique. In their study, neither flame retardant agent nor fiber was treated, but a compatibilizer in the form of polyethyleneoctene-grafted-maleic anhydride (POE-g-MAH) was added to the fiber/matrix composites. The authors in this study chose POE because it can mix faster and it showed better dispersion with polypropylene when compared with the conventional polyolefin elastomers. Furthermore, POE can form hydrogen bond between maleic anhydride group of the POE and hydroxyl group of the fibers. Generally, the addition and increase of APP in the PP/KF/APP and PP/RH/ APP composites increased the LOI values. The results confirmed an improvement in the flammability resistance of the composites with the addition of APP. The mechanism of APP as an intumescent flame retardant 
Table 9. Flammability properties of some selected natural fiber hybrid composites [64, 147-149, 174, 176, 178-183].

\begin{tabular}{|c|c|c|}
\hline Hybrid system & Remarks & Refs \\
\hline $\begin{array}{l}\text { PP/wood flour with: } \\
\text { (i) Ammonium polyphosphate (APP) } \\
\text { (ii) Melamine polyphosphate (MPP) } \\
\text { (iii) Aluminium hydroxide }\end{array}$ & $\begin{array}{l}\text { Wood-plastic composites (WPC) with } 10 \mathrm{wt} \% \text { of APP showed the best fire perform- } \\
\text { ance, and flammability class was V- } 0 \text {, which means that it showed self-extinguish } \\
\text { property at vertical burning test. } 10 \mathrm{wt} \% \text { was the minimum amount of fire retardants } \\
\text { to satisfy V- } 0 \text { class for WPCs with } 50 \mathrm{wt} \% \text { of wood flour. }\end{array}$ & {$[155]$} \\
\hline $\begin{array}{l}\text { Polypropylene wood flour with: } \\
\text { (i) Magnesium hydroxide } \\
\text { (ii) Expandable graphite } \\
\text { (iii) Ammonium polyphosphate }\end{array}$ & $\begin{array}{l}\text { Cone calorimeter results indicated that EG showed the best properties on fire retar- } \\
\text { dant and suppression of smoke. }\end{array}$ & {$[178]$} \\
\hline $\begin{array}{l}\text { Epoxy/empty fruit bunch (EFB)/expandable } \\
\text { graphite }\end{array}$ & $\begin{array}{l}\text { Expandable graphite (EG) weighing } 3,5 \text { and } 7 \mathrm{wt} \% \text { was incorporated into } 20 \mathrm{wt} \% \\
\text { natural fibre (NF) reinforced epoxy. Increasing EG content in the composites signif- } \\
\text { icantly improved the fire resistivity and the thermal properties. This, however, was } \\
\text { found to reduce the mechanical properties. }\end{array}$ & {$[174]$} \\
\hline $\begin{array}{l}\text { PLA/kenaf fiber/ammonium polyphosphate } \\
\text { (APP) }\end{array}$ & $\begin{array}{l}\text { APP was shown to be very effective in improving flame retardancy properties ac- } \\
\text { cording to the limiting oxygen index (LOI) because of increased char residue at high } \\
\text { temperatures. However, because APP decreased the compatibility between PLA and } \\
\text { kenaf, there was a significant reduction in mechanical properties of PLA Biocom- } \\
\text { posites }\end{array}$ & {$[64]$} \\
\hline $\begin{array}{l}\text { Wood-flour/polypropylene/ammonium poly- } \\
\text { phosphate (APP) and ammonium hydroxide } \\
\text { (ATH) }\end{array}$ & $\begin{array}{l}\text { It was observed that APP appeared to be more effective than ATH in reducing the } \\
\text { peak of heat release rate (PHRR). Wood plastic composites (WPC) containing a com- } \\
\text { bination of } 20 \mathrm{wt} \% \text { APP and } 10 \mathrm{wt} \% \text { ATH (WPC/APP-20/ATH-10) showed the low- } \\
\text { est PHRR and total heat release in all of the formulations. The addition of } 30 \mathrm{wt} \% \\
\text { APP decreased the flexural strength (MOR) of the composites from ( } 72.6 \pm 0.4) \text { to } \\
(63.7 \pm 1.8) \text { MPa. The MOR and flexural modulus MOE values were not significantly } \\
\text { affected by the APP to ATH mass ratios. }\end{array}$ & {$[179]$} \\
\hline $\mathrm{PP} / \mathrm{KF} / \mathrm{APP}$ and $\mathrm{PP} / \mathrm{RH} / \mathrm{APP}$ & $\begin{array}{l}\text { The addition of APP increased the flame retardancy of the PP/KF/APP and } \\
\text { PP/RH/APP composites with a significant increase of LOI at } 10 \mathrm{phr} \text {. Apparently the } \\
\text { flexural strength of the composites also increased by the incorporation of } 10 \mathrm{phr} \text { APP. }\end{array}$ & {$[176]$} \\
\hline $\begin{array}{l}\text { Wood-flour/polypropylene/[ammonium poly- } \\
\text { phosphate (APP) + synthetic zeolites ((type } \\
4 \text { A and } 13 \mathrm{X})]\end{array}$ & $\begin{array}{l}\text { APP and zeolites ( } 4 \mathrm{~A} \text { and } 13 \mathrm{X} \text { ) showed an effective synergistic effect which was de- } \\
\text { noted by an improvement in the flame retardancy of WPCs. It was noted that the } \\
\text { WPC/APP/zeolites (type 4A or 13X) had better flexural properties and higher impact } \\
\text { strength than WPC/APP. }\end{array}$ & {$[180]$} \\
\hline $\begin{array}{l}\mathrm{PP} / \text { kenaf } /[\text { (halloysite nanotubes (HNTs) and } \\
\text { montmorillonite (MMT) nanoclay)] }\end{array}$ & $\begin{array}{l}\text { ESEM char analysis confirmed the formation of aluminosilicate barrier effect from } \\
\text { MMT and HNT nanoparticles, which improved the thermal stabilization of phosphor } \\
\text { carbonaceous structure. }\end{array}$ & {$[154]$} \\
\hline $\begin{array}{l}\text { Epoxy/palm empty fruit bunch (EFB) } \\
\text { fiber/(ATH/APP hybrid) }\end{array}$ & $\begin{array}{l}\text { The } 10 \mathrm{wt} \% \text { ATH and } 5 \mathrm{wt} \% \text { APP hybrid showed the most promising flame retar- } \\
\text { dancy with a self-extinguishing property as well as the lowest gross heat and greatest } \\
\text { char residue amongst the various formulations investigated. There was an increase } \\
\text { in moduli of the flame retardant filled (FR)-filled composites compared to that of } \\
\text { the natural fiber (NF)/epoxy composite, due to a more brittle characteristic. }\end{array}$ & {$[181]$} \\
\hline $\begin{array}{l}\text { Thermoplastic starch (TPS)/cellulose deriva- } \\
\text { tives/coconut fiber (CF)/aluminium trihy- } \\
\text { drate (ATH) }\end{array}$ & $\begin{array}{l}\text { It was reported that CF produced charring activity to some extent, slightly decreasing } \\
\text { the fire load. Aluminium trihydrate (ATH) acted as a fuel dilution and residual pro- } \\
\text { tection layer reducing flame retardancy because it decomposed endothermically into } \\
\text { water and inorganic residue. Furthermore, it was observed that the replacing part of } \\
\text { ATH with coconut fibers improved the flame retardancy (i.e. heat release rate, igni- } \\
\text { tion, fire growth rate, etc.) of the system. }\end{array}$ & [182] \\
\hline $\begin{array}{l}\text { Thermoplastic starch-phosphorus containing } \\
\text { polyol (TPS/P-polyol)/phosphorus treated } \\
\text { biofibers (P-fibers) }\end{array}$ & $\begin{array}{l}\text { In the study, the authors investigated phosphorus containing polyol for plasticizing } \\
\text { starch and phosphorus treated biofibers. It was reported that the TPS-polyol and P- } \\
\text { treated biofibers showed an increase in mechanical performance followed by im- } \\
\text { proved flame retardancy i.e. } 45 \% \text { reduction in pkHRR than the reference TPS. }\end{array}$ & [183] \\
\hline
\end{tabular}

depends on the formation of an expanded carbonized layer on the surface of the polymer during thermal degradation. The layer acted as an insulating barrier, thereby, preventing heat transfer from the polymer towards the flame as well as oxygen from diffusing into the material. Table 9 summarizes the flammability characteristics of selective natural fiber hybrid composites [64, 147-149, 174, 176, 178-183].

\subsection{Synergistic effect of flame-retardants filler reinforced natural fiber composites}

A considerable attention was recently devoted to the synergistic effect of two or more flame-retardants fillers in order to improve the flammability resistance natural fiber-reinforced composites. In most studies, ammonium polyphosphate APP was investigated with other flame retardant agent to form a 
synergy. There are a couple of reasons mentioned in the literature as to why synergistic effect of flame retardant agent fillers was used for natural fiber-reinforced composites. In some cases, flame retardant fillers require higher content for them to be effective flame-retardants and high contents reduce the mechanical properties of the system. Furthermore, there is poor compatibility between flame retardant agent and fiber polymer matrix. It is well known that poor fiber-matrix and or flame retardant agent reduces the mechanical properties of the system. As explained earlier in this review, in some cases, they may treat the flame retardant filler with other reactive groups, such as MA, which normally interacts with the fibermatrix interface. The treatments were done in order to ensure that the addition of flame retardant filler does not compromise, negatively, the mechanical properties. Alternatively, another flame retardant agent with high mechanical strength, good thermal and chemical stability, may be added to the flame retardant natural fiber hybrid composites. It should be noted that when two or more flame retardant fillers are incorporated into the natural fiber/polymer composites, their contents are normally low, which does not compromise the mechanical properties of the system. The idea is such that the addition of flame retardant filler is expected to improve the flame resistance properties of the natural fiber-reinforced composites, but not at the expense of the mechanical properties of the system. It has been observed that the synergistic effect of flame retardant fillers in natural fiber-reinforced composites, improved the flammability of the composites more than when a single flame retardant agent was used. The synergistic of synthetic zeolites and ammonium polyphosphates (APP) on the flammability of wood-flour/polypropylene composites was investigated [180]. It is well-known that APP enhances the flame retardancy of WPCs with obvious decrease in the mechanical properties, because of the poor compatibility between APP and WPC matrix. Zeolites (type 4A and 13X) with four different concentrations (2, 4, 6 and $8 \mathrm{wt} \%$ ) was chosen as synergistic filler with APP because of its high mechanical strength, good thermal and chemical stability. Both the limiting oxygen index (LOI) and cone calorimetry tests were performed in order to investigate the flame performance of WPCs and the results showed that the addition of $4 \mathrm{~A}$ or $13 \mathrm{X}$ zeolites had synergistic effect on the flame retardancy of WPCs. The resultant mechanical properties showed that the addition of zeolites to the APP/ WPCs, increased the flexural properties and impact strength, whereas the tensile properties of the WPCs decreased. The zeolites (4A or 13X)/APP/WPCs formed a compact and continuous char layer; whereas APP/WPCs formed, a less compact and discontinuous char. Therefore, the addition of zeolites (4A or 13X)/APP formed a better char, which can protect the underlying material from further degradation. Such a char layer (compact and stable) will provide good protection against the entering of heat and the release of flammable volatiles, thereby leading to good flame retardancy. Furthermore, the release of toxic gases is considered as an important parameter for flame retardant materials. Carbon monoxide (CO) emanating from fires is believed to be the dominant toxicant in fire deaths. The incorporation of APP in WPC produced high carbon monoxide yield, whereas the addition of zeolites to WPC/APP, resulted in low CO yield, which proved that zeolites could decrease the release of toxic gases during the combustion of WPC. A comparative study of the effects of two different nanoparticles (halloysite nanaotubes and montmorillonite (MMT) nanoclay) on the flammability properties of an intumescent APP-based polypropylene/kenaf system was investigated [154]. Pure PP (without kenaf fiber) and intumescent flame retardant (IFR) in the form of ammonium polyphosphate (APP) showed rapid combustion by releasing high peak heat release rate (pk-HRR) (Figure 6). A reduction in pk-HRR was observed with the addition of kenaf into the polymer matrix, even though the fiber cannot be regarded as a flame retardant agent. However, as much as kenaf reduced the pk-HRR of PP, the HRR value of $\mathrm{PP} / \mathrm{kenaf}$ was still quite high, i.e. between 600 to $800 \mathrm{~kW} / \mathrm{m}^{2}$, which is a clear evidence that both PP and kenaf are flammable. According to the authors, kenaf-PP-APP (KeC-IFR) showed a $67 \%$ reduction in pk-HRR in comparison to neat PP matrix. This is due to a combination of the unstable lignocellulosic ash and the more stable intumescent char. There was an observation of a double peak in the HRR (Figure 6a) of APP (KeC-IFR) system. The second peak, in most cases, is attributed to the gradual degradation of the protective layer, as the sample is continuously exposed to heat and the formation of a new protective char [154].

The addition of halloysite nanaotubes and montmorillonite (MMT) nanoclay enhanced the flammability resistance of the system further, in comparison to 

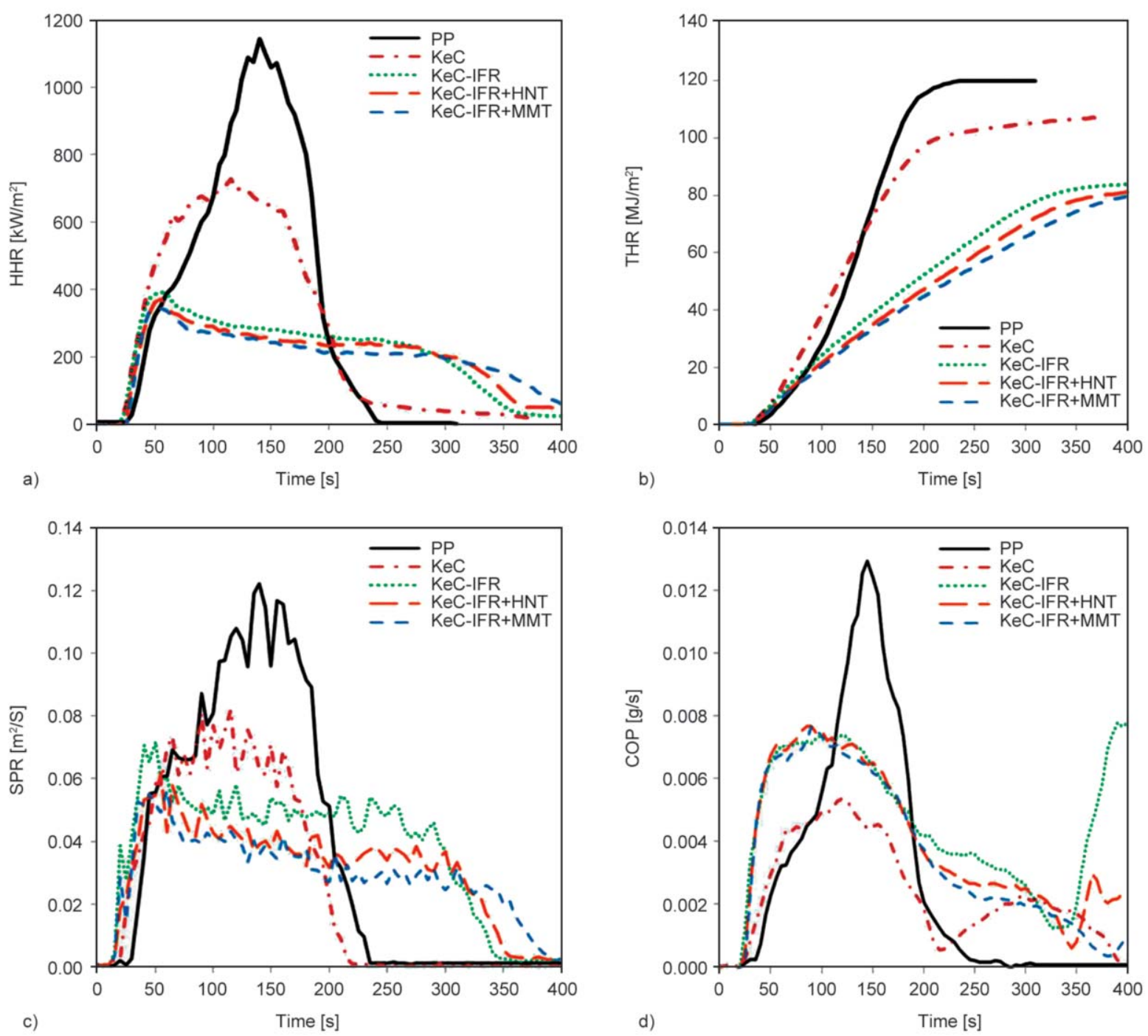

Figure 6. Cone calorimeter analysis: (a) HRR; (b) THR; (c) SPR; (d) carbon monoxide production (COP) [154]. Open access.

the APP (KeC-IFR) system by lowering the HRR and reduction in both smoke production rate as well as carbon monoxide production (Figure 6). It was further noted by the authors that effective particle dispersion played a major role in the formation of compact and stable char layer, which was clearer with MMT than HNT. A better-dispersed particle leads to an effective performance during combustion process as denoted by low HRR peak (Figure 6a). The observed HRR peaks are summarized by the micro scale char residues analysis ESEM, with each sample showing voids, thereby resulting in instability of the protection system, more especially at higher temperature (Figure 7).

Figure $7 \mathrm{a}$ and $7 \mathrm{~b}$ shows a loose char structure with the presence of voids in a KeC-IFR composite. This kind of a char will provide poor protection against the entering of heat and the release of flammable volatiles and as a result, providing poor flame retardancy.
However, the incorporation of $3 \mathrm{wt} \%$ of HNT in the $\mathrm{KeC}-\mathrm{IFR}$ system, resulted in a more uniform and stable char layer (Figure 7d and 7e) than KeC-IFR system and therefore, it can slow down the volatile escape and entering of heat into the system. This type of char normally prevents further flame intensity of the flammable material at the surface and reduces smoke and gaseous products emission. The addition of MMT with better dispersion in the KeC-IFR system, improved the flammability performance better because of the better dense surface char (Figure 7e and 7f) than both $\mathrm{KeC}$-IFR and HNT-KeC-IFR. However, as much as the formed chars in the presence of nanoparticles were stronger and compact, the authors noted that the presence of silicate platelets on the surface created island-like structures (Figure 7c and 7e), whereby protection is not strong. Table 9 summarizes some selective studies on the synergistic effect of flame retardant fillers added to natural fiber/ composites. 


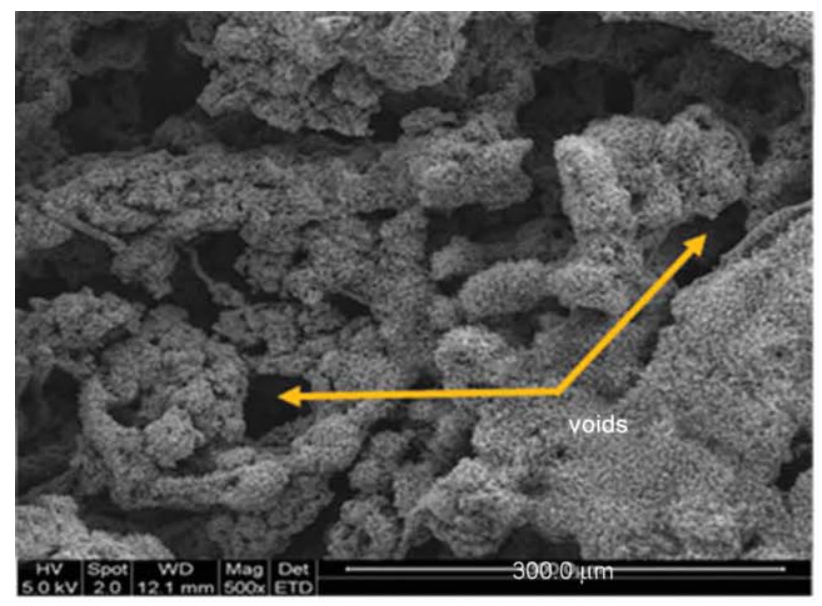

a)

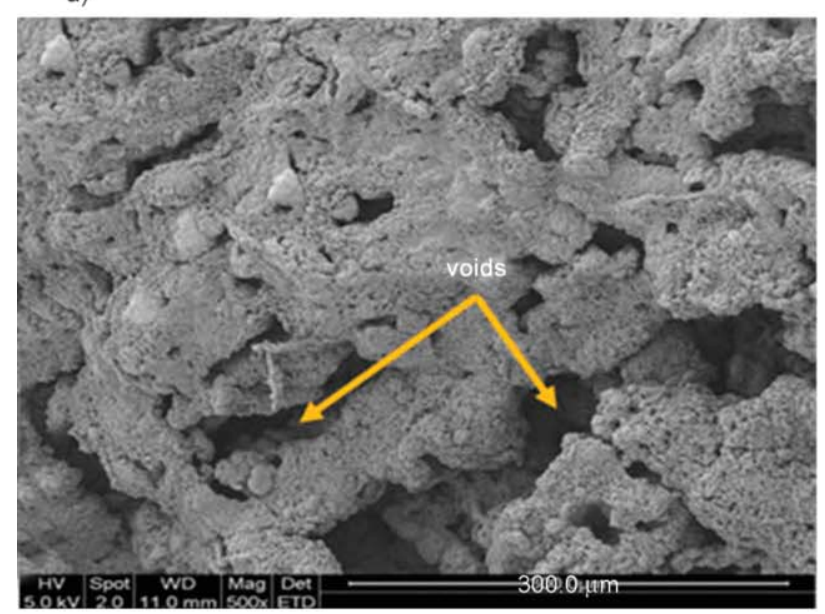

c)

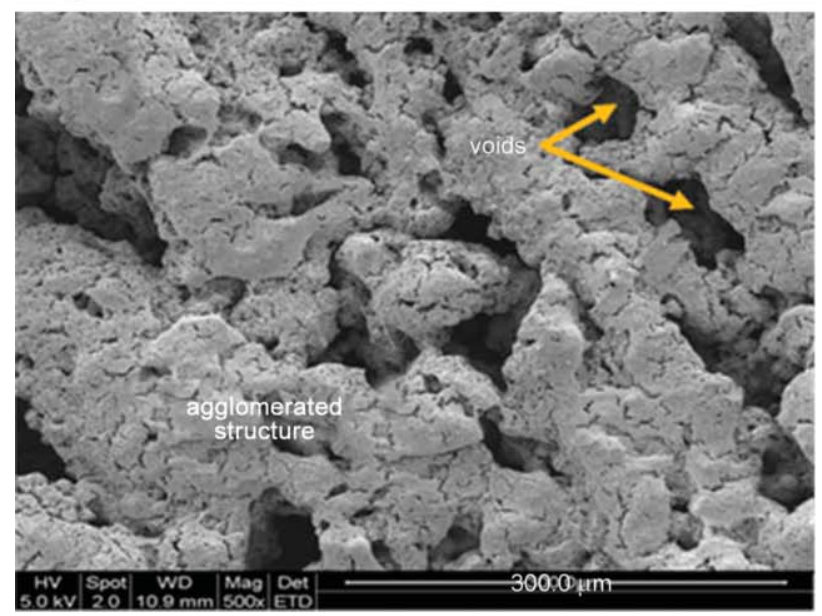

e)

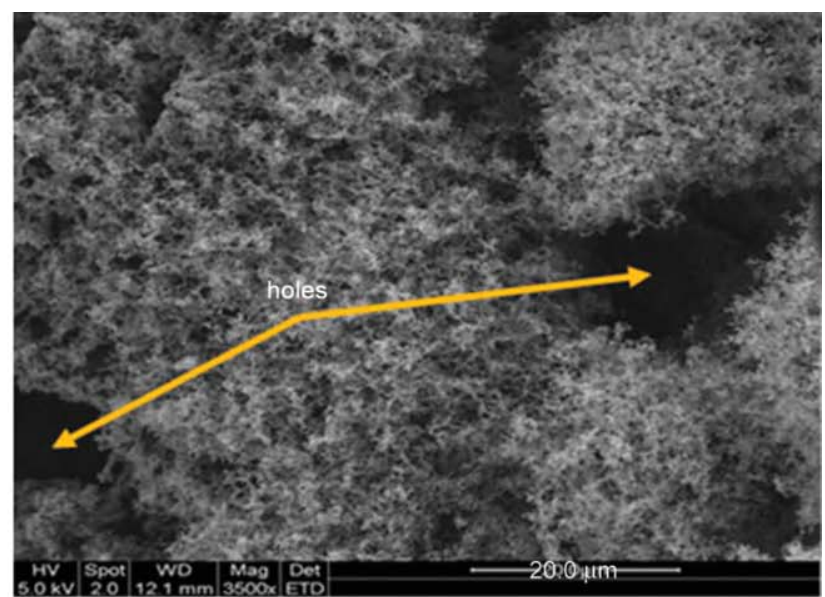

b)

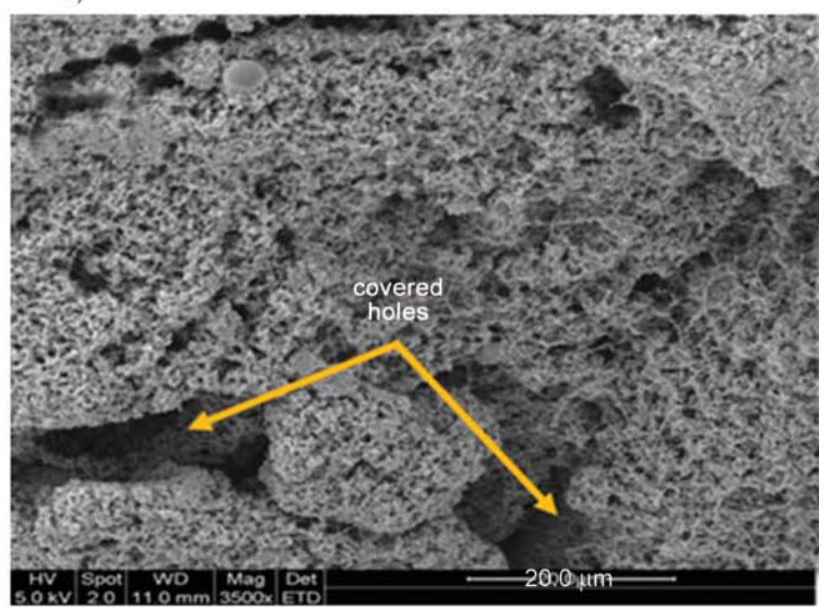

d)

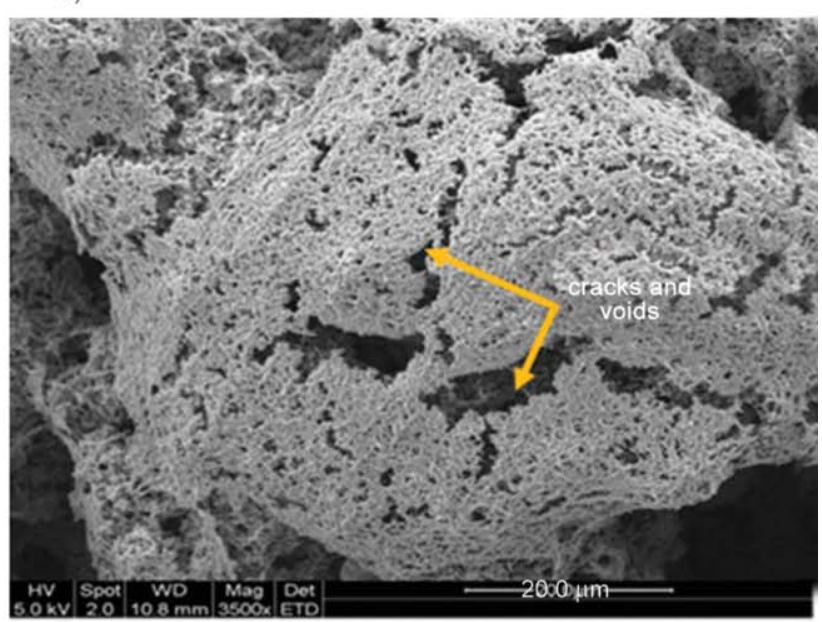

f)

Figure 7. ESEM images of $\mathrm{CC}$ char residues of $\operatorname{KeC}-\operatorname{IFR}(a, b), \operatorname{KeC}-\operatorname{IFR}+\mathrm{HNT}(\mathrm{c}, \mathrm{d})$ and $\operatorname{KeC}-\operatorname{IFR}+\mathrm{MMT}(\mathrm{e}, \mathrm{f})$ [154]. Open access.

\section{Applications}

\subsection{Transportation}

Hybridized composite materials have spurred considerable interest in the attempt to replace the conventional composites materials because of their improved performance when compared to their conventional counterparts. Carbon fiber-based composites have received popular attention because of the properties featured by the carbon fibers, which include high tensile strength and modulus. The drawbacks of carbon fibers, such as: cost and low ratio of compressive-to-tensile strength limit its application, which opens doors for the addition of a second filler with high ratio of compressive-to-tensile strength. 
Several studies were conducted in which glass fibers were introduced to find the performance balance of the resulting hybridized composite product [184, 185]. Irina et al. [185] studied the possibility of replacing part of carbon fibers with glass fibers (i.e. E-glass plain woven and E-glass stitch by bi-axial $\left.\left( \pm 45^{\circ}\right)\right)$. The density of the hybrid composites was reduced following the introduction of glass fibers, which is the key for fuel efficiency and for reducing the environmental burden from automotive. Moreover, good mechanical properties were obtained, which opens door for manufacturers to utilize such combinations for lighter and better performing materials. A balance between the mechanical properties and weight ratio can be obtained by interchanging the stacking ratio of the woven fabrics of carbon fibers and glass fibers, which gives the opportunity to resolve the problems associated with carbon fibers [184]. On the other hand, natural fibers as complete replacement of synthetic fillers for high-performance applications with regard to their outstanding mechanical properties, low density and abundant availability, have been one of the topics in the industrial and the academic communities $[42,186]$. Kenaf fibers with mechanical properties comparable to glass fibers were studied in [42] in order to evaluate their applicability in automotive. In this case, nanoparticles $\left(\mathrm{MgCO}_{3}\right)$ were introduced via an in-situ process in order to improve, not only the mechanical properties of the resulting composite material, but also to improve the interaction between the natural fibers and the matrix. In comparison with glass fibers reinforced composite (i.e. glass fibers usually used for automotive), natural fiber-based composites performed better, which encourages the possibility of replacing glass fiber composites in automotive applications. Despite the addition of nanoparticles, natural fibers can be combined with glass fibers in order to enhance the properties of the hybrid composite material $[81,85,185,187]$. This balances the performance-to-weight ratio; thereby producing a hybrid composite that can be applied in automotive. It is noteworthy to mention that the moisture absorption was however, also reduced when the glass fibers were incorporated into the hybrid system. Hybrid of natural and glass fibers reinforced composite were selected by using Analytical Hierarchy Process (AHP) to produce automotive brake lever, based on the formulated product design specifications [8]. Kenaf fiber emerged as a suitable candidate out of the 13 candidates hybridized with glass fiber reinforced composites for the design of a passenger vehicle center lever parking brake component.

Several aspects have to be met by the resulting composite material for their application in aerospace. The most important aspects when comes to aerospace are safety and weight. Therefore, it is not only mechanical properties, which qualify the composite material in aerospace but also flammability property plays major role. The combination of the flame retardants and fibers in order to produce hybridized composites with high flammability resistance, has been one of the hottest topics in recent years [66, 173]. It is recognized that one of the fatalities from airplanes is as result of fire. Reinforced composites are often used in the ceiling panels, interior wall panels, partitions, galley structures, large cabinet walls, structural flooring and overhead stowage bins. The most commonly used composite is made of thermosets reinforced with carbon fibers and they have high flammability. This has resulted in more research on the thermosets that have high flammability resistance; however, the price of these thermosets and their poor mechanical properties have driven more researchers to develop hybrid materials that have balanced mechanical and flammability resistance. Alexander and Churchill [75] conducted a comparison between hybrid composites composed of sisal/ glass, sisal/basalt and sisal/glass/basalt. It was reported that sisal/basalt/epoxy composites performed better than other combinations; this is due to the bond strength between sisal fiber and basalt fibers, which implies the possibility for their usefulness in aircraft structural applications.

\subsection{Energy generation}

Renewable energy sources have become the central subjects of researchers, governments and environmentalists. Wind and solar energies are two the largest renewable energies that have received considerable interest as alternatives to the petroleum-based energy sources. In the case of solar energy, hybridized composites were recently applied as part of the trough for the collection of energy from the sun [188]. The production of the parabolic trough collector (PTC) is expensive, due to the costs associated with their molds. In such cases, the addition of natural fibers is of significance in an effort to compensate for the overall costs of the resulting composite materials. It was recently demonstrated that it is possible to 
reduce the price of the trough collectors by including natural fibers and other synthetic fillers, as the reinforcing phase of the continuous phase [188].

Two major components that play a major role in the performance in wind turbines, are the blades and wind rotor. The elements that make-up these major components, control the power generation efficiency and the price. Many countries, which include United States of America (USA) and Ukraine, invested in researches, based on the optimization of the turbine blades that can perform better at very low wind speeds (i.e. 4 to $6 \mathrm{~m} \cdot \mathrm{s}^{-1}$ ). Carbon and glass fibers hybrid are the most used fillers in the turbine blades. The major disadvantages of carbon and glass fiber are the price and weight. The use of relatively cheaper fillers with considerably less weight when compared with carbon fibers, can improve the efficiency of the wind turbines. A recent study demonstrated that it is possible to replace $20-30 \%$ of carbon fibers with basalt fibers for turbine blades application, without significantly influencing the properties of the resulting composite product [189]. In another study [80], a combination of woven/silicon/mesoporous silica showed a possibility of being used in wind turbine. The composites displayed excellent flexural modulus with only 3 vol $\%$ of mesoporous silica, due to the strong interaction between the fillers and the matrix.

\subsection{Electromagnetic interference shielding (EMI)}

Electromagnetic interference has been the major topic in various sectors, such as the: military, aerospace and communication [43, 44, 143]. The fast moving technology introduced many instruments and electronic devices, which produce lot of electrical and magnetic fields. The electromagnetic pollution affects signal to electronic devices and can damage their internal components, which in turn can affect the overall performance. Moreover, magnetic fields have major interaction with biological system and affect the human body DNA structure. This can also cause headaches and insomnia. Various materials, such as metal sheets received popularity as electromagnetic interference shielding (EMI). The disadvantages of the metal sheets are low mechanical properties and corrosion resistance. On the other hand, coating of the EMI shielding materials, such as: gold, silver, copper, iron and aluminum were adopted [47]. However, the ease wear out of the coated materials requires the need for novel strategies, such as the addition of the EMI shielding particles into the system under investigation. Quite a number of fillers, either alone or in combination, have been studied in order to establish a cheaper and lighter material that can be applied for electromagnetic shielding and absorption [143]. These include metals, metallic oxides and carbon-based materials. A recent study carried out through the mixing of magnetite and kenaf fiber as reinforcements of polyester matrix, indicates the fact that the hybridized composite is a good alternative to produce EMI shielding [143]. It is noteworthy to mention the fact that the water absorption of the hybridized composite was also reduced due to the interaction between the magnetite and fibers, through hydrogen bonding, which decreased the number of $-\mathrm{OH}$ groups on the surface of the fibers. Xia et al. [44] produced kenaf fiber-reinforced composite by VARTM, which was sputtered with $\mathrm{Cu}$ film magnetron in order to produce a hybridized composite material for EMI shielding. EMI shielding efficiency was found to have increased with an increase in the $\mathrm{Cu}$ coating time. A maximum shielding effectiveness of $48.3 \mathrm{~dB}(99.99 \%)$ was achieved for 3 hours of coating with $\mathrm{Cu}$. In another work, Xia et al. [43] studied the application of kenaf fiber-reinforced polyester composites by introducing cheaper material, i.e. activated carbon in order to evaluate the electromagnetic shielding properties of the resulting hybridized composite material. Composite containing $30 \mathrm{~g}$ of activated carbon showed high electromagnetic shielding and absorption, thereby achieving, respectively 93 and 64\%, while the EMI absorption/ shielding was $68.7 \%$, which was $37.1 \%$ higher than the kenaf-polyester composite. By using retted fibers, it was possible to produce magnetized fibers by soaking the retted fibers in a solution of $\mathrm{FeCl}_{3}$ and $\mathrm{FeCl}_{2}$ for 14 hours [47]. This process allowed the opportunity to grow iron oxide nanoparticles on the surface of the fibers. The composites, based on these magnetized fibers (i.e. 18\% of Fe nanoparticles), showed high shielding efficiency from 75 to $80 \%$ at frequency of between 9 to $11 \mathrm{GHz}$. In order to prevent corrosion of metal films, the protection from the natural fibers-based is another alternative to produce high electromagnetic interference shielding hybrid composite [54]. Xia et al. [54] covered the aluminum sheets with hemp fiber mats in order to prepare a hybrid composite through VARTM, with epoxy as the matrix. The introduced aluminum sheets increased the EMI shielding to above commercial 
requirements, i.e. $20 \mathrm{~dB}$. The EMI shielding was increased from $1.0-4.8$ to $30.7-46.8 \mathrm{~dB}$, following the introduction of one layer of aluminum sheet and from $1.4-6.3$ to $28.5-53.5 \mathrm{~dB}$ after the introduction of a 2-layers of aluminum sheets at a frequency range of between $8-12 \mathrm{GHz}$.

\subsection{Armor systems}

Synthetic fibers, such as aramid fibers, carbon and glass have been widely used as reinforcement of resins in order to study their applicability in armor systems [190, 191]. It is recognized that the armor system is usually composed of two layers. The outside layer is made-up of high strength metals, rolled homogeneous armor material (titanium or uranium). The interior (second) layer (spall liners), is often installed for protection from high projectile impacts. Polymers laminates (ultra-high molecular weight polyethylene and aramid fibers) are the most often used for spall liners due to their capability to withstand high impact because of their high modulus, high strength and high elongation-at-break. The cost associated with their production has been a major setback. The use of accessible and cheaper fibers without necessarily, compromising the safety/protection has been studied. Some fibers, such as glass, Kevlar and carbon fibers and their hybrids were explored as suitable candidates. Recently, natural fibers, combined with synthetic fibers, have garnered considerable interests for ballistic applications. Stacking sequence, areal or surface density, orientation and thickness, were found to play significant role in the ballistic perforation. Yahaya et al. [192] studied the Kevlar layer and nonwoven kenaf fiber layer, by using different sequences, i.e. kenaf at the innermost layers, outer most layers and at alternating layers. The $V_{50}$ (i.e. velocity of ballistic impact, with $50 \%$ chance of penetration and $50 \%$ of non-perforation) of the hybrid with kenaf at the outermost layers, was found to be superior to other systems. However, the Kevlarreinforced composite performed better than all other samples under that study i.e. negative hybrid effect. Moreover, it was found out that $V_{50}$ increased with an increase in the specimen's thickness due to the extra distance to be travelled, corresponding to an increase in the surface energy dissipation. Their follow up study, based on the woven kenaf fiber-Kevlar hybrid, recorded better performance when compared to the previous study, based on randomly orientated kenaf fibers [193]. They reported similar observations where $V_{50}$ and energy absorbed increased as functions of the specimen thickness. The failure mechanism of the hybrid composites for the front surface was due to shear plugging, while the rear surface showed fiber tension. It was concluded that high velocities are required for the penetration of thicker samples to occur due to the higher resistance to the projectile penetration, produced by thicker samples. Hence, this reduces the residual velocity and absorbs more of the projectile kinetic energy. Moreover, it was reported that the energy absorption increased with increase in areal density. The hybrid composed of two woven kenaf layers, located at the third layers, from front and back surfaces, performed better because they were thicker and had higher areal density when compared to the other. These studies showed the possibility of using natural fibers in combination with synthetic fibers in armor systems.

\section{Conclusions and future remarks}

In this report, natural-fiber-based composites have been reviewed, in particular, in the case of their properties viz. flammability, mechanical, thermomechanical, water absorption and applications. Hybridization received popularity not only because of the improved performance of the resulting products but also the possibility of overcoming the limitations that hurdles the applicability of natural fibers in technical structures. There is a huge possibility that large percentage of natural fibers can be incorporated in conventional synthetic reinforced composites product, which is a big step from ecological and economical viewpoints. However, the quality of the natural fibers, which depend on the growth conditions and maturity still bring inconsistency in the resulting properties of hybrid composite products. Without a doubt, research on the modification and control over the quality of natural fibers can revolutionize their commercialization. On the other hand, the addition of a second filler in either micro or nano-size can overcome some of the natural fiber reinforced composites limitations. The addition of flame-retardants improves their thermal stability and flammability, which can open doors for engineering polymers for highend applications. It is worth mentioning that natural fiber-based hybrid composites bring a competitive market for various industrial applications. Moreover, the models play significant role in predicting the properties of the hybrid products in which the designers can save time and money by using these models to 
predict the resulting properties. In future, the modifications of models in order to include all aspects, such the interaction between the components will perfect the predicted results.

\section{Acknowledgements}

The authors would like to acknowledge the national research foundation (NRF) for funding the project

\section{References}

[1] Kiruthika A.: A review on physico-mechanical properties of bast fibre reinforced polymer composites. Journal of Building Engineering, 9, 91-99 (2017). https://doi.org/10.1016/j.jobe.2016.12.003

[2] Ahmad F., Choi H. S., Park M. K.: A review: Natural fiber composites selection in view of mechanical, light weight, and economic properties. Macromolecular Materials and Engineering, 300, 10-24 (2015). https://doi.org/10.1002/mame.201400089

[3] Saba N., Paridah M. T., Abdan K., Ibrahim N. A.: Dynamic mechanical properties of oil palm nano filler/ kenaf/epoxy hybrid nanocomposites. Construction and Building Materials, 124, 133-138 (2016). https://doi.org/10.1016/j.conbuildmat.2016.07.059

[4] Gurunathan T., Mohanty S., Nayak S. K.: A review of the recent developments in biocomposites based on natural fibres and their application perspectives. Composites Part A: Applied Science and Manufacturing, 77, 1-25 (2015). https://doi.org/10.1016/j.compositesa.2015.06.007

[5] Pickering K. L., Efendy M. G. A., Le T. M.: A review of recent developments in natural fibre composites and their mechanical performance. Composites Part A: Applied Science and Manufacturing, 83, 98-112 (2016). https://doi.org/10.1016/j.compositesa.2015.08.038

[6] Saba N., Jawaid M., Paridah M., Al-othman O.: A review on flammability of epoxy polymer, cellulosic and non-cellulosic fiber reinforced epoxy composites. Polymers for Advanced Technologies, 27, 577-590 (2016). https://doi.org/10.1002/pat.3739

[7] Samanta S., Muralidhar M., Signh T. J., Sarkar S.: Characterization of mechanical properties of hybrid bamboo/GFRP and jute/GFRP composites. Materials Today: Proceedings, 2, 1398-1405 (2015). https://doi.org/10.1016/j.matpr.2015.07.059

[8] Mansor M. R., Sapuan S. M., Zainudin E. S., Nuraini A. A, Hambali A.: Hybrid natural and glass fibers reinforced polymer composites material selection using analytical hierarchy process for automotive brake lever design. Materials and Design, 51, 484-492 (2013). https://doi.org/10.1016/j.matdes.2013.04.072
[9] Rodriguez-Castellanos W., Rodrigue D.: Production and characterization of hybrid polymer composites based on natural fibers. in 'Composites from renewable and sustainable materials' (ed.: Poletto M.) InTech, Rijeka, 273-302 (2016). https://doi.org/10.5772/64995

[10] Azwa Z. N., Yousif B. F., Manalo A. C., Karunasena W.: A review on the degradability of polymeric composites based on natural fibres. Materials and Design, 47, 424-442 (2013). https://doi.org/10.1016/j.matdes.2012.11.025

[11] Marques A. R., de Oliveira Patrício P. S., dos Santos F. S., Monteiro M. L., de Carvalho Urashima D., de Souza Rodrigues C.: Effects of the climatic conditions of the southeastern Brazil on degradation the fibers of coirgeotextile: Evaluation of mechanical and structural properties. Geotextiles and Geomembranes, 42, 76-82 (2014). https://doi.org/10.1016/j.geotexmem.2013.07.004

[12] Sanjay M. R., Madhu P., Jawaid M., Senthamaraikannan P., Senthil S., Pradeep S.: Characterization and properties of natural fiber polymer composites: A comprehensive review. Journal of Cleaner Production, 172, 566-581 (2017). https://doi.org/10.1016/j.jclepro.2017.10.101

[13] Sanjay M. R., Arpitha G. R, Yogesha B.: Study on mechanical properties of natural-glass fibre reinforced polymer hybrid composites: A review. Materials Today: Proceedings, 2, 2959-2967 (2015). https://doi.org/10.1016/j.matpr.2015.07.264

[14] Neher B., Bhuiyan M. M. R., Kabir H., Gafur M. A., Qadir M. R., Ahmed F.: Thermal properties of palm fiber and palm fiber-reinforced ABS composite. Journal of Thermal Analysis and Calorimetry, 124, 12811289 (2016). https://doi.org/10.1007/s10973-016-5341-x

[15] Gupta M. K.: Effect of frequencies on dynamic mechanical properties of hybrid jute/sisal fibre reinforced epoxy composite. Advances in Materials and Processing Technologies, 3, 651-664 (2017). https://doi.org/10.1080/2374068X.2017.1365443

[16] Tan B. K., ChingY. C., Poh S. C., Abdullah L. C., Gan S. N.: A review of natural fiber reinforced poly(vinyl alcohol) based composites: Application and opportunit. Polymers, 7, 2205-2222 (2015). https://doi.org/10.3390/polym7111509

[17] El-Sabbagh A., Steuernagel L., Ring J., Toepfer O.: Development of natural fiber/engineering plastics composites with flame retardance properties. AIP Conference Proceedings, 1779, 030020/1-030020/5 (2016). https://doi.org/10.1063/1.4965490

[18] Ramnath B. V., Manickavasagam V. M., Elanchezhian C., Krishna C. V., Karthik S., Saravanan K.: Determination of mechanical properties of intra-layer abacajute-glass fiber reinforced composite. Materials and Design, 60, 643-652 (2014). https://doi.org/10.1016/j.matdes.2014.03.061 
[19] Arthanarieswaran V. P., Kumaravel A., Kathirselvam M.: Evaluation of mechanical properties of banana and sisal fiber reinforced epoxy composites: Influence of glass fiber hybridization. Materials and Design, 64, 194-202 (2014). https://doi.org/10.1016/j.matdes.2014.07.058

[20] Maslinda A. B., Majid M. S. A., Ridzuan M. J. M., Afendi M., Gibson A. G.: Effect of water absorption on the mechanical properties of hybrid interwoven cellulosiccellulosic fibre reinforced epoxy composites. Composite Structures, 167, 227-237 (2017).

https://doi.org/10.1016/j.compstruct.2017.02.023

[21] Bisaria H., Gupta M. K., Shandilya P., Srivastava R. $\mathrm{K}$.: Effect of fibre length on mechanical properties of randomly oriented short jute fibre reinforced epoxy composite. Materials Today: Proceedings, 2, 1193-1199 (2015).

https://doi.org/10.1016/j.matpr.2015.07.031

[22] Al-Oqla F. M., Sapuan S. M.: Natural fiber reinforced polymer composites in industrial applications: feasibility of date palm fibers for sustainable automotive industry. Journal of Cleaner Production, 66, 347-354 (2014).

https://doi.org/10.1016/j.jclepro.2013.10.050

[23] Edhirej A., Sapuan S. M., Jawaid M., Zahari N. I.: Cassava/sugar palm fiber reinforced cassava starch hybrid composites: Physical, thermal and structural properties. International Journal of Biological Macromolecules, 101, 75-83 (2017).

https://doi.org/10.1016/j.ijbiomac.2017.03.045

[24] Mashouf Roudsari G., Mohanty A. K., Misra M.: Green approaches to engineer tough biobased epoxies: A review. ACS Sustainable Chemistry and Engineering, 5, 9528-9541 (2017).

https://pubs.acs.org/doi/abs/10.1021/acssuschemeng.7b01422

[25] Fei M-E., Xie T., Liu W., Chen H., Qiu R.: Surface grafting of bamboo fibers with 1,2-epoxy-4-vinylcyclohexane for reinforcing unsaturated polyester. Cellulose, 24, 5505-5514 (2017). https://doi.org/10.1007/s10570-017-1497-1

[26] Lai S-M., Kao Y-H., Liu Y-K., Chiu F-C.: Preparation and properties of luffa fiber- and kenaf fiber-filled poly (butylene succinate-co-lactate)/starch blend-based biocomposites. Polymer Testing, 50, 191-199 (2016). https://doi.org/10.1016/j.polymertesting.2016.01.015

[27] Kwon H-J., Sunthornvarabhas J., Park J-W., Lee J-H., Kim H-J., Piyachomkwan K., Sriroth K., Cho D.: Tensile properties of kenaf fiber and corn husk flour reinforced poly(lactic acid) hybrid bio-composites: Role of aspect ratio of natural fibers. Composites Part B: Engineering, 56, 232-237 (2014). https://doi.org/10.1016/j.compositesb.2013.08.003
[28] Lu T., Liu S., Jiang M., Xu X., Wang Y., Wang Z., Gou J., Hui D., Zhou Z.: Effects of modifications of bamboo cellulose fibers on the improved mechanical properties of cellulose reinforced poly(lactic acid) composites. Composites Part B: Engineering, 62, 191-197 (2014).

https://doi.org/10.1016/j.compositesb.2014.02.030

[29] Brostow W., Datashvili T., Jiang P., Miller H.: Recycled HDPE reinforced with sol-gel silica modified wood sawdust. European Polymer Journal, 76, 28-39 (2016) https://doi.org/10.1016/j.eurpolymj.2016.01.015

[30] Sakthivel M., Vijayakumar S., Ramesh S.: Production and characterization of luffa/coir reinforced polypropylene composite. Procedia Materials Science, 5, 739745 (2014). https://doi.org/10.1016/j.mspro.2014.07.323

[31] Hao A., Zhao H., Chen J. Y.: Kenaf/polypropylene nonwoven composites: The influence of manufacturing conditions on mechanical, thermal, and acoustical performance. Composites Part B: Engineering, 54, 44-51 (2013). https://doi.org/10.1016/j.compositesb.2013.04.065

[32] Schirp A., Su S.: Effectiveness of pre-treated wood particles and halogen-free flame retardants used in wood-plastic composites. Polymer Degradation and Stability, 126, 81-92 (2016). https://doi.org/10.1016/j.polymdegradstab.2016.01.016

[33] Amir N., Abidin K. A. Z., Shiri F. B. M.: Effects of fibre configuration on mechanical properties of banana fibre/ $\mathrm{pp} /$ mapp natural fibre reinforced polymer composite. Procedia Engineering, 184, 573-580 (2017). https://doi.org/10.1016/j.proeng.2017.04.140

[34] Idumah C. I., Hassan A.: Characterization and preparation of conductive exfoliated graphene nanoplatelets kenaf fibre hybrid polypropylene composites. Synthetic Metals, 212, 91-104 (2016). https://doi.org/10.1016/j.synthmet.2015.12.011

[35] Chen P-Y., Lian H-Y., Shih Y-F., Chen-Wei S-M., Jeng R-J.: Preparation, characterization and crystallization kinetics of kenaf fiber/multi-walled carbon nanotube/ polylactic acid (PLA) green composites. Materials Chemistry and Physics, 196, 249-255 (2017). https://doi.org/10.1016/j.matchemphys.2017.05.006

[36] Wang Y-N., Weng Y-X., Wang L.: Characterization of interfacial compatibility of polylactic acid and bamboo flour (PLA/BF) in biocomposites. Polymer Testing, 36, 119-125 (2014). https://doi.org/10.1016/j.polymertesting.2014.04.001

[37] Couture A., Lebrun G., Laperrière L.: Mechanical properties of polylactic acid (PLA) composites reinforced with unidirectional flax and flax-paper layers. Composite Structures, 154, 286-295 (2016). https://doi.org/10.1016/j.compstruct.2016.07.069 
[38] Birnin-Yauri A. U., Ibrahim N. A., Zainuddin N., Abdan K., Then Y. Y., Chieng B. W.: Effect of maleic anhydride-modified poly(lactic acid) on the properties of its hybrid fiber biocomposites. Polymers, 9, 1-16 (2017).

https://doi.org/10.3390/polym9050165

[39] Yantaboot K., Amornsakchai T.: Effect of preparation methods and carbon black distribution on mechanical properties of short pineapple leaf fiber-carbon black reinforced natural rubber hybrid composites. Polymer Testing, 61, 223-228 (2017).

https://doi.org/10.1016/j.polymertesting.2017.05.026

[40] Stelescu M-D., Manaila E., Craciun G., Chirila C.: Development and characterization of polymer eco-composites based on natural rubber reinforced with natural fibers. Materials, 10, 1-20 (2017). https://doi.org/10.3390/ma10070787

[41] Atiqah A., Maleque M. A., Jawaid M., Iqbal M.: Development of kenaf-glass reinforced unsaturated polyester hybrid composite for structural applications. Composites Part B: Engineering, 56, 68-73 (2014).

https://doi.org/10.1016/j.compositesb.2013.08.019

[42] Xia C., Shi S. Q., Wu Y., Cai L.: High pressure-assisted magnesium carbonate impregnated natural fiber-reinforced composites. Industrial Crops and Products, 86, 16-22 (2016). https://doi.org/10.1016/j.indcrop.2016.03.023

[43] Xia C., Zhang S., Ren H., Shi S. Q., Zhang H., Cai L., Li J.: Scalable fabrication of natural-fiber reinforced composites with electromagnetic interference shielding properties by incorporating powdered activated carbon. Materials, 9, 1-9 (2015). https://doi.org/10.3390/ma9010010

[44] Xia C., Ren H., Shi S. Q., Zhang H., Cheng J., Cai L., Chen K., Tan H-S.: Natural fiber composites with EMI shielding function fabricated using VARTM and $\mathrm{Cu}$ film magnetron sputtering. Applied Surface Science, 362, 335-340 (2016). https://doi.org/10.1016/j.apsusc.2015.11.202

[45] Xia C., Shi S. Q., Cai L., Hua J.: Property enhancement of kenaf fiber composites by means of vacuumassisted resin transfer molding (VARTM). Holzforschung, 69, 307-312 (2015). https://doi.org/10.1515/hf-2014-0054

[46] Dhakal H. N., Sarasini F., Santulli C., Tirillò J., Zhang Z., Arumugam V.: Effect of basalt fibre hybridisation on post-impact mechanical behaviour of hemp fibre reinforced composites. Composites Part A: Applied Science and Manufacturing, 75, 54-67 (2015). https://doi.org/10.1016/j.compositesa.2015.04.020

[47] Ding Z., Shi S. Q., Zhang H., Cai L.: Electromagnetic shielding properties of iron oxide impregnated kenaf bast fiberboard. Composites Part B: Engineering, 78, 266-271 (2015).

https://doi.org/10.1016/j.compositesb.2015.03.044
[48] Saba N., Paridah M. T., Abdan K., Ibrahim N. A.: Physical, structural and thermomechanical properties of oil palm nano filler/kenaf/epoxy hybrid nanocomposites. Materials Chemistry and Physics, 184, 64-71 (2016).

https://doi.org/10.1016/j.matchemphys.2016.09.026

[49] Jumah T. A., Abood M. B.: Evaluation of the intermediate layer of graphite bonded metal. American Journal of Materials Science, 6, 58-66 (2016).

http://doi.org/10.5923/j.materials.20160602.03

[50] Sapiai N., Jumahat A., Mahmud J.: Flexural and tensile properties of kenaf/glass fibres hybrid composites filled with carbon nanotubes. Jurnal Teknologi, 76, 115120 (2015).

https://doi.org/10.11113/jt.v76.5524

[51] Kumara B. P.,Vas J. P., Bhat S., Madhyastha N. K.: A study on the vibration characteristics of bagasse-banana fibre hybrid composite. International Journal of Composite Materials, 7, 150-154 (2017).

http://doi.org/10.5923/j.cmaterials.20170705.04

[52] Kumar C. S., Arumugam V., Dhakal H. N., John R.: Effect of temperature and hybridisation on the low velocity impact behavior of hemp-basalt/epoxy composites. Composite Structures, 125, 407-416 (2015). https://doi.org/10.1016/j.compstruct.2015.01.037

[53] Mohan K., Rajmohan T.: Fabrication and characterization of MWCNT filled hybrid natural fiber composites. Journal of Natural Fibers, 14, 864-874 (2017). https://doi.org/10.1080/15440478.2017.1300115

[54] Xia C., Yu J., Shi S. Q., Qiu Y., Cai L., Wu H. F., Ren H., Nie X., Zhang H.: Natural fiber and aluminum sheet hybrid composites for high electromagnetic interference shielding performance. Composites Part B: Engineering, 114, 121-127 (2017).

https://doi.org/10.1016/j.compositesb.2017.01.044

[55] Saba N., Paridah M. T., Abdan K., Ibrahim N. A.: Effect of oil palm nano filler on mechanical and morphological properties of kenaf reinforced epoxy composites. Construction and Building Materials, 123, 15-26 (2016). https://doi.org/10.1016/j.conbuildmat.2016.06.131

[56] Guo G., Chen J. C., Gong G.: Injection molding of polypropylene hybrid composites reinforced with carbon fiber and wood fiber. Polymer Composites, 39, 3329-3335 (2017).

https://doi.org/10.1002/pc.24350

[57] Al-Maadeed M. A., Shabana Y. M., Khanam P. N.: Processing, characterization and modeling of recycled polypropylene/glass fibre/wood flour composites. Materials and Design, 58, 374-380 (2014). https://doi.org/10.1016/j.matdes.2014.02.044

[58] Jeencham R., Suppakarn N., Jarukumjorn K.: Effect of flame retardants on flame retardant, mechanical, and thermal properties of sisal fiber/polypropylene composites. Composites Part B: Engineering, 56, 249 253 (2014). https://doi.org/10.1016/j.compositesb.2013.08.012 
[59] Zuhaira A. A. N., Mohamed R.: Effects of kenaf and rice husk on thermal properties of kenaf/ $\mathrm{CaCO}_{3} /$ HDPE and rice husk/ $\mathrm{CaCO}_{3} / \mathrm{HDPE}$ hybrid composites. Advanced Materials Research, 748, 201-205 (2013).

https://doi.org/10.4028/www.scientific.net/AMR.748.201

[60] Zolfaghari A., Behravesh A. H., Adli A.: Continuous glass fiber reinforced wood plastic composite in extrusion process: mechanical properties. Materials and Design, 51, 701-708 (2013). https://doi.org/10.1016/j.matdes.2013.04.082

[61] Chen R. S., Ahmad S.: Mechanical performance and flame retardancy of rice husk/organoclay-reinforced blend of recycled plastics. Materials Chemistry and Physics, 198, 57-65 (2017).

https://doi.org/10.1016/j.matchemphys.2017.05.054

[62] Khanam P. N., AlMaadeed M. A.: Improvement of ternary recycled polymer blend reinforced with date palm fibre. Materials and Design, 60, 532-539 (2014). https://doi.org/10.1016/j.matdes.2014.04.033

[63] Fang Y., Wang Q., Guo C., Song Y., Cooper P. A.: Effect of zinc borate and wood flour on thermal degradation and fire retardancy of polyvinyl chloride (PVC) composites. Journal of Analytical and Applied Pyrolysis, 100, 230-236 (2013).

https://doi.org/10.1016/j.jaap.2012.12.028

[64] Shukor F., Hassan A., Islam M. S., Mokhtar M., Hasan M.: Effect of ammonium polyphosphate on flame retardancy, thermal stability and mechanical properties of alkali treated kenaf fiber filled PLA biocomposites. Materials and Design, 54, 425-429 (2014). https://doi.org/10.1016/j.matdes.2013.07.095

[65] Foruzanmehr M., Vuillaume P. Y., Elkoun S., Robert M.: Physical and mechanical properties of PLA composites reinforced by $\mathrm{TiO}_{2}$ grafted flax fibers. Materials and Design, 106, 295-304 (2016). https://doi.org/10.1016/j.matdes.2016.05.103

[66] Dorez G., Taguet A., Ferry L., Cuesta J-M. L.: Phosphorous compounds as flame retardants for polybutylene succinate/flax biocomposite: Additive versus reactive route. Polymer Degradation and Stability, 102, 152-159 (2014). https://doi.org/10.1016/j.polymdegradstab.2014.01.018

[67] Ibrahim H., Farag M., Megahed H., Mehanny S.: Characteristics of starch-based biodegradable composites reinforced with date palm and flax fibers. Carbohydrate Polymers, 101, 11-19 (2014). https://doi.org/10.1016/j.carbpol.2013.08.051

[68] Dunne R., Desai D., Sadiku R.: Material characterization of blended sisal-kenaf composites with an ABS matrix. Applied Acoustics, 125, 184-193 (2017). https://doi.org/10.1016/j.apacoust.2017.03.022
[69] Yu M., Huang R., He C., Wu Q., Zhao X.: Hybrid composites from wheat straw, inorganic filler, and recycled polypropylene: Morphology and mechanical and thermal expansion performance. International Journal of Polymer Science, 2016, 2520670/1-2520670/12 (2016). https://doi.org/10.1155/2016/2520670

[70] Aldousiri B., Alajmi M., Shalwan A.: Mechanical properties of palm fibre reinforced recycled HDPE. Advances in Materials Science and Engineering, 2013, 508179/1-508179/7 (2013). https://doi.org/10.1155/2013/508179

[71] Suharty N. S., Ismail H., Diharjo K., Handayani D. S., Firdaus M.: Effect of kenaf fiber as a reinforcement on the tensile, flexural strength and impact toughness properties of recycled polypropylene/halloysite composites. Procedia Chemistry, 19, 253-258 (2016). https://doi.org/10.1016/j.proche.2016.03.102

[72] Mohammed M., Rozyanty A. R., Adam T., Betar B. O.: Study of the weathering effect in a natural environment on the hybrid kenaf bast/glass fibre-filled unsaturated polyester composite. AIP Conference Proceedings, 1885, 020201/1-020201/7 (2017). https://doi.org/10.1063/1.5002395

[73] Akil H. M., Santulli C., Sarasini F., Tirillò J., Valente T.: Environmental effects on the mechanical behaviour of pultruded jute/glass fibre-reinforced polyester hybrid composites. Composites Science and Technology, 94, 62-70 (2014). https://doi.org/10.1016/j.compscitech.2014.01.017

[74] Karikalan L., Chandrasekran M., Ramasubramanian S., Baskar S.: Hybridization of composites using natural and synthetic fibers for automotive application. International Journal of Scientific Research in Science and Technology, 7, 916-920 (2017).

[75] Alexander J., Churchill S. J. E.: Mechanical characterization of baslat based natural hybrid composites for aerospace applications. IOP Conference Series: Materials Science and Engineering, 197, 012008/1012008/8 (2017). https://doi.org/10.1088/1757-899X/197/1/012008

[76] Dhakal H. N., Zhang Z. Y., Guthrie R., MacMullen J., Bennett N.: Development of flax/carbon fibre hybrid composites for enhanced properties. Carbohydrate Polymers, 96, 1-8 (2013). https://doi.org/10.1016/j.carbpol.2013.03.074

[77] Habibi M., Laperrière L., Lebrun G., Toubal L.: Combining short flax fiber mats and unidirectional flax yarns for composite applications: Effect of short flax fibers on biaxial mechanical properties and damage behaviour. Composites Part B: Engineering, 123, 165178 (2017).

https://doi.org/10.1016/j.compositesb.2017.05.023 
[78] Akash, Girisha K. G., Gupta N. S. V., Rao K. V. S.: A study on flammability and moisture absorption behavior of sisal/coir fiber reinforced hybrid composites. IOP Conference Series: Materials Science and Engineering, 012003/1-012003/5 (2017). https://doi.org/10.1088/1757-899X/191/1/012003

[79] Braga R. A., Magalhaes Jr. P. A. A.: Analysis of the mechanical and thermal properties of jute and glass fiber as reinforcement epoxy hybrid composites. Materials Science and Engineering: C, 56, 269-273 (2015). https://doi.org/10.1016/j.msec.2015.06.031

[80] Hua C., Mazlan N.: Investigation on the flexural properties and glass transition temperature of kenaf/epoxy composite filled with mesoporous silica for wind turbine applications. Pertanika Journal of Science and Technology, 25, 1261-1274 (2017).

[81] Ramesh M., Palanikumar K., Reddy K. H.: Comparative evaluation on properties of hybrid glass fibersisal/jute reinforced epoxy composites. Procedia Engineering, 51, 745-750 (2013). https://doi.org/10.1016/j.proeng.2013.01.106

[82] Saidane E. H., Scida D., Assarar M., Ayad R.: Damage mechanisms assessment of hybrid flax-glass fibre composites using acoustic emission. Composite Structures, 174, 1-11 (2017). https://doi.org/10.1016/j.compstruct.2017.04.044

[83] Sarasini F., Tirillò J., D'Altilia S., Valente T., Santulli C., Touchard F., Chocinski-Arnault L., Mellier D., Lampani L., Gaudenzi P.: Damage tolerance of carbon/flax hybrid composites subjected to low velocity impact. Composites Part B: Engineering, 91, 144-153 (2016). https://doi.org/10.1016/j.compositesb.2016.01.050

[84] Fiore V., Calabrese L., Di Bella G., Scalici T., Galtieri G., Valenza A., Proverbio E.: Effects of aging in salt spray conditions on flax and flax/basalt reinforced composites: wettability and dynamic mechanical properties. Composites Part B: Engineering, 93, 35-42 (2016). https://doi.org/10.1016/j.compositesb.2016.02.057

[85] Ramnath B. V., Kokan S. J., Raja R. N., Sathyanarayanan R., Elanchezhian C., Prasad A. R., Manickavasagam V. M.: Evaluation of mechanical properties of abaca-jute-glass fibre reinforced epoxy composite. Materials and Design, 51, 357-366 (2013). https://doi.org/10.1016/j.matdes.2013.03.102

[86] Assarar M., Zouari W., Sabhi H., Ayad R., Berthelot J-M.: Evaluation of the damping of hybrid carbon-flax reinforced composites. Composite Structures, 132, 148-154 (2015). https://doi.org/10.1016/j.compstruct.2015.05.016

[87] Palanikumar K., Ramesh M., Reddy K. H.: Experimental investigation on the mechanical properties of green hybrid sisal and glass fiber reinforced polymer composites. Journal of Natural Fibers, 13, 321-331 (2016).

https://doi.org/10.1080/15440478.2015.1029192
[88] Petrucci R., Santulli C., Puglia D., Nisini E., Sarasini F., Tirillò J., Torre L., Minak G., Kenny J. M.: Impact and post-impact damage characterisation of hybrid composite laminates based on basalt fibres in combination with flax, hemp and glass fibres manufactured by vacuum infusion. Composites Part B: Engineering, 69, 507-515 (2015).

https://doi.org/10.1016/j.compositesb.2014.10.031

[89] Fragassa C., Pavlovic A., Santulli C.: Mechanical and impact characterisation of flax and basalt fibre vinylester composites and their hybrids. Composites Part B: Engineering, 137, 247-259 (2018).

https://doi.org/10.1016/j.compositesb.2017.01.004

[90] Almansour F. A., Dhakal H. N., Zhang Z. Y.: Effect of water absorption on Mode I interlaminar fracture toughness of flax/basalt reinforced vinyl ester hybrid composites. Composite Structures, 168, 813-825 (2017). https://doi.org/10.1016/j.compstruct.2017.02.081

[91] Gupta M. K., Srivastava R. K.: Effect of sisal fibre loading on dynamic mechanical analysis and water absorption behaviour of jute fibre epoxy composite. Materials Today: Proceedings, 2, 2909-2917 (2015).

https://doi.org/10.1016/j.matpr.2015.07.253

[92] Kureemun U., Ravandi M., Tran L. Q. N., Teo W. S., Tay T. E., Lee H. P.: Effects of hybridization and hybrid fibre dispersion on the mechanical properties of woven flax-carbon epoxy at low carbon fibre volume fractions. Composites Part B: Engineering, 134, 28-38 (2018).

https://doi.org/10.1016/j.compositesb.2017.09.035

[93] Shanmugam D., Thiruchitrambalam M.: Static and dynamic mechanical properties of alkali treated unidirectional continuous palmyra palm leaf stalk fiber/jute fiber reinforced hybrid polyester composites. Materials and Design, 50, 533-542 (2013).

https://doi.org/10.1016/j.matdes.2013.03.048

[94] Ramana M. V., Ramprasad S.: Experimental investigation on jute/carbon fibre reinforced epoxy based hybrid composites. Materials Today: Proceedings, 4, 8654-8664 (2017).

https://doi.org/10.1016/j.matpr.2017.07.214

[95] Safri S. N. A., Sultan M. T. H., Jawaid M., Jayakrishna K.: Impact behaviour of hybrid composites for structural applications: A review. Composites Part B: Engineering, 133, 112-121 (2017).

https://doi.org/10.1016/j.compositesb.2017.09.008

[96] Essabir H., Bensalah M. O., Rodrigue D., Bouhfid R., Qaiss A.: Structural, mechanical and thermal properties of bio-based hybrid composites from waste coir residues: Fibers and shell particles. Mechanics of Materials, 93, 134-144 (2016).

https://doi.org/10.1016/j.mechmat.2015.10.018

[97] Yusoff R. B., Takagi H., Nakagaito A. N.: Tensile and flexural properties of polylactic acid-based hybrid green composites reinforced by kenaf, bamboo and coir fibers. Industrial Crops and Products, 94, 562-573 (2016).

https://doi.org/10.1016/j.indcrop.2016.09.017 
[98] Venkateshwaran N., Elayaperumal A., Sathiya G. K.: Prediction of tensile properties of hybrid-natural fiber composites. Composites Part B: Engineering, 43, 793 796 (2012).

https://doi.org/10.1016/j.compositesb.2011.08.023

[99] Banerjee S., Sankar B. V.: Mechanical properties of hybrid composites using finite element method based micromechanics. Composites Part B: Engineering, 58, 318-327 (2014).

https://doi.org/10.1016/j.compositesb.2013.10.065

[100] Naito K., Oguma H.: Tensile properties of novel carbon/glass hybrid thermoplastic composite rods. Composite Structures, 161, 23-31 (2017).

https://doi.org/10.1016/j.compstruct.2016.11.042

[101] Battegazzore D., Salvetti O., Frache A., Peduto N., Sio A. D., Marino F.: Thermo-mechanical properties enhancement of bio-polyamides (PA10.10 and PA6.10) by using rice husk ash and nanoclay. Composites Part A: Applied Science and Manufacturing, 81, 193-201 (2016). https://doi.org/10.1016/j.compositesa.2015.11.022

[102] Lazzeri A., Phuong V. T.: Dependence of the Pukánszky's interaction parameter $B$ on the interface shear strength (IFSS) of nanofiller- and short fiber-reinforced polymer composites. Composites Science and Technology, 93, 106-113 (2014). https://doi.org/10.1016/j.compscitech.2014.01.002

[103] Móczó J., Pukánszky B.: Polymer micro and nanocomposites: Structure, interactions, properties. Journal of Industrial and Engineering Chemistry, 14, 535-563 (2008). https://doi.org/10.1016/j.jiec.2008.06.011

[104] Islam M. R., Beg M. D., Gupta A.: Characterization of laccase-treated kenaf fibre reinforced recycled polypropylene composites. BioResources, 8, 3753-3770 (2013).

[105] Das S.: Mechanical properties of waste paper/jute fabric reinforced polyester resin matrix hybrid composites. Carbohydrate Polymers, 172, 60-67 (2017). https://doi.org/10.1016/j.carbpol.2017.05.036

[106] Akash., Gupta N. S. V., Rao K. V. S.: An experimental study on sisal/hemp fiber reinforced hybrid composites. Materials Today: Proceedings, 5, 7383-7387 (2018). https://doi.org/10.1016/j.matpr.2017.11.408

[107] Naidu A. L., Kona S.: Experimental study of the mechanical properties of banana fiber and groundnut shell ash reinforced epoxy hybrid composite. International Journal of Engineering, 31, 659-665 (2018). https://doi.org/10.5829/ije.2018.31.04a.18

[108] Sarasini F., Tirillò J., Puglia D., Dominici F., Santulli C., Boimau K., Valente T., Torre L.: Biodegradable polycaprolactone-based composites reinforced with ramie and borassus fibres. Composite Structures, 167, 20-29 (2017). https://doi.org/10.1016/j.compstruct.2017.01.071
[109] Jumaidin R., Sapuan S. M., Jawaid M., Ishak M. R., Sahari J.: Thermal, mechanical, and physical properties of seaweed/sugar palm fibre reinforced thermoplastic sugar palm starch/agar hybrid composites. International Journal of Biological Macromolecules, 97, 606-615 (2017). https://doi.org/10.1016/j.ijbiomac.2017.01.079

[110] Pappu A., Thakur V. K.: Towards sustainable micro and nano composites from fly ash and natural fibers for multifunctional applications. Vacuum, 146, 375-385 (2017). https://doi.org/10.1016/j.vacuum.2017.05.026

[111] Majeed K., Jawaid M., Hassan A., Bakar A. A., Khalil H. P. S. A., Salema A. A., Inuwa I.: Potential materials for food packaging from nanoclay/natural fibres filled hybrid composites. Materials and Design, 46, 391-410 (2013). https://doi.org/10.1016/j.matdes.2012.10.044

[112] Essabir H., Boujmal R., Bensalah M. O., Rodrigue D., Bouhfid R., el kacem Qaiss A.: Mechanical and thermal properties of hybrid composites: Oil-palm fiber/ clay reinforced high density polyethylene. Mechanics of Materials, 98, 36-43 (2016).

https://doi.org/10.1016/j.mechmat.2016.04.008

[113] Arrakhiz F. Z., Benmoussa K., Bouhfid R., Qaiss A.: Pine cone fiber/clay hybrid composite: Mechanical and thermal properties. Materials and Design, 50, 376-381 (2013). https://doi.org/10.1016/j.matdes.2013.03.033

[114] Piekarska K., Sowinski P., Piorkowska E., Haque M. M-U., Pracella M.: Structure and properties of hybrid PLA nanocomposites with inorganic nanofillers and cellulose fibers. Composites Part A: Applied Science and Manufacturing, 82, 34-41 (2016).

https://doi.org/10.1016/j.compositesa.2015.11.019

[115] Ridzuan M. J. M., Majid M. S. A., Afendi M., Mazlee M. N., Gibson A. G.: Thermal behaviour and dynamic mechanical analysis of Pennisetum purpureum/glassreinforced epoxy hybrid composites. Composite Structures, 152, 850-859 (2016).

https://doi.org/10.1016/j.compstruct.2016.06.026

[116] Romanzini D., Lavoratti A., Ornaghi Jr H. L., Amico S. C., Zattera A. J.: Influence of fiber content on the mechanical and dynamic mechanical properties of glass/ramie polymer composites. Materials and Design, 47, 9-15 (2013). https://doi.org/10.1016/j.matdes.2012.12.029

[117] Bakare F. O., Ramamoorthy S. K., Åkesson D., Skrifvars M.: Thermomechanical properties of bio-based composites made from a lactic acid thermoset resin and flax and flax/basalt fibre reinforcements. Composites Part A: Applied Science and Manufacturing, 83, 176-184 (2016). https://doi.org/10.1016/j.compositesa.2015.09.002 
[118] Kumar S., Satapathy B. K., Patnaik A.: Thermo-mechanical correlations to erosion performance of short glass/carbon fiber reinforced vinyl ester resin hybrid composites. Computational Materials Science, 60, 250 260 (2012).

https://doi.org/10.1016/j.commatsci.2012.03.021

[119] Jawaid M., Khalil H. P. S. A., Hassan A., Dungani R., Hadiyane A.: Effect of jute fibre loading on tensile and dynamic mechanical properties of oil palm epoxy composites. Composites Part B: Engineering, 45, 619-624 (2013).

https://doi.org/10.1016/j.compositesb.2012.04.068

[120] Rajesh M., Pitchaimani J.: Mechanical and dynamic mechanical behaviour of novel glass-natural fibre intraply woven polyester composites. Sādhanā, 42, 1215 1223 (2017). https://doi.org/10.1007/s12046-017-0676-y

[121] Matykiewicz D., Barczewski M., Knapski D., Skórczewska K.: Hybrid effects of basalt fibers and basalt powder on thermomechanical properties of epoxy composites. Composites Part B: Engineering, 125, 157-164 (2017).

https://doi.org/10.1016/j.compositesb.2017.05.060

[122] Mokhothu T. H., John M. J.: Review on hygroscopic aging of cellulose fibres and their biocomposites. Carbohydrate Polymers, 131, 337-354 (2015). https://doi.org/10.1016/j.carbpol.2015.06.027

[123] Zafeiropoulos N. E.: Interface engineering of natural fibre composites for maximum performance. Woodhead publishing, New Delhi (2011).

[124] Deshpande S., Rangaswamy T.: A comparative study on dry sliding wear characteristics of $\mathrm{Al}_{2} \mathrm{O}_{3}$ and bone powder filled hybrid composites. Journal of Minerals and Materials Characterization and Engineering, 4, 65166/1-65166/17 (2016).

https://doi.org/10.4236/jmmce.2016.42016

[125] Zhang D., Milanovic N. R., Zhang Y., Su F., Miao M.: Effects of humidity conditions at fabrication on the interfacial shear strength of flax/unsaturated polyester composites. Composites Part B: Engineering, 60, 186192 (2014).

https://doi.org/10.1016/j.compositesb.2013.12.031

[126] Panthapulakkal S., Sain M.: Studies on the water absorption properties of short hemp-glass fiber hybrid polypropylene composites. Journal of Composite Materials, 41, 1871-1883 (2007).

https://doi.org/10.1177/0021998307069900

[127] Zhou J., Lucas J. P.: The effects of a water environment on anomalous absorption behavior in graphite/ epoxy composites. Composites Science and Technology, 53, 57-64 (1995). https://doi.org/10.1016/0266-3538(94)00078-6

[128] Ashik K. P., Sharma R. S., Guptha V. L. J.: Investigation of moisture absorption and mechanical properties of natural/glass fiber reinforced polymer hybrid composites. Materials Today: Proceedings, 5, 3000-3007 (2018).

https://doi.org/10.1016/j.matpr.2018.01.099
[129] Hosseini S. B., Hedjazi S., Jamalirad L., Sukhtesaraie A.: Effect of nano- $\mathrm{SiO}_{2}$ on physical and mechanical properties of fiber reinforced composites (FRCs). Journal of the Indian Academy of Wood Science, 11, 116121 (2014).

https://doi.org/10.1007/s13196-014-0126-y

[130] Kaboorani A.: Characterizing water sorption and diffusion properties of wood/plastic composites as a function of formulation design. Construction and Building Materials, 136, 164-172 (2017).

https://doi.org/10.1016/j.conbuildmat.2016.12.120

[131] Apeagyei A. K., Grenfell J. R. A., Airey G. D.: Influence of aggregate absorption and diffusion properties on moisture damage in asphalt mixtures. Road Materials and Pavement Design, 16, 404-422 (2015). https://doi.org/10.1080/14680629.2015.1030827

[132] Zannen S., Ghali L., Halimi M. T., Hassen M. B.: Effect of fiber weight ratio and fiber modification on flexural properties of posidonia-polyester composites. Open Journal of Composite Materials, 6, 67931/1-67931/9 (2016). https://doi.org/10.4236/ojcm.2016.63007

[133] Sreekumar P. A., Joseph K., Unnikrishnan G., Thomas S.: A comparative study on mechanical properties of sisal-leaf fibre-reinforced polyester composites prepared by resin transfer and compression moulding techniques. Composites Science and Technology, 67, 453461 (2007).

https://doi.org/10.1016/j.compscitech.2006.08.025

[134] Choi H. S., Ahn K. J., Nam J-D., Chun H. J.: Hygroscopic aspects of epoxy/carbon fiber composite laminates in aircraft environments. Composites Part A: Applied Science and Manufacturing, 32, 709-720 (2001). https://doi.org/10.1016/S1359-835X(00)00145-7

[135] Bessadok A., Langevin D., Gouanvé F., Chappey C., Roudesli S., Marais S.: Study of water sorption on modified agave fibres. Carbohydrate Polymers, 76, 74-85 (2009). https://doi.org/10.1016/j.carbpol.2008.09.033

[136] Sen T., Reddy H. N. J.: Pretreatment of woven jute frp composite and its use in strengthening of reinforced concrete beams in flexure. Advances in Materials Science and Engineering, 2013, 128158/1-128158/15 (2013). https://doi.org/10.1155/2013/128158

[137] Mokhothu T. H., John M. J.: Bio-based coatings for reducing water sorption in natural fibre reinforced composites. Scientific Reports, 7, 133351-133358 (2017). https://doi.org/10.1038/s41598-017-13859-2

[138] Wu C-M., Lai W-Y., Wang C-Y.: Effects of surface modification on the mechanical properties of flax $/ \beta$ polypropylene composites. Materials, 9, 314/1-314/11 (2016). https://doi.org/10.3390/ma9050314 
[139] Yahaya R., Sapuan S. M., Jawaid M., Leman Z., Zainudin E. S.: Effect of moisture absorption on mechanical properties of natural fibre hybrid composite. in 'Proceedings of the $13^{\text {th }}$ International Conference on Environment, Ecosystems and Development, Kuala Lumpur, Malaysia' 141-145 (2015).

[140] Sature P., Mache A.: Mechanical characterization and water absorption studies on jute/hemp reinforced hybrid composites. American Journal of Materials Science, 5, 133-139 (2015). https://doi.org/10.5923/c.materials.201502.27

[141] Ramesh M., Logesh R., Manikandan M., Kumar N. S., Pratap D. V.: Mechanical and water intake properties of banana-carbon hybrid fiber reinforced polymer composites. Materials Research, 20, 365-376 (2017). https://doi.org/10.1590/1980-5373-mr-2016-0760

[142] de Almeida Cruz V., Delgado J., Barbosa de Lima A., Silva Nóbrega M., de Carvalho L., Cavalcanti W.: Moisture diffusion in unsaturated polyester composites reinforced with macambira natural fiber: A finite-volume approach. Diffusion Foundations, 3, 89-101 (2015). https://doi.org/10.4028/www.scientific.net/DF.3.89

[143] Xia C., Wang K., Dong Y., Zhang S., Shi S. Q., Cai L., Ren H., Zhang H., Li J.: Dual-functional natural-fiber reinforced composites by incorporating magnetite. Composites Part B: Engineering, 93, 221-228 (2016). https://doi.org/10.1016/j.compositesb.2016.03.016

[144] Borba P. M., Tedesco A., Lenz D. M.: Effect of reinforcement nanoparticles addition on mechanical properties of SBS/curauá fiber composites. Materials Research, 17, 412-419 (2014). https://doi.org/10.1590/S1516-14392013005000203

[145] Xia C., Zhang S., Shi S. Q., Cai L., Huang J.: Property enhancement of kenaf fiber reinforced composites by in situ aluminum hydroxide impregnation. Industrial Crops and Products, 79, 131-136 (2016). https://doi.org/10.1016/j.indcrop.2015.11.037

[146] Saw S. K., Akhtar K., Yadav N., Singh A. K.: Hybrid composites made from jute/coir fibers: Water absorption, thickness swelling, density, morphology, and mechanical properties. Journal of Natural Fibers, 11, 39 53 (2014). https://doi.org/10.1080/15440478.2013.825067

[147] Dan-mallam Y., Hong T. W., Majid M. S. A.: Mechanical characterization and water absorption behaviour of interwoven kenaf/PET fibre reinforced epoxy hybrid composite. International Journal of Polymer Science, 2015, 371958/1-371958/13 (2015).

https://doi.org/10.1155/2015/371958

[148] Terzi E., Kartal S., Muin M., Hassanin A., Hamouda T., Kiliç A., Candan Z.: Biological performance of novel hybrid green composites produced from glass fibers and jute fabric skin by the VARTM process. BioResources, 13, 662-677 (2018). https://doi.org/10.15376/biores.13.1.662-677
[149] Tufan M., Akbas S., Aslan M.: Decay resistance, thermal degradation, tensile and flexural properties of sisal carbon hybrid composites. Maderas. Ciencia y Tecnología, 18, 599-606 (2016). https://doi.org/10.4067/S0718-221X2016005000052

[150] Catto A. L., Montagna L. S., Almeida S. H., Silveira R. M. B., Santana R. M. C.: Wood plastic composites weathering: Effects of compatibilization on biodegradation in soil and fungal decay. International Biodeterioration and Biodegradation, 109, 11-22 (2016). https://doi.org/10.1016/j.ibiod.2015.12.026

[151] Harnnecker F., dos Santos Rosa D., Lenz D. M.: Biodegradable polyester-based blend reinforced with curauá fiber: Thermal, mechanical and biodegradation behaviour. Journal of Polymers and the Environment, 20, 237-244 (2012). https://doi.org/10.1007/s10924-011-0382-5

[152] Rasouli D., Dintcheva N. T., Faezipour M., La Mantia F. P., Farahani M. R. M., Tajvidi M.: Effect of nano zinc oxide as UV stabilizer on the weathering performance of wood-polyethylene composite. Polymer Degradation and Stability, 133, 85-91 (2016). https://doi.org/10.1016/j.polymdegradstab.2016.08.004

[153] Turku I., Kärki T.: Accelerated weathering of fire-retarded wood-polypropylene composites. Composites Part A: Applied Science and Manufacturing, 81, 305312 (2016).

https://doi.org/10.1016/j.compositesa.2015.11.028

[154] Subasinghe A., Das R., Bhattacharyya D.: Study of thermal, flammability and mechanical properties of intumescent flame retardant PP/kenaf nanocomposites. International Journal of Smart and Nano Materials, 7, 202-220 (2016). https://doi.org/10.1080/19475411.2016.1239315

[155] Umemura T., Arao Y., Nakamura S., Tomita Y., Tanaka T.: Synergy effects of wood flour and fire retardants in flammability of wood-plastic composites. Energy Procedia, 56, 48-56 (2014). https://doi.org/10.1016/j.egypro.2014.07.130

[156] Nie S., Song L., Tai Q., Zhan J., Lu H., Hu Y.: Synergistic effects of nanoporous nickel phosphates VSB-1 on an intumescent flame-retardant low-density polyethylene (LDPE) system. Polymer-Plastics Technology and Engineering, 48, 464-469 (2009). https://doi.org/10.1080/03602550902725464

[157] Makhlouf G., Hassan M., Nour M., Abdel-Monem Y. K., Abdelkhalik A.: Evaluation of fire performance of linear low-density polyethylene containing novel intumescent flame retardant. Journal of Thermal Analysis and Calorimetry, 130, 1031-1041 (2017). https://doi.org/10.1007/s10973-017-6418-x

[158] Liu W., Wang D., Zhang Y., Bai T., Li J.: Flammability and flame-retardant mechanism of high density polyethylene/wood fiber/modified ammonium polyphosphate composite. Polymer Composites, 39, 1192-1199 (2018).

https://doi.org/10.1002/pc.24048 
[159] Gao Y., Wang Q., Wang J., Huang L., Yan X., Zhang X., He Q., Xing Z., Guo Z.: Synthesis of highly efficient flame retardant high-density polyethylene nanocomposites with inorgano-layered double hydroxides as nanofiller using solvent mixing method. ACS Applied Materials and Interfaces, 6, 5094-5104 (2014).

https://pubs.acs.org/doi/10.1021/am500265a

[160] Jiang Y., Hao Z., Luo H., Shao Z., Yu Q., Sun M., Ke Y., Chen Y.: Synergistic effects of boron-doped silicone resin and a layered double hydroxide modified with sodium dodecyl benzenesulfonate for enhancing the flame retardancy of polycarbonate. RSC Advances, 8, 11078-11086 (2018). https://doi.org/10.1039/C8RA01086B

[161] Jian R-K., Chen L., Zhao B., Yan Y-W., Li X-F., Wang Y-Z.: Acrylonitrile-butadiene-styrene terpolymer with metal hypophosphites: Flame retardance and mechanism research. Industrial and Engineering Chemistry Research, 53, 2299-2307 (2014). https://pubs.acs.org/doi/abs/10.1021/ie403726m

[162] Pan M., Guan D., Wang T., Huang R., Mu J., Zhang C.: Morphology, thermal properties, and fire behavior of epoxy resin nanocomposites containing octaammonium polyhedral oligomeric silsesquioxane-modified montmorillonite. High Performance Polymers, 25, 992-999 (2013).

https://doi.org/10.1177/0954008313493101

[163] Wang X., Kalali E. N., Wang D-Y.: Renewable cardanol-based surfactant modified layered double hydroxide as a flame retardant for epoxy resin. ACS Sustainable Chemistry and Engineering, 3, 3281-3290 (2015).

https://doi.org/10.1021/acssuschemeng.5b00871

[164] Chen C., Gu X., Jin X., Sun J., Zhang S.: The effect of chitosan on the flammability and thermal stability of polylactic acid/ammonium polyphosphate biocomposites. Carbohydrate Polymers, 157, 1586-1593 (2017). https://doi.org/10.1016/j.carbpol.2016.11.035

[165] Chen Y., Wang W., Qiu Y., Li L., Qian L., Xin F.: Terminal group effects of phosphazene-triazine bi-group flame retardant additives in flame retardant polylactic acid composites. Polymer Degradation and Stability, 140, 166-175 (2017). https://doi.org/10.1016/j.polymdegradstab.2017.04.024

[166] Zhou K., Gao R.: The influence of a novel two dimensional graphene-like nanomaterial on thermal stability and flammability of polystyrene. Journal of Colloid and Interface Science, 500, 164-171 (2017). https://doi.org/10.1016/j.jcis.2017.04.018

[167] Hou Y., Hu W., Hu Y.: Preparation of layered organicinorganic aluminum phosphonate for enhancing fire safety of polystyrene. Materials Chemistry and Physics, 196, 109-117 (2017).

https://doi.org/10.1016/j.matchemphys.2017.04.057
[168] Pandey P., Dayanidhi A., Mohanty S., Nayak S. K.: Effect of clay loading on flammability of poly(methyl methacrylate)/clay nanocomposites. Journal of Thermoplastic Composite Materials, 26, 663-679 (2013). https://doi.org/10.1177/0892705711428655

[169] Hatanaka L. C., Ahmed L., Sachdeva S., Wang Q., Cheng Z., Mannan M. S.: Thermal degradation and flammability of nanocomposites composed of silica cross-linked to poly(methyl methacrylate). Plastics, Rubber and Composites, 45, 375-381 (2016). https://doi.org/10.1080/14658011.2016.1204773

[170] Pei B., Song G-Y., Lu C.: The application of cone calorimeter on the study of burning performance of liquorices. Procedia Engineering, 71, 291-295 (2014). https://doi.org/10.1016/j.proeng.2014.04.042

[171] Arao Y., Nakamura S., Tomita Y., Takakuwa K., Umemura T., Tanaka T.: Improvement on fire retardancy of wood flour/polypropylene composites using various fire retardants. Polymer Degradation and Stability, 100, 79-85 (2014).

https://doi.org/10.1016/j.polymdegradstab.2013.12.022

[172] Subasinghe A. D. L., Das R., Bhattacharyya D.: Fiber dispersion during compounding/injection molding of PP/kenaf composites: Flammability and mechanical properties. Materials and Design, 86, 500-507 (2015). https://doi.org/10.1016/j.matdes.2015.07.126

[173] Szolnoki B., Bocz K., Sóti P. L., Bodzay B., Zimonyi E., Toldy A., Morlin B., Bujnowicz K., Władyka-Przybylak M., Marosi G.: Development of natural fibre reinforced flame retarded epoxy resin composites. Polymer Degradation and Stability, 119, 68-76 (2015). https://doi.org/10.1016/j.polymdegradstab.2015.04.028

[174] Khalili P., Tshai K., Kong I.: Natural fiber reinforced expandable graphite filled composites: Evaluation of the flame retardancy, thermal and mechanical performances. Composites Part A: Applied Science and Manufacturing, 100, 194-205 (2017).

https://doi.org/10.1016/j.compositesa.2017.05.015

[175] Karunakaran S., Majid D. L., Tawil M. L. M.: Flammability of self-extinguishing kenaf/ABS nanoclays composite for aircraft secondary structure. IOP Conference Series: Materials Science and Engineering, 152, 012068/1-012068/11 (2016). https://doi.org/10.1088/1757-899X/152/1/012068

[176] Arjmandi R., Ismail A., Hassan A., Bakar A. A.: Effects of ammonium polyphosphate content on mechanical, thermal and flammability properties of kenaf/ polypropylene and rice husk/polypropylene composites. Construction and Building Materials, 152, 484493 (2017).

https://doi.org/10.1016/j.conbuildmat.2017.07.052

[177] Yu T., Tuerhongjiang T., Sheng C., Li Y.: Phosphoruscontaining diacid and its application in jute/poly(lactic acid) composites: Mechanical, thermal and flammability properties. Composites Part A: Applied Science and Manufacturing, 97, 60-66 (2017).

https://doi.org/10.1016/j.compositesa.2017.03.004 
[178] Sun L., Wu Q., Xie Y., Cueto R., Lee S., Wang Q.: Thermal degradation and flammability behavior of fire-retarded wood flour/polypropylene composites. Journal of Fire Sciences, 34, 226-239 (2016). https://doi.org/10.1177/0734904116637632

[179] Wang W., Peng Y., Zammarano M., Zhang W., Li J.: Effect of ammonium polyphosphate to aluminum hydroxide mass ratio on the properties of wood-flour/ polypropylene composites. Polymers, 9, 1-16 (2017). https://doi.org/10.3390/polym9110615

[180] Wang W., Zhang W., Chen H., Zhang S., Li J.: Synergistic effect of synthetic zeolites on flame-retardant wood-flour/polypropylene composites. Construction and Building Materials, 79, 337-344 (2015). https://doi.org/10.1016/j.conbuildmat.2015.01.038

[181] Khalili P., Tshai K. Y., Hui D., Kong I.: Synergistic of ammonium polyphosphate and alumina trihydrate as fire retardants for natural fiber reinforced epoxy composite. Composites Part B: Engineering, 114, 101-110 (2017).

https://doi.org/10.1016/j.compositesb.2017.01.049

[182] Gallo E., Sánchez-Olivares G., Schartel B.: Flame retardancy of starch-based biocomposites - Aluminum hydroxide-coconut fiber synergy. Polimery, 58, 395402 (2013).

https://doi.org/10.14314/polimery.2013.395

[183] Bocz K., Szolnoki B., Władyka-Przybylak M., Bujnowicz K., Harakály G., Bodzay B., Zimonyi E., Toldy A., Marosi G.: Flame retardancy of biocomposites based on thermoplastic starch. Polimery, 58, 385-394 (2013). https://doi.org/10.14314/polimery.2013.385

[184] Murugan R., Ramesh R., Padmanabhan K.: Investigation on static and dynamic mechanical properties of epoxy based woven fabric glass/carbon hybrid composite laminates. Procedia Engineering, 97, 459-468 (2014). https://doi.org/10.1016/j.proeng.2014.12.270

[185] Irina M. M. W., Azmi A. I., Tan C. L., Lee C. C., Khalil A. N. M.: Evaluation of mechanical properties of hybrid fiber reinforced polymer composites and their architecture. Procedia Manufacturing, 2, 236-240 (2015). https://doi.org/10.1016/j.promfg.2015.07.041
[186] Gopinath A., Kumar M. S., Elayaperumal A.: Experimental investigations on mechanical properties of jute fiber reinforced composites with polyester and epoxy resin matrices. Procedia Engineering, 97, 2052-2063 (2014). https://doi.org/10.1016/j.proeng.2014.12.448

[187] Bhoopathi R., Ramesh M., Deepa C.: Fabrication and property evaluation of banana-hemp-glass fiber reinforced composites. Procedia Engineering, 97, 20322041 (2014).

https://doi.org/10.1016/j.proeng.2014.12.446

[188] Reddy K. S., Singla H.: Optimization of woven jute/ glass fibre-reinforced polyester hybrid composite solar parabolic trough collector. IOP Conference Series: Materials Science and Engineering, 222, 012016/1012016/8 (2017).

https://doi.org/10.1088/1757-899X/222/1/012016

[189] Chikhradze N. M., Marquis F. D. S, Abashidze G. S.: Hybrid fiber and nanopowder reinforced composites for wind turbine blades. Journal of Materials Research and Technology, 4, 60-67 (2015). https://doi.org/10.1016/j.jmrt.2015.01.002

[190] Zhang D., Sun Y., Chen L., Zhang S., Pan N.: Influence of fabric structure and thickness on the ballistic impact behavior of ultrahigh molecular weight polyethylene composite laminate. Materials and Design, 54, 315-322 (2014). https://doi.org/10.1016/j.matdes.2013.08.074

[191] Bandaru A. K., Ahmad S., Bhatnagar N.: Ballistic performance of hybrid thermoplastic composite armors reinforced with Kevlar and basalt fabrics. Composites Part A: Applied Science and Manufacturing, 97, 151165 (2017). https://doi.org/10.1016/j.compositesa.2016.12.007

[192] Yahaya R., Sapuan S. M., Jawaid M., Leman Z., Zainudin E. S.: Quasi-static penetration and ballistic properties of kenaf-aramid hybrid composites. Materials and Design, 63, 775-782 (2014). https://doi.org/10.1016/j.matdes.2014.07.010

[193] Yahaya R., Sapuan S. M., Jawaid M., Leman Z., Zainudin E. S.: Measurement of ballistic impact properties of woven kenaf-aramid hybrid composites. Measurement, 77, 335-343 (2016).

https://doi.org/10.1016/j.measurement.2015.09.016 